\title{
Summary of Data from the Sixth AIAA CFD Drag Prediction Workshop: CRM Cases 2 to 5
}

\author{
Edward N. Tinoco ${ }^{1}$ \\ Retired, Kent, WA, 98031, USA \\ Olaf P. Brodersen ${ }^{2}$ and Stefan Keye ${ }^{3}$ \\ DLR Institute of Aerodynamics and Flow Technology, 38108 Braunschweig, Germany \\ Kelly R. Laflin ${ }^{4}$ and Edward Feltrop 5 \\ Textron Aviation, Wichita, KS 67215, USA \\ John C. Vassberg ${ }^{6}$, Mori Mani ${ }^{7}$, and Ben Rider ${ }^{8}$ \\ The Boeing Company, Seattle, WA, 98124, Huntington Beach, CA 92647, St. Louis, MO, 63301, USA \\ Richard A. Wahls ${ }^{9}$, and Joseph H. Morrison ${ }^{10}$ \\ NASA Langley Research Center, Hampton, VA 23681, USA \\ David Hue ${ }^{11}$ \\ ONERA-The French Aerospace Lab, 92190 Meudon, France \\ Martin Gariepy ${ }^{12}$ \\ École Polytechnique de Montréal, Montréal, Québec H3C 1K3, Canada \\ Christopher J. Roy ${ }^{13}$ \\ Virginia Tech, Blacksburg, VA 24061, USA \\ Dimitri J. Mavriplis ${ }^{14}$ \\ University of Wyoming, Laramie, WY 82071, USA \\ and \\ Mitsuhiro Murayama ${ }^{15}$ \\ Japan Aerospace Exploration Agency, Chofu, Tokyo 182-8522, Japan
}

\begin{abstract}
Results from the Sixth AIAA CFD Drag Prediction Workshop Common Research Model Cases 2 to 5 are presented. As with past workshops, numerical calculations are performed using industry-relevant geometry, methodology, and test cases. Cases 2 to 5 focused on force/moment and pressure predictions for the NASA Common Research Model wing-body and wing-body-nacelle-pylon configurations, including Case 2 - a grid refinement study and nacelle-pylon drag increment prediction study; Case 3 - an angle-of-attack buffet study;
\end{abstract}

\footnotetext{
${ }^{1}$ Boeing Technical Fellow (Retired), AIAA Associate Fellow

${ }^{2}$ Vice Director, AIAA Member

${ }^{3}$ Research Scientist, AIAA Member

${ }^{4}$ Engineer Specialist, Sr., AIAA Associate Fellow

${ }^{5}$ Engineer Specialist, Sr., AIAA Member

${ }^{6}$ Boeing Technical Fellow, AIAA Fellow

${ }^{7}$ Boeing Sr. Technical Fellow, AIAA Associate Fellow

${ }^{8}$ Sr. Engineer, AIAA Member

${ }^{9}$ Strategic Technical Advisor-AAVP, AIAA Fellow

${ }^{10}$ Chief Engineer for Modeling and Simulation, Research Directorate, AIAA Associate Fellow

${ }^{11}$ Research Engineer, Applied Aerodynamics Department, AIAA Member

${ }^{12}$ Research Associate

13 Professor, Aerospace and Ocean Engineering Department, AIAA Associate Fellow

${ }^{14}$ Professor Mechanical Engineering, AIAA Associate Fellow

15 Research Engineer, AIAA Member
} 
Case 4 - an optional wing-body grid adaption study; and Case 5 - an optional wing-body coupled aero-structural simulation. The Common Research Model geometry differed from previous workshops in that it was deformed to the appropriate static aeroelastic twist and deflection at each specified angle-of-attack. The grid refinement study used a common set of overset and unstructured grids, as well as user created Multiblock structured, unstructured, and Cartesian based grids. For the supplied common grids, six levels of refinement were created resulting in grids ranging from $7 \times 10^{6}$ to $208 \times 10^{6}$ cells. This study (Case 2) showed further reduced scatter from previous workshops, and very good prediction of the nacellepylon drag increment. Case 3 studied buffet onset at $M=0.85$ using the Medium grid (20 to 40x10 6 nodes) from the above described sequence. The prescribed alpha sweep used finely spaced intervals through the zone where wing separation was expected to begin. Although the use of the prescribed aeroelastic twist and deflection at each angle-of-attack greatly improved the wing pressure distribution agreement with test data, many solutions still exhibited premature flow separation. The remaining solutions exhibited a significant spread of lift and pitching moment at each angle-of-attack, much of which can be attributed to excessive aft pressure loading and shock location variation. Four Case 4 grid adaption solutions were submitted. Starting with grids less than $2 \times 10^{6}$ grid points, two solutions showed a rapid convergence to an acceptable solution. Four Case 5 coupled aerostructural solutions were submitted. Both showed good agreement with experimental data. Results from this workshop highlight the continuing need for CFD improvement, particularly for conditions with significant flow separation. These comparisons also suggest the need for improved experimental diagnostics to guide future CFD development.

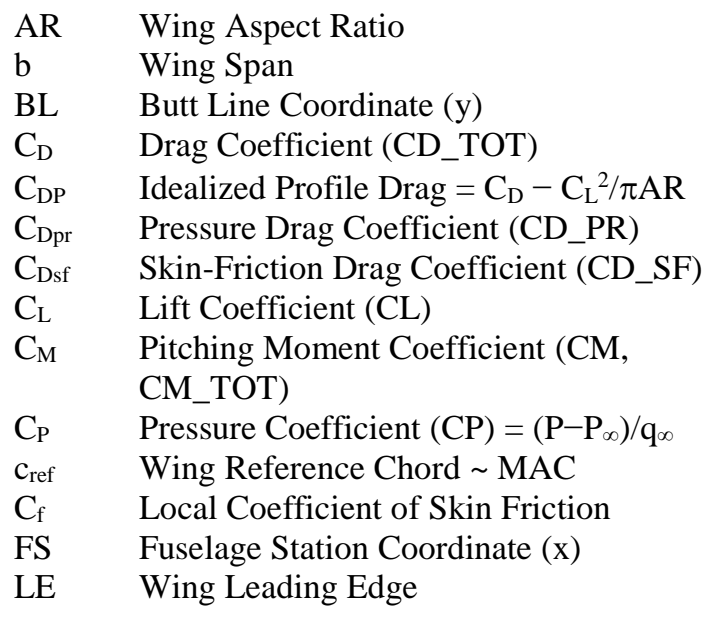

\section{Nomenclature}

$\begin{array}{ll}\text { MAC } & \text { Mean Aerodynamic Chord } \\ \mathrm{N} & \text { Number of unknowns (GRIDSIZE) } \\ \text { RANS } & \text { Reynolds-Averaged Navier-Stokes } \\ \mathrm{RE} & \text { Reynolds Number } \\ \mathrm{S}_{\mathrm{ref}} & \text { Reference Area } \\ \mathrm{SOB} & \text { Side-of-Body } \\ \mathrm{TE} & \text { Wing Trailing Edge } \\ \mathrm{WL} & \text { Water Line Coordinate (z) } \\ \mathrm{w} & \text { Wing Section Bending Deflection } \\ \mathrm{x} / \mathrm{c} & \text { Wing Chord Fraction } \\ \mathrm{y}^{+} & \text {Normalized Wall Distance } \\ \alpha & \text { Angle-of-attack (ALPHA) } \\ \varepsilon & \text { Wing Section Twist Deflection } \\ \Lambda_{\mathrm{c} / 4} & \text { Quarter Chord Sweep } \\ \lambda & \text { Wing Taper Ratio } \\ \text { eta (n) } & \text { Fraction of Wing Semi-Span }\end{array}$




\section{Introduction}

The AIAA CFD Drag Prediction Workshop (DPW) Series was initiated by a working group of members from the Applied Aerodynamics Technical Committee of the American Institute of Aeronautics and Astronautics. The primary goal of the workshop series is to assess the state-of-the-art of modern computational fluid dynamics methods using geometries and conditions relevant to commercial aircraft. From the onset, the DPW organizing committee has adhered to a primary set of guidelines and objectives for the DPW series:

- Assess state-of-the-art Computational Fluid Dynamics (CFD) methods as practical aerodynamic tools for the prediction of forces and moments on industry-relevant geometries, with a focus on absolute drag.

- Provide an impartial international forum for evaluating the effectiveness of CFD Navier-Stokes solvers.

- Promote balanced participation across academia, government labs, and industry.

- Use common public-domain subject geometries, simple enough to permit high-fidelity computations.

- Provide baseline grids to encourage participation and help reduce variability of CFD results.

- Openly discuss and identify areas needing additional research and development.

- Conduct rigorous statistical analyses of CFD results to establish confidence levels in predictions.

- Schedule open-forum sessions to further engage interaction among all interested parties.

- Maintain a public-domain accessible database of geometries, grids, and results.

- Document workshop findings; disseminate this information through publications and presentations.

Five previous workshops have been held prior to the present study, all held in conjunction with the AIAA Applied Aerodynamics Conference for that year.

\begin{tabular}{|l|l|l|l|}
\hline Year & Location & Configuration & Case Descriptions \\
\hline 2001 & Anaheim, CA & DLR-F4 Wing-Body & $\begin{array}{l}\text { Single Point Drag Prediction } \\
\text { Drag Polar } \\
\text { Drag Rise Curves at Constant CL }\end{array}$ \\
\hline 2003 & Orlando, FL & $\begin{array}{l}\text { DLR-F6 Wing-Body } \\
\text { Wing-Body-Nacelle }\end{array}$ & $\begin{array}{l}\text { Single Point Grid Convergence Study } \\
\text { Drag Polar } \\
\text { Boundary Layer Trip Study* } \\
\text { Drag Rise Curves at Constant C }{ }_{\text {L }}^{*}\end{array}$ \\
\hline 2006 & $\begin{array}{l}\text { San Francisco, } \\
\text { CA }\end{array}$ & $\begin{array}{l}\text { DLR-F6 Wing-Body with } \\
\text { and without FX2B fairing; } \\
\text { W1/W2 Wing Alone }\end{array}$ & $\begin{array}{l}\text { Single Point Grid Convergence Study } \\
\text { Drag Polar } \\
\text { Grid Convergence Study } \\
\text { Drag Polar }\end{array}$ \\
\hline 2009 & $\begin{array}{l}\text { San Antonio, } \\
\text { TX }\end{array}$ & $\begin{array}{l}\text { NASA Common Research Model } \\
\text { Wing-Body and Wing-Body-Tail }\end{array}$ & $\begin{array}{l}\text { Grid Convergence Study } \\
\text { Downwash Study } \\
\text { Mach Sweep Study* } \\
\text { Reynolds Number Study* }\end{array}$ \\
\hline 2012 & $\begin{array}{l}\text { New Orleans, } \\
\text { LA }\end{array}$ & $\begin{array}{l}\text { NASA Common Research Model } \\
\text { Wing-Body } \\
\text { 2-D Flat Plate* } \\
\text { 2-D Bump-in-channel* } \\
\text { 2-D NACA 0012 Airfoil* }\end{array}$ & $\begin{array}{l}\text { Grid Convergence Study } \\
\text { Alpha Sweep Buffet Study } \\
\text { Turbulence Model Verification* }\end{array}$ \\
\hline
\end{tabular}

While there have been some variations, the workshops have typically used subjects based on commercial transport wing-body configurations - a consensus of the organizing committee based on a reasonable compromise between simplicity and industry relevance. The vast majority of the participants 
submit results generated with Reynolds Averaged Navier-Stokes (RANS) codes, although the organizing committee does not restrict the methodology.

The first Drag Prediction Workshop ${ }^{1}$ used the DLR-F4 geometry for the above reasons and due to the availability of publically released geometry and wind tunnel results ${ }^{2}$. The focus of the workshop was to compare absolute drag predictions, including the variation due to grid type and turbulence model type. The results were also compared directly to the available wind tunnel data. The workshop committee provided a standard set of Multiblock structured, overset, and unstructured grids for the DLR-F4 geometry to encourage participation in the workshop and reduce variability in the CFD results. However, participants were also encouraged to construct their own grids using their best practices so that learned knowledge concerning grid generation and drag prediction might be shared among workshop attendees. The test cases were chosen to reflect the interests of industry and included a fixed- $\mathrm{C}_{\mathrm{L}}$ single point solution, drag polar, and constant- $\mathrm{C}_{\mathrm{L}}$ drag rise data sets. To help encourage wide participation, a formal paper documenting results was not required at the workshop. Eighteen participants submitted results, using 14 different CFD codes; many submitted multiple sets of data exercising different options in their codes, e.g., turbulence models and/or different grids. A summary of these results was documented by the DPW-I organizing committee ${ }^{3}$. Because of strong participation, DPW-I successfully amassed a CFD data set suitable for statistical analysis ${ }^{4}$. However, the results of that analysis were rather disappointing, showing a 270-drag-count (a drag count $=0.0001 C_{D}$ ) spread in the fixed- $C_{L}$ data, with a 100:1 confidence interval of more than \pm 50 drag counts.

Despite the somewhat disappointing results, the consensus of the participants and organizers was that DPW-I was a definitive success. First and foremost, it was initiated as a "grass roots" effort by CFD developers, researchers, and practitioners to focus on a common problem of interest to the aerospace industry. There was open and honest exchange of common practices and issues that identified areas for further research and scrutiny. The workshop framework was tested successfully on high fidelity 3D RANS methods using a common geometry, grids, and test cases. Finally, it reminded the CFD community that CFD is not a fully mature discipline.

The interest generated from the workshop was continued and resulted in several individual efforts documenting results more formally $y^{5-8}$, presented at a special session of the 2002 AIAA Aerospace Sciences Meeting and Exhibit in Reno, NV. The interest generated by DPW-I naturally led to the planning and organization of the 2nd AIAA Drag Prediction Workshop, DPW-II. The DPW-II organizing committee, recognizing the success of DPW-I, maintained the format and objectives for DPW-II.

The second workshop ${ }^{9}$ used the DLR-F6 as the subject geometry in both wing-body (WB, similar to DLR-F4) and wing-body-nacelle-pylon (WBNP) form. The DPW-II organizing committee worked with DLR and ONERA to make pertinent experimental data available to the public domain. One specific objective of DPW-II was the prediction of the incremental drag associated with nacelle/pylon installation. The F6 geometry contained known pockets of flow separation more severe than the F4; occurring predominantly at the wing/body and wing/pylon juncture regions. The results from the workshop were documented with a summary paper, ${ }^{10}$ a statistical analysis, ${ }^{11}$ an invited reflections paper ${ }^{12}$ on the workshop series, and numerous participant papers ${ }^{13-21}$ in two special sessions of the 2004 AIAA Aerospace Sciences Meeting in Reno, NV. A conclusion of DPW-II was that the separated flow regions made it difficult to draw meaningful conclusions with respect to grid convergence and drag prediction. During the follow-up open-forum discussions, the CFD community voiced the desire for the organizing committee to include in the third workshop: a) Blind Test Cases, and b) Simpler Geometries. The request for blind test cases is motivated by an earnest attempt to better establish a measure of the CFD community's capability to predict absolute drag, rather than match it after-the-fact. The request for simpler geometries allows more extensive research in studies of asymptotic grid convergence.

The third workshop ${ }^{22}$ retained the DLR-F6 WB from DPW-II as a baseline configuration to provide a bridge to the previous workshop. However, to test the hypothesis that the grid-convergence issues of DPW-II were the direct result of the large pockets of flow separation, a new wing-body fairing was designed to eliminate the side-of-body separation. Details of the FX2B fairing design are documented by Vassberg $^{23}$. In addition, to help reduce the wing upper-surface trailing-edge flow separation, a higher Reynolds number was introduced for the WB test cases. These changes in both geometry and flow condition also provided the DPW-III participants a blind test since no test data would be available prior to the workshop. Furthermore, two wing-alone geometries were created to provide workshop participants with simpler configurations on which more extensive grid-convergence studies could be conducted; these 
wings were designed to exhibit no appreciable separation at their design conditions. The DPW-III was heavily documented with summary papers ${ }^{24,25}$, a statistical analysis paper $^{26}$, participant papers ${ }^{27-30}$, and a special section of the AIAA Journal of Aircraft, edited by Vassberg ${ }^{31-36}$. After three workshops, the organizing committee recognized that a recurring theme of the workshop series was related to grid quality and resolution - see Mavriplis et al. ${ }^{37}$

For the fourth workshop ${ }^{38}$ a completely new geometry was developed, called the Common Research Model (CRM). The NASA Subsonic Fixed Wing (SFW) Aerodynamics Technical Working Group (TWG), in collaboration with the DPW Organizing Committee, developed the CRM. This wing-body (with and without nacelle-pylons and horizontal tail) configuration is representative of a contemporary highperformance transonic transport. A detailed description of its development is given by Vassberg et al. ${ }^{39}$

One aspect of DPW-IV different from the other workshops was in the timing of the availability of windtunnel test data on the subject geometries. In DPW-IV, the workshop was held before any experimental data were collected and is a set of blind tests. Due to past observations of grid dependence on the solutions, a greater emphasis was placed on establishing a comprehensive set of meshing guidelines for the generation of baseline grid families. With these guidelines in place, grids were requested from several organizations for structured multiblock, overset, and unstructured types. Each grid family was required to include a Coarse (C), Medium (M), and Fine (F) grid; adding an optional Extra-Fine (X) grid was also encouraged. Target sizes for these grids were 3.5, 10, 35, and 100 million unknowns, respectively. The Medium mesh was intended to be representative of current engineering applications of CFD being used to estimate absolute drag levels on similar configurations. A total of 74 meshes of 18 families were provided and made available to participants for use.

The fourth workshop requested grid convergence and Mach sweep computations as in the previous workshops, plus downwash and Reynolds Number studies. Data were submitted from 19 organizations totaling 29 individual datasets. For the grid refinement study, a Richardson Extrapolation methodology was employed to estimate a continuum value for the total drag coefficient. Excluding a single outlier, the scatter band for DPW-IV reduces dramatically to 41 counts, which is a definite improvement over DPW-I (with one outlier, the range for the total drag coefficient spanned 152 counts). While this improvement is quite significant, the confidence level is not down to a low enough level to compete with experimental methods. Documentation for these results can be found in summary papers ${ }^{40-41}$ and in individual contributing papers ${ }^{42-56}$ from two special sessions held at the $28^{\text {th }}$ Applied Aerodynamics Conference in June 2010.

Despite the emphasis placed on grid generation with the intent of reducing the associated errors, the variation in the DPW-IV results was still disappointing. For the fifth workshop ${ }^{57}$, which was held in conjunction with the $30^{\text {th }}$ AIAA Applied Aerodynamics conference in June 2012, a new approach was taken with the goal of reducing grid-related errors even further. As with the fourth workshop, the NASA Common Research Model wing body configuration was used for the geometry (without tail). For the grids, a unified baseline ${ }^{58}$ family of Multiblock structured meshes was developed with six different levels ranging in size from $0.64 \times 10^{6}$ (Tiny) to $136 \times 10^{6}$ (Superfine) mesh points. Each successive coarse level was derived directly from the finest mesh. Only five blocks were used. Once the cloud of points was defined for this series of grids, then Overset and Unstructured grids were derived. The unstructured grids were defined in Hexahedral, and Prismatic elements, plus a hybrid grid with Prismatic boundary layer and Tetrahedral field elements was defined.

The test cases included a grid refinement study using the common grids or user-supplied custom grids if desired. The second case focused on buffet prediction, with a finely spaced alpha sweep spanning the range where flow separation on the wing was observed in the wind tunnel data and the results in DPW-IV. This was a change from previous workshops, where angle-of-attack sweeps from $0^{\circ}$ to $4^{\circ}$ were calculated for the purpose of determining trimmed drag polars. For a commercial transport like the CRM, high-speed lines development is undoubtedly very important, as it would contribute to whether speed and range goals are met. However, it usually comprises less than $25 \%$ of the total aerodynamics-related airplane development effort. Significant effort must also be paid to loads, handling qualities, and other constraints that are required to meet structural and certification requirements. Many of these high-speed flight concerns occur at the edges of the flight envelope, which are characterized by large regions of separated flows. For the Fifth Drag Prediction Workshop, the buffet study was included to assess CFD prediction in this regime. The optional third test case used geometries, grids, and conditions from the Turbulence Model 
Resource website ${ }^{59}$ prepared by the Turbulence Model Benchmarking Working Group. Three cases were selected: 1) 2D Zero Pressure Gradient Flat Plate, 2) 2D Bump-in-channel, and 3) 2D NACA 0012 Airfoil. These test cases were designed to discriminate between turbulence model implementations through rigorous grid convergence studies. Documentation for these results can be found in summary papers ${ }^{60-61}$ and in individual contributing papers ${ }^{62-70}$ from two special sessions held at the $51^{\text {st }}$ Aerospace Sciences Meeting, January 2013, the $52^{\text {nd }}$ Aerospace Sciences Meeting, January 2014, and a special collection in the AIAA Journal of Aircraft ${ }^{71}$.

This paper presents an overview of the computational results, geometry, and grid definitions used for Cases 2-5 of the Sixth Drag Prediction Workshop (DPW-VI) ${ }^{72}$. The Sixth Drag Prediction Workshop was held in conjunction with AIAA Aviation 2016, and included 25 participant teams from 4 continents representing government, industry, academic, and commercial CFD organizations. The workshop again focused on the CRM model and the NACA 0012 airfoil. Detailed grid convergence studies for drag and skin friction coefficient for the Case 1 Turbulence Modeling results based on the NACA 0012 airfoil are presented in Ref. 73. Cases 2-5, which involve the CRM model, are presented in this paper. For the CRM, four case studies were specified, two of which were optional. The four test cases are described in more detail in Section IV of this paper. New for DPW-VI is the inclusion of the static aeroelastic deformation in the definition of the CRM models for each angle-of-attack/ $\mathrm{C}_{\mathrm{L}}$ condition specified in the test cases. This makes comparisons to force, moment, and pressure data from the related wind tunnel tests more meaningful in that the geometry of the computational model better represents that of the wind tunnel model at the specified flow condition. The participant data for the Case 2 grid refinement study of both the CRM WingBody (WB) and the Wing-Body-Nacelle-Pylon (WBNP) models are analyzed, including Force/Moment predictions, wing pressure distributions, and flow separation patterns at the wing/body trailing edge juncture. Richardson extrapolation can be used to estimate the continuum force levels and the drag increment between the two configurations. Results of a statistical analysis of Case 2 are presented in Ref. 74. Analysis of the Case 3 static aeroelastic/buffet study is presented, including force/moment and pressure predictions with comparisons to wind tunnel test data. Flow separation predictions at the wing/body trailing edge juncture and wing trailing edge are also shown. The goal here was the assessment of CFD in flight regimes where increasing levels of flow separation are expected. Results are also shown for the two optional cases: Case 4 grid adaptation, and Case 5 coupled aerostructural simulation. Case 5 is only briefly covered here for completeness. A detailed description of Case 5 results can be found in Ref. 75 .

\section{Geometry and Experimental Data Description}

The subject geometry for DPW-VI Cases 2 through 5 is the Common Research $\operatorname{Model}^{39}$ (CRM) developed jointly by the NASA Subsonic Fixed Wing (SFW) Aerodynamics Technical Working Group (TWG) and the DPW Organizing Committee. The CRM represents a modern transonic commercial transport airplane, and was designed as a full configuration with a low wing, body, horizontal tail, and engine nacelles mounted below the wing. For this workshop, the wing-body and wing-body-nacelle-pylon configurations were used. A rendering of the wing-body-nacelle-pylon configuration geometry is shown in Fig. 1, along with a photo of the wing-body wind tunnel model (with horizontal tail) installed in the NASA Ames Research Center Unitary Plan Wind Tunnel 11- by 11-Foot Transonic Wind Tunnel (11-Foot TWT). The CRM was also the subject geometry for DPW-IV and DPW-V.

The wing is designed for a nominal condition of Mach $=0.85, \mathrm{C}_{\mathrm{L}}=0.50$, and Reynolds Number $40 \times 10^{6}$ based on $\mathrm{c}_{\text {ref. }}$ Pertinent geometric parameters are listed in Table 1. The wing is a supercritical design, and the Boeing Company took the lead on the aerodynamic design. Certain features are designed into the wing profile for the purposes of research and development. For example, the upper-surface pressure recovery over the outboard wing is intentionally made aggressively adverse over the last $10-15 \%$ local chord. This promotes separation of the upper-surface boundary layer in close proximity to the wing trailing edge (TE) at lift conditions slightly above the design point. The strong adverse pressure gradient will likely amplify the differences in various turbulence models that may be employed by DPW participants. Another feature is that the span loading is designed to be very nearly elliptical as compared to a more practical design that would use a compromise distribution (more triangular) to reduce structural loads and decrease airframe weight. This feature is included to provide a challenge for possible future workshops on aerodynamic shape optimization that might explore structure and fuel weight trade-offs. 
In assessing the accuracy of CFD, wind tunnel results are frequently used as the "gold standard." However, even if we had the perfect CFD code, we would not, nor should we get perfect agreement with wind tunnel results, because the wind tunnel is also imperfect. Each wind tunnel experiment has its own imperfections, which must be understood or at least recognized in order to assess or validate the CFD. Differences in the "test" setup between Wind Tunnel and CFD are well known, and a few are listed below:

Wind Tunnel
Walls
Support System (Sting)
Laminar/Turbulent (Tripped)
Aeroelastic Deformation
Measurement Uncertainty
Corrections for known effects

\section{CFD}

Free Air

Free Air

"Fully" Turbulent Specified (usually)

Rigid Shape (except Case 5)

Numerical Uncertainty and Error

No Corrections

Clearly there are potentially significant differences between what Wind Tunnel and CFD are measuring/computing. Effective CFD assessment requires intimate knowledge of both the CFD and the experimental data being compared. CFD assessment cannot consist of the comparison of the results of one code to those of one experiment. Rather, it is the agglomeration of comparisons at multiple conditions, code-to-code comparisons, an understanding of the wind tunnel corrections, etc., that leads to the understanding of the CFD for use as an engineering tool.

An advantageous outcome of the collaborative endeavor sponsored by the NASA Aerodynamics Technical Working Group (TWG) has been that the CRM has now been tested in several facilities thus far, and the data from several of these tests are now publicly available. The National Transonic Facility (NTF) at NASA Langley tested the CRM during January - February 2010, followed by a test at the NASA Ames 11-Foot TWT (Unitary Plan Wind Tunnel 11- by 11-Foot Transonic Wind Tunnel) during March - April 2010. Data from the Langley and Ames tests have been released to the public domain by Rivers and Dittberner ${ }^{76-78}$. The CRM Wing-Body configuration was tested at the European Transonic Wind Tunnel (ETW) facility in February $2014^{79}$. These data have also been released to the public domain ${ }^{80}$. These three tests all used the same physical wind tunnel model. A slightly larger version of the CRM Wing-Body-Tail was more recently built by ONERA and tested in the ONERA S1MA wind tunnel ${ }^{81}$. In 2012, an 80\% scale model of the NASA CRM built by JAXA was tested in the JAXA $2 \mathrm{~m} \times 2 \mathrm{~m}$ Transonic Wind Tunnel ${ }^{82}$.

A comparison of data from the various wind tunnels shows that the wing pressure distributions are virtually indistinguishable at the conditions specified for DPW-VI. Whether this is true for other conditions has not been checked in detail. Force and moment data from the different wind tunnels do differ. It is believed that these differences are mainly due to the corrections applied to the "raw" measured data to account for wind tunnel walls, mounting system, nonuniform flow (buoyancy, upflow, etc.), Mach blockage, lift interference, etc. Each wind tunnel facility tries very hard to determine the "best" set of corrections to its data to simulate "free air." The CRM test data do not include mounting system corrections. Mounting system effects, which require a special set of tests to determine, are usually not included in the standard set of corrections applied to the wind tunnel data. Because of the flow anomalies present in every wind tunnel and the approximate nature of the corrections applied to account for these irregularities, the absolute measurement of forces and moments corresponding to "free air" is impractical if not impossible. It is therefore not unusual that the drag levels will differ between wind tunnels. Today's CFD requires modeling of turbulence and transition. Perhaps when direct numerical simulation of the Navier-Stokes equations is possible for complex configurations at high Reynolds number will the calculation of absolute forces and moments will be possible. However, the calculation or measurement of increments between two similar configurations should certainly be feasible with carefully executed wind tunnel test programs and CFD. For comparison purposes, test data from the NASA 11-Foot TWT and NTF tests will be used. Both the Wing-Body and the Wing-Body-Nacelle-Pylon configurations of the same physical model were tested in these two tunnel facilities.

New for DPW-VI is the inclusion of the static aeroelastic deformation in the definition of the CRM models for each angle-of-attack/ $\mathrm{C}_{\mathrm{L}}$ condition specified in the test cases. The wing static aeroelastic bending and twist deflection were derived using a videogrammetry technique in which the position of 
markers on the wing was measured during the test. The bending and twist deflection used to define the geometries for DPW-VI were based on data measured in the ETW test in 2014. While the test results from the ETW test and those from the NASA NTF and 11-Foot TWT tests were quite similar, it was decided to use the ETW results. These data were interpolated to the angles-of-attack required in test cases 2 to 4 to define the various geometries ${ }^{83}$. Static aeroelastic wing twist for various angles-of-attack is shown in Fig. 2. Note that the resulting aeroelastic twist is small, amounting to only a little over one degree near the wing tip. However, at transonic flow conditions, this small amount of aeroelastic wing twist has a significant effect on the resulting pressure distributions as shown in Fig. 3 for two spanwise locations. Computed lift, drag, and pitching moment are also affected. Inclusion of the aeroelastic deformation makes comparisons to force, moment, and pressure data from the related wind tunnel tests more meaningful in that the geometry of the computational model better represents that of the wind tunnel model at the specified flow condition.

Limitations in the total number of pressure taps that can be built into the wind tunnel model and subsequent plugged and/or "slow" taps may result in inadequate definition of the experimental pressure distributions at the various span stations. This is particularly the case in defining the wing shock location in transonic flow and adequately defining the aft loading near the wing trailing edge. For attached flow conditions, there is very little change in the pressures near the wing trailing edge. In order to calculate section lift and moment characteristics, it was necessary to "enhance" the experimental pressure distributions. The "enhancement" to the pressures near the wing trailing edge was based on a combination of interpolation/extrapolation guided by experience with test data and CFD. At three midspan stations, missing or very "slow" taps required a further "enhancement." These "enhanced pressures" were based on pressure measurements from the JAXA 80\% CRM model, which did not suffer these pressure tap manufacturing deficiencies. An example of these enhancements is shown in Fig. 4 for two spanwise stations. The original pressure data are shown by the open symbols, the enhanced distributions are shown by the solid symbols.

\section{Gridding Guidelines and Description of Common Grids}

This section describes the baseline grid families provided by the DPW-VI organizing committee. This set includes an overset grid family by Boeing, an unstructured mesh family by NASA, and an unstructured mesh family by DLR. Additional information of each baseline grid family is provided in this section below. Since these grids were developed by several different people from different institutions, a set of gridding guidelines were developed beforehand, in order to maintain some level of consistency between the baseline grid families of the various types of grid systems. These gridding guidelines were then used by the various grid developers as a target end state of their grid systems and families. We note that while these gridding guidelines are fairly comprehensive, the resulting grid systems do not strictly conform to them. The reasons for this vary, but are usually the result of being difficult to implement. Hence, the baseline grid families closely conform to most of the gridding guidelines. The DPW-VI gridding guidelines are given in Table 2.

\section{A. Baseline Overset Grid Families for DPW-VI}

The baseline overset grid family was developed by Leonel Serrano and John Vassberg of Boeing, and reviewed by Tony Sclafani, Mark DeHaan, Gaetan Kenway, Jim Coder and Tom Pulliam. This group also comprised the principal set of participants who used the baseline overset grid systems in DPW-VI.

The basic layout of the overset structured meshes began with an exercise in numerology which addressed the gridding guidelines on: a) family members being parametrically equivalent, b) growth between family member sizes being about $1.5 x$, c) grid blocks being multigrid friendly, d) having at least two constantly-spaced cells at all viscous walls, and e) retaining feature lines in all members of the grid family. In order to grow grid size by a factor of about $1.5 \mathrm{x}$, the growth factor in each of the three computational directions should be about $1.15 \mathrm{x}$, as $1.15^{3} \sim 1.5$, whereas 1.15 is about $8 / 7$, and we adopted this rational growth factor for our fine-to-extrafine mesh. Working backward and forward, this established the growth factor sequence of: Tiny $x(5 / 4)^{3}=$ Coarse $x(6 / 5)^{3}=$ Medium $x(7 / 6)^{3}=$ Fine $\times(8 / 7)^{3}=$ Extrafine $x(9 / 8)^{3}=$ Ultrafine. Hence, the grid sizes of this six-member grid family span just over an orderof-magnitude, or a factor of $11.4 \mathrm{x}=(9 / 4)^{3}$. Also, by using a cell-count dimension that is evenly divisible 
by 4 on each pertinent segment of the Tiny mesh, the span of the segments will be exactly maintained for each of the members of the grid family. For example, the segments of the airfoil sections on the wing of the Tiny mesh were dimensioned as 16 cells on the trailing-edge, 88 cells on the upper surface, and 88 cells on the lower surface, for a total of 192 cells around the airfoils. Hence, all members of the overset grid family retain the two trailing-edge lines as well as the leading-edge line in their surface grids. Applying this approach throughout the grid layout, the intersection lines of the wing-body, the wing-pylon, and the nacelle-pylon, as well as the wing planform break, and pylon and nacelle leading and trailing edges were all consistently maintained across all grid-family members.

With a basic understanding of our strategy to grid dimensions, a template mesh and topology layout was developed for the wing/body/nacelle/pylon (WBNP) geometry. The WBNP grid layout was comprised of 25 blocks. This template mesh was used to generate a parametrically equivalent family of WBNP grids. To generate the wing/body (WB) grid family, the NP grids were simply removed from the WBNP grids, leaving 8 blocks to define the WB overset grid systems. The gridding guidelines recommended a ratio of grid sizes between the WBNP and WB systems of $1.3 \mathrm{x}-1.5 \mathrm{x}$, whereas this ratio for the overset grid systems was about 1.6x.

The topology of the near-field grid blocks about the WBNP with a focus on the NP group is shown in Fig. 5. Here, the fuselage is fully defined by three grid blocks; a half O-mesh covering most of the fuselage, a warped block at the nose, and a collar grid at the wing-body juncture. The wing is represented by an O-mesh wrapping around the airfoil sections, the wing-body collar grid, and a wingtip grid. The nacelle is comprised of five surface-abutting blocks; clamp grids at the leading and trailing edges, a collar grid, and inner and outer O-meshes. The pylon has collar grids at the wing and nacelle juncture regions, as well as a number of patch grids. Finally, a global box grid encompasses all of the above and places the farfield boundary at about 100 semispans from the CRM configuration. The WBNP surface grids for each grid size were created using ICEM-CFD HEXA using the template blocking file developed for this topology and ICEM replay scripts. Then, the surface-abutting grid blocks were generated using the NASA Chimera Grid Tools (CGT); more specifically, using BUILDVOL and HYPGEN. Finally, the hole-cutting and block-stitching steps were performed with the BUILDPEG5i script. This complete process was repeated to develop the WBNP family of grid resolution and another WBNP family of aeroelastic deflection. The corresponding WB families were developed by dropping the NP grids and rerunning BUILDPEG5i. This process yielded WB grids without any orphan points and WBNP grids with at most five orphans. Table 3 provides statistics for the grid family of increasing sizes. Note that for the Tiny mesh, the viscous spacing was $y+\sim 1$, its maximum stretching through the boundary-layer region was about 1.235, and that 4 cells of constant spacing at the viscous walls were utilized. These characteristics adhere closely to the gridding guidelines provided above. Note that the grid sizes are given as a total number of grid points in the systems.

Fig. 6a provides close-up views of the WBNP surface grids for the Medium mesh. Note that the spanwise clustering of the wing grid is established to capture gradients induced by the NP group. Retaining this clustering is somewhat of an overkill for WB simulations, however, provides accurate results for the NP delta drag evaluations. Fig. $6 \mathrm{~b}$ depicts a close-up of the nacelle/pylon surface grids that illustrate the wing-pylon and pylon-nacelle collar grids, as well as numerous patch grids to complete the pylon surface. In addition to these body-conforming meshes, near-field box grids enclose the fuselage, the wing, and the nacelle inlet and nozzle openings. The WB collar grid, the O-mesh about the wing, and the wingtip clamp grid of the Medium mesh are depicted in Figs. 7a, 7b, and 7c, respectively.

The baseline overset grids can be downloaded from the DPW-VI website ${ }^{72}$ and are located in the overset_grids_Boeing_Serrano.REVOO directory. Included in this location is a README.BoeingSerrano file for additional information about these grid families. There are six WBNP grids and six WB grids about the $a e 2 p 75$ geometry that constitute the grid resolution families, and an additional seven WB grids at the Medium mesh density to fill out the aeroelastic family. All grids were built relative to the version v09 IGES geometry definitions of the CRM WBNPH configuration, also available for download at the DPW-VI website.

\section{B. Baseline NASA GeoLab Unstructured Meshes for DPW-VI}

The baseline unstructured-mesh families for DPW-VI were developed by Norma Farr and Mike Wiese of NASA's GeoLab group. These grids can be downloaded from the DPW-VI website under the unstructured_NASA_GeoLab.REV01 directory. Sample surface grids are shown in Fig 8. Statistics of the 
WB and WBNP grid-refinement families are given in Tables 4 and 5, respectively, and for the WB aeroelastic family in Table 6.

\section{DLR SOLAR Unstructured Meshes for DPW-VI}

Unstructured quadrilateral/hexahedral dominated grids were generated by Stefan Melber-Wilkending and Stefan Keye using the commercial, hybrid, quad-dominant grid generation package SOLAR formerly developed by a consortium of ARA, BAE Systems, QinetiQ, and Airbus ${ }^{84}$ Four grid levels, Tiny to Fine, were successfully built on both configurations. Grid generation was started from the Fine level, deriving the coarser grids through a linear scaling of meshing sources by a factor of $1 / 1.51 / 3=0.873$. All meshes are compliant to the DPW-6 gridding guidelines with two exceptions: a) wing and nacelle trailing edge base spatial resolution was reduced from the required $\gg 8$ cells to 2 cells inboard, increasing to 7 cells at the wing tip; b) wing spanwise spacing was increased from $<0.1 \% \times$ semi-span at root and engine to $\sim 0.34 \%$. Table 7 presents the data of the grids available. Fig. 9 shows the quadrilateral-dominated surface grid on the CRM with pylon and nacelle.

\section{Additional Available Meshes for DPW-VI}

Several other grid families were available for download from the DPW-VI website. Mixed element and all-tet element unstructured grids can be found in the Boeing_Babcock_Unstructured_CC.REVOO directory. The mixed element grids were generated using the MADCAP/AFLR toolset. A mesh sizing template was developed for the WBNP case and used to generate the 7 grid levels. The nacelle/pylon was removed and hole filled for the WB cases. The mixed element grids were converted to generate the all-tets grid sets.

Another set of unstructured grids was made available by the China Aerodynamics Research and Development Center (CARDC). These unstructured grids were generated with Pointwsie (version 17.1 R4) by Dr. Zhang Yaobing. The grids are formatted with CGNS 2.54 and best fitting for cell centered solvers. These are found in the CARDC_ZhangYB_unstructured_CC.REVOO directory.

Embraer and CFS Engineering created Multiblock structured grids for the CRM. Embraer made a set of Multiblock Structured grids for the WB configuration available. These were generated by Marcello Areal Ferrari using Embraer's Automatic Mesh Generator (GMA) with Ansys ICEM. These grids are in GCNS format and are found in the Embraer_Ferrari directory.

Dominique Charbonnier from CFS Engineering used Ansys ICEM to generate the WBNP grids. These are also in CGNS format and are found in the CFSE_Charbonnier directory on the DPW-VI website.

Further details on all the grid families can be found in the presentations in the DPW-VI website.

\section{Test Case Descriptions}

It is recognized that many of the DPW participants are from industry and academia and may have limited time and resources to devote to this type of study. The test case specifications, as with the grid definitions, are set to encourage participation by restricting the number of cases to a manageable number while also providing a challenge to test the state of the art in CFD prediction capabilities. Five test cases were specified for the Sixth AIAA CFD Drag Prediction Workshop; a verification case based on a twodimensional airfoil and four CRM based case studies of which, two were optional.

Case 1 - Verification Study: 2D NACA0012 Airfoil from the Turbulence Modeling Resource (TMR) sponsored by the AIAA Fluid Dynamics Technical Committee Turbulence Model Benchmarking Working Group (TMBWG). Summary results for Case 1 are presented in Reference 73.

Case 2 - CRM Nacelle-Pylon Drag Increment: Calculate the drag increment between the CRM wingbody-nacelle-pylon (WBNP) and the CRM wing-body (WB) configurations. Flow conditions are: $\mathrm{M}=0.85 ; \mathrm{Re}=5$ million; fixed $\mathrm{C}_{\mathrm{L}}=0.5+/-0.0001$; Reference temperature $=100^{\circ} \mathrm{F}$; aeroelastic deflections at the angle-of-attack 2.75 degrees geometry. Grid convergence study on Baseline WB and WBNP grids.

Case 3 - CRM WB Static Aero-Elastic Effect: Angle-of-attack sweeps are conducted using the aeroelastic deflections measured in the ETW Wind Tunnel Test. Flow conditions are: $\mathrm{M}=0.85$; 
$\operatorname{Re}=5$ million; Reference temperature $=100^{\circ} \mathrm{F}$; Angle-of-attack sweep $=[2.50,2.75,3.00,3.25$, $3.50,3.75,4.00]$ degrees. The Medium Baseline grids defined for each angle-of-attack [7 solutions on 7 grids] are to be used.

Case 4 - CRM WB Grid Adaptation [Optional]: Fixed lift condition for the CRM Wing-Body using an adapted grid family provided by the participant. Flow conditions are: $\mathrm{M}=0.85 ; \operatorname{Re}=5$ million; fixed $\mathrm{C}_{\mathrm{L}}=0.5+/-0.0001$; Reference temperature $=100^{\circ} \mathrm{F}$; aeroelastic deflections at the angle-ofattack 2.75 degrees geometry. Start the adaptation process from the Tiny (or Coarse) Baseline Mesh. Participants are to document the adaptation process.

Case 5 - CRM WB Coupled Aero-Structural Simulation [Optional]: Fixed lift condition for the CRM Wing-Body coupled with computational structural analysis. Flow conditions are: $\mathrm{M}=0.85 ; \mathrm{Re}=5$ million; fixed $\mathrm{C}_{\mathrm{L}}=0.5+/-0.0001$; Reference temperature $=100^{\circ} \mathrm{F}$; static aeroelastic deflections calculated, starting from the undeformed geometry. Start with the undeformed Medium Baseline Grid. A structural FEM has been supplied by NASA via the CRM Website. Modal shapes have also been made available.

All CRM simulations are to be "free air" with no wind tunnel walls or support system. The boundary layer is to be modeled as "fully turbulent" for all cases. No free or fixed laminar to turbulent transition is to be specified.

To collect a consistent set of data from each participant, template datasets were supplied. These templates request lift, drag (broken down into skin friction and pressure components), pitching moment, pressure distributions at specified span stations, trailing-edge separation locations, dimensions of the sideof-body separation bubble, grid family and sizes, turbulence model, computing platform and code performance, number of processors used, number of iterations required, etc. For Case 5, values of the calculated wing twist and bending deflections were also requested. These workshops capture an extensive amount of information that serves as a snapshot of the industry capabilities of the time. For example, in the five workshops held thus far, one obvious trend is that the grid size has grown dramatically. The average size of the medium WB meshes in DPW-I through DPW-IV have been 3.2, 5.4, 7.8 and 10.9 million, respectively. This represents a growth rate of $\sim 17 \%$ per year during the eight years between DPW-I and DPW-IV. For DPW-VI, this number has grown from 25 to $50 \mathrm{M}$ points for the various families of grids available. The finest level grids have increased steadily, from just over 3 million unknowns in DPW-I to 225 million for the WBNP in DPW-VI.

\section{Results}

The level of participation in DPW-VI was excellent by many counts. Users submitted data from a wide variety of sources, code types, grid types, and turbulence models. Some performed studies that specifically addressed the effects of gridding and/or turbulence modeling with the same code. As mentioned above, the geometry, test cases, and data format were all uniformly controlled to facilitate the analysis.

\section{A. Participant Descriptions}

The Drag Prediction Workshop is open to any individual, group or organization that wishes to perform the calculations according to the specifications set out by the organizing committee. The response for DPW-VI has increased somewhat from the previous workshop, following a trend of gradually increasing participation.

A total of 54 datasets were submitted from 25 different teams or organizations. Of these teams, broken down by location and type as follows:

- 12 North America, 6 Europe, 6 Asia, 1 South America

- 8 Government, 5 Industry, 7 Academia, 5 Commercial

The presentations by each participant can be found at the DPW-VI website ${ }^{72}$ and contain a description of the computational method used and results presented. For Cases 2 to 5, the grid type and turbulence model breakdown included: 
- Grid Types: 7 Common Overset (4 Teams)

4 Common Structured Multiblock (3 Teams)

21 Common Unstructured (12 Teams)

15 Custom Unstructured (12 Teams)

7 Custom Cartesian (4 Teams)

$\begin{array}{lll}\text { - Turbulence Models: } & 21 & \text { SA (many variants) } \\ & 15 & \text { SA-QCR (many variants) } \\ 8 & \text { SST (many variants) } \\ 2 & \text { k-kLe-MEAH2015 } \\ 3 & \text { k- } \varepsilon \text { Lam Bremhorst } \\ 1 & \text { EARSM } \\ 1 & \text { RSM- } \omega \\ 1 & \text { Realizable k- } \varepsilon \\ 1 & \text { k- } \varepsilon \\ 1 & \text { LBM-VLES }\end{array}$

$\begin{array}{lcl}\text { - Solvers: } & 23 & \text { Finite Volume } \\ 2 & \text { Finite Element } \\ & 1 & \text { Lattice-Boltzmann Method }\end{array}$

New to the DPW series this year was a solution based on the Lattice-Boltzmann Method ${ }^{85}$ that is totally different from the classical finite volume/finite element methods used to date. Two sets of solutions were based on finite element SUPG solvers ${ }^{86,87}$ - one more than DPW-V. All participants were asked to submit forces, moments, pressure, and separation data in the standard format.

The large number of datasets poses a challenge in the presentation of the data. Each dataset is assigned an alphanumeric (including Greek) symbol type while colors are used to denote grid or turbulence model type depending on context. All of the force/moment and pressure plots below follow the scheme listed in Table 8.

\section{B. Case 2: CRM Nacelle-Pylon Drag Increment}

Case 2 focused on computing the drag increment between the CRM Wing-Body-Nacelle Pylon and the CRM Wing-Body configurations. This included a grid refinement study for both configurations at $\mathrm{M}=0.85$ and $\mathrm{C}_{\mathrm{L}}=0.500$. All computational values for Case 2 are for these values of Mach number and lift coefficient. A standard technique in grid convergence studies is to use Richardson extrapolation. Computational results are plotted versus grid factor, $\mathrm{N}^{-2 / 3}$ (called GRIDFAC in figures), where $\mathrm{N}$ is the number of unknowns. For second order codes, a linear fit should be observed with decreasing error as long as the refinement is in the asymptotic region. The y-intercept then estimates the theoretical infinite resolution (continuum) result. The trends with grid factor, broken out by grid type and turbulence model, for total drag of the Wing-Body configuration are shown in Fig. 10. Overall, with some exceptions, the variation of total drag with increasing grid size (decreasing grid factor) is very flat. An extrapolation to the theoretical infinite resolution indicates that the bulk of the results converge to a band about 5-10 counts wide! A more detailed parsing of these results will follow shortly. A look at the pressure drag with increasing grid size shows an even tighter grouping for most solutions, Fig. 11. The skin friction drag trend, Fig. 12, is also pretty tight, again with a few exceptions. The variation of pitching moment with increasing grid size is shown in Fig. 13. For many solutions, there is little variation in pitching moment with increasing grid size while for others there was, but even these appeared to be trending to a similar continuum level as the other solutions.

In order to get a better understanding of the total drag trends shown in Fig. 10, those solutions have been further parsed according to turbulence model for each grid type family. These trends are shown in Fig. 14 for the GeoLab, Boeing, and custom unstructured grids, the overset grids, the multiblock grids, and the custom Cartesian grids. Also shown for reference in the figure are experimental values from three different test runs each at the NTF and 11-Foot TWT wind tunnels. (These wind tunnel campaigns included both the WB and the WBNP configurations.) It should not be a surprise that the tightest grouping of drag 
values with increasing grid size is for the overset and multiblock grids. Some of this could be due to the smaller number of solutions, but it is easier to maintain a degree of consistency in generating a family of structured grids than it is for unstructured grids. These solutions, based on three different types of turbulence models, are trending to a drag value in the continuum within 2-3 counts! The solutions based on the unstructured grids show a 6 to 8 count spread, although several are also converging to the same level of that of the structured codes, especially when hexahedral dominated unstructured grids are used. The custom Cartesian grid solutions are interesting. Note the changed scale for these results. One family, I1(I) and I2( $\beta$ ) starts with much smaller grids than other solutions. Their biggest grid was about the size as the smallest of the other families. While solution I2 appears to diverge from the expected trend line, solution I1 shows an indication that it might trend in the continuum to a value similar to most other solutions. Solutions $\mathrm{K} 3(\gamma)$ and $\mathrm{K} 4(\Gamma)$ are right inline with those of the overset and multiblock grids. Solution G1, based on a Lattice-Boltzmann method, is trending to a value in the continuum that, while high, is not too different from that of the other solutions.

The trends with grid factor, broken out by grid type and turbulence model, for total drag of the WingBody-Nacelle-Pylon configuration are shown in Fig. 15. Overall, the variation of total drag with increasing grid size (decreasing grid factor) is very similar to that seen for the Wing-Body configuration. Rather than dissect these results in a similar manner to what was done for the Wing-Body configuration, we will instead focus on the drag increment between the Wing-Body-Nacelle-Pylon and the Wing-Body configurations. Values of total drag for the two configurations were interpolated to common grid factor values and differenced. The drag increments (deltaCD $=\mathrm{CD}_{\mathrm{WBNP}}-\mathrm{CD}_{\mathrm{WB}}$ ) are plotted vs. grid factor shown in Fig. 16. These have been parsed according to grid type and turbulence model similar to that shown in Fig. 14. It is interesting to note that in most cases the computed drag increment with increasing grid size falls within the experimentally determined value of $22.8 \pm 1.2$ counts. This value is based on 3 runs for each configuration from both the NTF and 11-Foot TWT wind tunnels. Careful application of CFD and careful wind tunnel testing with several repeats can yield very credible drag increments.

Wing pressure distributions at three wing stations from one data set for the Wing-Body configuration are shown in Fig. 17. The pressure distributions are from three grid sizes, L1 the smallest to L7 the largest. Experimental data from the 11-Foot TWT wind tunnel test are shown for two different lift coefficient, $\mathrm{C}_{\mathrm{L}}$, values that bracketed the computational value of $C_{L}=0.50$. There is very little difference in the distributions due to grid size. Similar comparisons from other data sets showed even less variation. This is an indication that even the smallest grids were already quite adequate for predictions of pressure distributions. This is also attested to by the relative flatness of the drag prediction seen in Fig. 14. Pressure distributions from the finest grid for the Wing-Body from each solution set submitted are shown in Fig. 18. It should not be too surprising that, with the exception of distributions for the solution I2, there is little difference between all the solutions. The differences between the remaining solutions are seen mainly in the shock location with the differences increasing on the outboard wing stations. Wing and nacelle pressure distributions from the finest grid for the Wing-Body-Nacelle-Pylon configuration from each solution set submitted are shown in Figs. 19 and 20. Similar to that of the Wing-Body, very little difference is seen between wing pressures for the Wing-Body-Nacelle-Pylon sets. Nacelle pressure distributions were submitted by less than half of the participants. These were practically identical to each other.

New for DPW-VI, wing section characteristics, lift (normal force) and pitching moment coefficients were requested. These are obtained by integrating pressure coefficient, $\mathrm{Cp}$, vs. chord fraction, $\mathrm{x} / \mathrm{c}$. Less than half of the participants submitted these data sets. Wing section characteristics vs. span fraction, eta, are shown for both the Wing-Body and Wing-Body-Nacelle-Pylon configurations in Fig. 21. Given that there is little difference in wing pressures between data sets for the two configurations, it is not surprising that the resulting section lift (normal force) and pitching moment characteristics are nearly identical at the scale plotted in this figure. It is interesting to note that there is little difference between the two configurations from either the computational or experimental results.

Results of a statistical analysis of Case 2 are presented in Ref. 74.

\section{Case 3 - CRM WB Static Aeroelastic Effect}

The second mandatory CRM case is based on a Wing-Body static aeroelastic/buffet study to investigate the CFD predictions in an angle-of-attack range where significant flow separation is expected. This flight regime is of particular importance to determining aerodynamic loads and stability and control 
characteristics. Seven angles-of-attack were specified between $2.5^{\circ}$ and $4.0^{\circ}$ at $0.25^{\circ}$ increments. As noted in Section II, in order to account for the static aeroelastic deformation of the wind tunnel model, a separate geometry/grid was defined for each angle-of-attack requested. Computed results of lift, drag, pitching moment, wing section pressure and skin friction coefficients at specified spanwise locations, and locations of flow separation on the wing and side of body were requested at each angle-of-attack. Over 40 data sets were provided by the Workshop participants for Case 3.

Lift and pitching moment results from all the Workshop submittals, along with the NTF and 11-Foot TWT test data are shown in Fig. 22. Most of the solutions are clustered within a "fan" that gets progressively wider with increasing angle-of-attack. In general, the solutions are indicating a higher lift at a given angle-of-attack, and a more negative (nose down) pitching moment at a given lift coefficient than indicated by the test data. Some of this level difference could be due to the lack of mounting system corrections to the wind tunnel data. It should also be noted that at the higher angles-of-attack there is $\mathrm{s}$ significant amount of buffeting of the wind tunnel model due to the increasing flow separation and shock movement. There is some unsteady content at the higher angles-of-attack that is not represented by the test data. The wind tunnel force data are heavily filtered and represent an average value at the particular flight condition measured. The pressure transducers measuring the wing pressure distributions are not capable of measuring high frequency variations and also present average values. Mounting system effects and unsteady aerodynamic content will not account for the significant spread of predicted lift and pitching moment at the lower angles-of-attack where the flow is well attached.

All the solutions were examined to determine outliers, and if there was some defining characteristic that determined the quality of the solution. In order to get a better understanding of the lift trends shown in Fig. 22 , those solutions have been further parsed according to turbulence model for each grid type family. These trends are shown in Fig. 23 for the GeoLab, Boeing, and custom unstructured grids, the overset grids, the multiblock grids, and the custom Cartesian grids. The outliers were defined as solutions that exhibited a break in lift (relative to the linear lift vs. $\alpha$ slope), exhibited lift and/or drag considerably outside the norm of the other solutions, or exhibited wing pressure distributions that were outside the norm of the other solutions and test data. Outliers were seen in solutions from all grid families, and from SA (without QCR), SST, and the k-e Lam-Bremhorst turbulence models. Lift break, which is indicative of a large increase in flow separation, occurred as early as $3^{\circ}$ angle-of-attack in one solution.

The source of the early break can be found by examining the separation data requested by the DPW organizing committee, shown in Fig. 24, and by examining the wing pressure distributions. Pressure distributions at select wing eta stations at angles-of-attack of $3.0^{\circ}, 3.5^{\circ}$, and $4.0^{\circ}$ are shown in Figs. 25 to 27. Several solutions exhibited a large side of body (SOB) separation bubble with increasing angle-ofattack whose effects could be seen in the wing pressure distributions, and in the force and moment data. The wind tunnel data do not exhibit any evidence of flow separation on the inboard portion of the wing (first row of pressures located at $\mathrm{BL}=151$ ), nor does it show an early lift break. All of the solutions identified with a separation bubble size greater than $\mathrm{BL}=151$ also exhibited a lift break at or below $4^{\circ}$ angle-of-attack and have been identified as outliers.

Another look at the wing section characteristics can be taken by integrating the pressure coefficients $\left(\mathrm{C}_{\mathrm{p}}\right)$ vs. chord fraction $(\mathrm{x} / \mathrm{c})$ to derive the section lift (normal force) and pitching moment characteristics shown in Figs. 28 and 29. The section pitching moment coefficients are taken about the quarter chord $(0.25$ $\mathrm{x} / \mathrm{c}$ ) of each section. Unfortunately these data were provided for less than half of the solutions submitted. Of the solution sets provided, some had obvious errors and had to be discarded. These figures clearly show the overprediction of lift and the magnitude of the negative pitching moment compared to the test data, which is also reflected in the total forces and moments shown in Fig. 22. The early lift loss on the inboard part of the wing is clearly shown for two of the solutions. The additional piece of information that is provided by these section characteristics is that the degree of disagreement between the computed and test results is increasing the further outboard the section is located on the wing.

Eliminating all the outliers as defined above, we have 21 solutions with lift and pitching moment characteristics shown in Fig. 30. Even with all the outliers removed there is still an increasing spread of the lift and pitching moment with increasing angle-of-attack. At $4^{\circ}$ angle-of-attack the value of lift coefficient varies by 0.063 and the spread in pitching moment coefficient is 0.045 ! This is a bigger spread than we saw for DPW-V! Each one of these solutions on its own is a valid solution, yet as angle-of-attack increases the variation between solutions also increases. 
The drag characteristics of the remaining solutions are shown in Fig. 31. Also shown are test results from three repeat runs at both the NTF and 11-Foot TWT wind tunnels. The drag characteristics are plotted in terms of the idealized profile drag defined as:

$$
\mathrm{C}_{\mathrm{DP}}=\mathrm{C}_{\mathrm{D}}-\mathrm{C}_{\mathrm{L}}^{2} /(\pi \mathrm{AR})
$$

Plotting $C_{D P}$ instead of $C_{D}$ can be very useful as its variation with $C_{L}$ is significantly diminished, and therefore, the scale of the plot can be greatly increased. The spread of the drag values is largely driven by the increasing spread of lift with increasing angle-of-attack. Note that the spread of the drag values at low lift coefficients is of the same order as the spread of the test data between the two tunnels. Two solutions, G1 and I1, have been included that on the basis of their total lift and moment characteristics would have been considered outliers. However, the wing pressure distributions of these solutions show no evidence of SOB premature separation and are in line with all the other solutions in this group. As shown for $\mathrm{C}_{\mathrm{L}}=0.50$, the excessive drag for G1 is largely due to pressure drag, Fig. 12, and to skin friction drag for I1, Fig. 13.

\section{Case 4 - CRM WB Grid Adaptation [Optional]}

New to DPW-VI was the request for grid adaptation solutions of the CRM Wing-Body configuration as an optional case. This consists of a series of fixed lift, $\mathrm{C}_{\mathrm{L}}=0.50$, solutions using an adapted grid family provided by the participant. This is an active area of CFD research and it was time to take a measure of the progress. Unfortunately, only five solution sets were provided by three organizations. Two solutions, I2 and I3, were based on the same solver, using the same adaptation technique, but differed in the treatment of the boundary layer. These employed a Cartesian mesh that can be successively refined to fit geometrical and flow features. The solver employs a Favre-averaged, cell-center finite volume method. Indicator functions drive the refinement or coarsening as the solution progresses. The difference between the two solutions is the wall-function treatment of the boundary layer. I3 features a more complete "thick" wallfunction treatment. I2 employs the original "thin" layer subgrid model. The other three, A1, P1 and P2, were based on different solvers. A1, OVERFLOW, employs an implicit $2^{\text {nd }}-$ order cell centered finite volume solver, and employed a feature-based adaption scheme ${ }^{88}$. P1, BCFD, employs an implicit $2^{\text {nd }}$-order cell centered finite volume solver. P2, GGNS, employs $2^{\text {nd }}$-order node centered SUPG finite-element discretization with a strong solver that achieves machine precision residual convergence ${ }^{86}$. Both P1 and P2 employ the EPIC (Edge Primitive Insertion Collapse) adaptive grid tool ${ }^{89}$ focusing on a sizing metric derived from the Mach Hessian or Entropy Adjoint error.

Total drag as a function of the grid factor (gridfac) for the five adapted grid solutions is shown on the left side of Fig. 32. Note that the gridfac scale has been greatly expanded compared to that shown in Fig. 10 for Case 2. The drag values for solutions I2 and I3 are somewhat misleading in that they are not for constant $C_{L}=0.50$ value. These cases were run at a constant angle-of-attack, which did not yield a $C_{L}=0.50$, resulting in an increasing value of lift and hence drag for the $\mathrm{I} 3$ solution, and an incompatible drag level for the I2 solution. A1 adaption began from the existing coarse grid from Case 2. Both the P1 and P2 solutions started with a relatively small grid of less than 2 million cells. Both show a rapid drop of drag with the first grid adaption followed by a steady convergence toward the continuum. On the right side of Fig. 32, the fixed grid solutions from Case 2 have been included and are shown by dashed lines. Note that drag scale has also been changed. This figure suggests that the P1 and P2 adaptive grid solutions are converging to the continuum similar to the fixed grid solutions. The wing pressure distributions from A1, P1, and P2 are essentially indistinguishable from those shown in Fig. 18, but with the characteristic of a sharper definition of the shocks. Pressures for the I2 and I3 solutions were not at the same $\mathrm{C}_{\mathrm{L}}$.

The P1 and P2 solutions started with small initial grids and ended up with solutions at moderate grid sizes that rivaled the carefully crafted "fixed" grids of Case 2. The promise that solution adaptive grids bring is that they should be able to deliver a consistent set of solutions for configurations, and/or conditions for which prior gridding experience may not be available. Even for this configuration, the "optimum" grid distribution will change dramatically for a drag rise series ranging from Mach $=0.70$ to 0.90 . Much work remains to be done to bring this technology to a "production" capability for 3-D RANS. It is a technology that needs to be matured. 


\section{E. Case 5 - CRM WB Coupled Aero-Structural Simulation [Optional]}

Another case new to DPW-VI was the request for a coupled aerostructural simulation. The effects of static aeroelastic twist and deflection can be very significant at transonic flow conditions. The inclusion of static aeroelastic deformation of the CRM wind tunnel model in DPW-VI attests to their importance. These included deformations were based on "after the fact" wind tunnel measurements. Unlike a wind tunnel model, the deformations of a full-scale airplane wing can be as much as an order of magnitude greater! An accurate CFD prediction of the flight characteristics of a full-scale airplane (or even a wind tunnel model) requires that actual static aeroelastic deformation be included in the computational model. A coupled aerostructural simulation is one approach in achieving this. A NASTRAN ${ }^{\circledR}$ finite element model was provided for structural analyses and coupling with an aerodynamic CFD flow solver for analysis of the CRM Wing-Body configuration at a fixed Mach and lift condition.

Data for Case 5 was submitted by a total of four teams. Table 9 gives an overview of the numerical methods used by the participants for CFD, computational structural mechanics (CSM), interpolation of aerodynamic forces, and mesh deformation. A detailed description of the results for Case 5 is given in Ref. 75.

Unfortunately, the NASTRAN ${ }^{\circledR}$ bulk data file provided on the CRM website did not include any definition of boundary conditions for the system matrices, leaving the structural analysis problem statically undetermined. As a result, the teams used differing locations for the model suspension, cf. Table 9. The correct suspension, i.e., the one corresponding to the actual model attachment in the wind tunnel, is inside the fuselage at the inner cylindrical surface of the balance interface. At this location, the model is mounted to the internal wind tunnel balance during the test. With the wing root suspension used by two participants, zero deflection is prescribed along the junction line between wing and belly fairing. This suspension results in neglecting the compliancy of the structural components located between balance interface and wing root, leading to smaller deformations. Generally, the different model suspensions used in the structural analysis cause minor differences in the computed wing deformations as will be discussed subsequently.

In Fig. 33, the chordwise distribution of static pressure coefficient is plotted. Four spanwise sections between $\eta=0.131$ and $\eta=0.950$ were selected for comparison. Sectional static pressure data has been submitted by teams J4, L2, and T1. Contrary to the preceding test cases, all experimental validation data has been taken from the 2014 ETW wind tunnel test campaign ${ }^{78}$ to ensure consistency between pressure and deformation data.

A generally good agreement is found between the different participants and measured data. All three teams predicted the shock location somewhat downstream of the experimental location. Shock location for teams J4 and T1 is predicted more upstream compared to L2. This is believed to be due to the one-equation turbulence model used by L2, whereas $\mathrm{J} 4$ and T1 have used a two-equation model. Although minor differences are also observed in the pressure distributions on the upper wing surface the aero-elastic effects appear to be correctly captured by all participants. The resulting wing pressure distributions were essentially identical to those from Case 2.

Fig. 34 shows the (a) spanwise wing bending and (b) twist distributions. Numerical results are compared to ETW deformation data from Run 182, data point $531\left(\alpha=2.99^{\circ}, C_{L}=0.514\right)$. Bending deflections are given in millimeters and refer to the $0.027 \%$ scale NTF/ 11-Foot wind tunnel model. For bending, the best agreement is found for team V5. Here, the maximum deflection deviation at the wing tip is $\Delta \mathrm{w}=-0.19 \mathrm{~mm}$, followed by teams $\mathrm{J} 4(\Delta \mathrm{w}=-1.80 \mathrm{~mm})$ and $\mathrm{L} 2(\Delta \mathrm{w}=-2.18 \mathrm{~mm})$. The largest deviation occurs for team $\mathrm{T} 1$ at $\Delta \mathrm{w}=-4.11 \mathrm{~mm}$. Apart from that, the deflection curve progression over span is very close to measured data for all participants, indicating that the spanwise lift distributions between the different teams match very well.

The aerodynamically more relevant twist deformation is plotted in Fig. 34(b). Here, the differences between the finite-element model suspensions become more apparent than for bending. For teams J4 and $\mathrm{T} 1$, who used the model suspension at the wing root, the twist deflection and spanwise deflection gradient at the innermost wing station are very close to zero, whereas the measurements show a small deflection and nonzero gradient caused by the compliance of the wind tunnel model structure.

Twist deflection results for participants T1 and V5 show a steeper gradient over most of the span compared to the experimental data. It is assumed that these differences are caused by differences in the structural analysis methods used. Team T1 performs a reduction of the stiffness matrix and computes the deflections outside NASTRAN ${ }^{\circledR}$, team V5 uses a modal coupling approach where the deflections are 
calculated from a set of normal modes of the system matrices, which, in contradiction to the static coupling approaches, also take into account the model's mass distribution. Unfortunately, no sectional lift and moment data, which would enable a more detailed deformation results analysis, has been submitted by the participants.

\section{Issues}

An important goal of the DPW series of workshops is to identify significant issues/shortfalls in need of further CFD development. DPW-VI highlights continuing issues that, while seeing some progress over the years, continue to plague the state of CFD and experiment. More detailed information about how the experimental data were generated is needed to better validate the CFD, and to provide the detailed information necessary to improve the turbulence models, unsteady simulations, etc.

The prediction of premature side of body separation continues to plague some simulations. At the design condition of $\mathrm{M}=0.85, \mathrm{C}_{\mathrm{L}}=0.50$, this is no longer an issue. However, as angle-of-attack is increased, some solutions do exhibit excessive side of body separation as shown in Figs. 24-27. The wind tunnel data do not exhibit any evidence of flow separation on the inboard portion of the wing (i.e., the first row of pressures located at BL=151). Solutions B3, D1, D2, F1, J1, J2, M1, N1, O1, P1, Q1, S1, V1, V2, V3, and V4 showed evidence of premature SOB separation along the first row of wing pressures. Solutions A1, B1, I1, I2, I3, J3, J4, L1, L2, P2, R1, U1, U2, W1, Y1, Z4, Z5, Z6, and Z7 either did not run the angle-of-attack series, or did not provide sufficient pressure distribution data to determine premature SOB separation. It should be noted that the force and moment data shown in Fig. 30 including solutions L1, L2, U1, and U2 did not show an early lift break, which is indicative of SOB separation. While some solutions using the SA and SST turbulence models manage to avoid the premature SOB separation, most did not. Past experience has shown that premature separation with these turbulence models is very sensitive to gridding details in the wing-body junction region. This type of 3D corner flow separation continues to need more attention in turbulence model development and CFD application. The use of the quadratic constitutive relation (QCR) in the SA turbulence model eliminated the premature separation. In addition, the k-kl-MEAH2015 (B1, B2), LMB-VLES (G1), EARSM (H2), and RSM-w (L1) turbulence models did not show any evidence of premature SOB separation up to $4^{\circ}$ angle-of-attack.

Another ongoing issue can be seen in Fig. 30 for lift and pitching moment. The solutions show a lift higher than experiment and pitching moment more negative than experiment. This can partially be explained by the lack of corrections to the experimental data for the upper swept sting support to the wind tunnel model. These corrections require a special set of wind tunnel tests using different mounting systems to the model. These were not carried out for the CRM in any of the wind tunnel campaigns. Computational studies ${ }^{87,90,91}$ on the impact of the mounting system show that its effect will be to reduce lift and reduce the nose-down pitching moment. These studies were based on the CRM model with the horizontal tail and therefore, cannot be applied this configuration. The mounting system will have a much greater effect on the model with the horizontal tail than without. In any case, the test corrections would still not explain the spread of values of the computational results at a given angle-of-attack/ $C_{L}$ conditions. However, the wing pressure distributions do offer a clue. Pressure distributions around the wing trailing edge from all the solutions and from test data are shown in Fig. 35. As long as the flow is attached, these distributions vary little over the range of conditions of interest. The computational results are from all the solutions submitted at the $\mathrm{M}=0.85, \mathrm{C}_{\mathrm{L}}=0.50$ condition. The pressure coefficient values on the upper surface of the wing are consistently lower (more negative) than those of the test data. The difference between the upper and lower surface represents lift and contributes to negative section pitching moment. These differences become more aggregative the further outboard on the wing. The effect of this increasing "aft loading" is clearly seen in the section lift (normal force) and pitching moment shown in Figs. 28 and 29. This excessive "aft loading" is seen from every turbulence model, gridding scheme, and solver type presented in this workshop. It is highly unlikely that this excessive "aft loading" is due to experimental issues. The computational results of pressure distribution, and forces and moments, are self-consistent. In the wind tunnel test, the instrumentation is completely independent. The geometry of the wind tunnel model has been validated. The nearly solid nature of the wing minimizes any chordwise aeroelastic effects. Pressure distributions from the Case 5 aerostructural aeroelastic computations are included in Fig. 35. This excessive "aft loading" prediction has also been seen on other wind tunnel models. While progress has been made with the premature SOB separation, the question of the excessive "aft loading" remains an issue. 
In addition to the "aft-loading" issue, Fig. 30 also shows that the spread in lift at a given angle-of-attack and the spread in the pitching moment at a given lift coefficient increases with increasing angle-of-attack and lift coefficient, respectively. This "spread" is in addition to the level changes caused by the excessive "aft loading." Looking at the wing pressure distributions at the outboardmost three wing stations shown in Figs. 25 to 27 provides a clue for the increasing spread. These show pressure distributions for increasing angles-of-attack. As the angle-of-attack is increased so does the spread of shock location at the outboard stations. Fig. 36 shows pressure distributions at $4^{\circ}$ angle-of-attack only from the solutions remaining after all the outliers have been eliminated. Note that the large variation of shock location from these solutions still exists. Compare this to the tight spread of shock locations shown in Fig. 18 from all solutions at $\mathrm{C}_{\mathrm{L}}=0.50$, which corresponds to an angle-of-attack between $2.50^{\circ}$ and $2.75^{\circ}$. Each one of these solutions on its own is a valid solution, yet as angle-of-attack increases so does the spread of shock location on the outboard portion of the wing. The chaotic situation at these high angles-of-attack may be physical as well as computational. At $4^{\circ}$, the wind tunnel model is buffeting quite a bit. The force and moment data are heavily filtered and the pressure transducers are incapable of responding to high frequency variations. One must ask if steady Reynolds Averaged Navier-Stokes is adequate for modeling this flow regime. Given the same turbulence model all steady RANS results should converge to the same answer. The results shown in Fig. 30 do show some clustering by turbulence model but the greatest variation is between the solutions based on some version of the SA model that did not exhibit premature separation. How much of these differences are due to convergence issues and/or grid discretization errors? Will URANS (Unsteady Reynolds Averaged Navier-Stokes) be any better, or must one go to an eddy-resolving method such as DES (Detached Eddy Simulation) to accurately simulate this flow regime? A presentation at the workshop by Exa, solution G1 based on the Lattice Boltzmann Method, showed significant unsteady content for solutions at angels-of-attack of $3.5^{\circ}$ and higher. The "steady" pressure distributions they submitted were in line with others that were not deemed outliers. Without detailed experimental measurements that adequately capture the flow separation and unsteadiness on these type of configurations recommendations as to the level of "unsteady" modeling necessary to adequately model these flows cannot be made.

\section{Conclusions}

The Sixth Drag Prediction Workshop was held in conjunction with AIAA Aviation 2016. The event was well attended by a diverse group of expert CFD practitioners from four continents representing government, industry, academia, and commercial code development institutions. 25 teams contributed results. This workshop focused on a 2-D turbulence model verification study, and several studies of the NASA Common Research Model, CRM, wing-body and wing-body-nacelle-pylon configurations. These included single point grid convergence and drag increment, high-alpha static aeroelastic/buffet conditions, optional grid adaptation, and optional coupled aerostructural studies. This paper covers the key results from the CRM Cases 2 to 5 of the workshop. Details of Case 1, the 2-D turbulence model verification study, are given in Ref. 73, additional details on Case 5 in Ref. 75, and a statistical analysis in Ref. 74.

A total of 54 datasets for the CRM cases were provided on structured, overset, unstructured, and Cartesian grids. The use of committee-provided or user-defined grids were pretty evenly divided. Some teams provided solutions using the same solver and turbulence model but with different grids. Others provided solutions using the same solver and grid but with different turbulence models.

The Case 2 Wing-Body grid convergence study showed a steady improvement over the similar study in DPW-V, especially with respect to unstructured grids. As a whole, the solutions exhibited a "tighter" convergence of total drag to the continuum with a spread of less than 10 drag counts. The grid convergence study for the Wing-Body-Nacelle-Pylon showed a somewhat greater spread. Only four entries would be considered to be significant outliers. Of significant importance to industry design processes is the prediction of the drag increment between the two configurations. Here we found that most participants were able to predict the drag increment within the uncertainty of the test data. With the exception of one case, there was very little difference seen in the wing or nacelle pressure distributions, or in wing section lift and pitching moments, due to grid type, turbulence model, convergence level, or solver. Results of a statistical analysis of Case 2 are presented in Ref. 74.

For the Case 3 static aeroelastic/buffet study, the lift and pitching moment from most of the solutions are clustered within a "fan" that gets progressively wider with increasing angle-of-attack. In general, the solutions indicate a higher lift at a given angle-of-attack, and a more negative (nose down) pitching moment at a given lift coefficient than observed in the test data. The primary cause appears to be due the 
excessive "aft loading" predicted by all the submittals, and by the increasing spread in the prediction of the shock wave on the outboard part of the wing. As in previous workshops, a set of outliers was observed that had uncharacteristically large wing trailing edge separation at the side of body that contributed to an early lift break. While some solutions using the SA and SST turbulence models manage to avoid the premature SOB separation, most did not. The use of the quadratic constitutive relation (QCR) in the SA turbulence model eliminated the premature separation. In addition, the k-kl-MEAH2015, LMB-VLES, EARSM, and RSM-w turbulence models did not show any evidence of premature SOB separation up to $4^{\circ}$ angle-ofattack. Inclusion of the static aeroelastic twist and deflection in the configuration definition significantly improved the agreement with test data of the pressure distributions on the outboard part of the wing. After the elimination of outliers, each one of the remaining solutions on its own is a valid solution, yet as angleof-attack increases so does the spread of shock location on the outboard portion of the wing. The shock location variation at these high angles-of-attack may be physical as well as computational. At $4^{\circ}$, the wind tunnel model is buffeting a significant amount. The wind tunnel forces, moments, and pressure data typically represent "average" steady results. One must ask if steady Reynolds Averaged Navier-Stokes is adequate for modeling this flow regime. Will URANS (Unsteady Reynolds Averaged Navier-Stokes) be adequate, or must one go to an eddy-resolving method such as DES (Detached Eddy Simulation) to accurately simulate this flow regime?

New to DPW-VI was the request for grid adaptation solutions of the CRM Wing-Body configuration as an optional case. This is an active area of CFD research and it was time to take a measure of the progress. Five solution sets were provided by three organizations. Three of the solutions exhibited a strong convergence to the same drag level in the continuum as the fixed grid solutions. The wing pressure distributions from these solutions are essentially indistinguishable from those of the carefully crafted fixed grid solutions but with the characteristic of a sharper definition of the shocks. The promise that solution adaptive grids bring is that they should be able to deliver a consistent set of solutions for configurations, and/or conditions for which prior gridding experience may not be available. Much work remains to be done to bring this technology to a "production" capability for 3-D RANS. It is a technology that needs to be matured.

Another case new to DPW-VI was the request for a coupled aero-structural simulation. The effects of static aeroelastic twist and bending can be very significant at transonic flow conditions. The inclusion of static aeroelastic deformation of the CRM wind tunnel model in DPW-VI attests to their importance. Four teams submitted solutions. A generally good agreement was found between the teams. The resulting wing pressure distributions were essentially identical to those from Case 2. Minor deviations from the experimental data were observed for chordwise shock location. These are likely caused by differences in wing twist distribution between the individual participants and the different turbulence models used. Some discrepancies were also found for the slope of the spanwise twist curve. At the wing root, these were traced back to different boundary conditions applied to the structural model. Other deviations from the experimental data are assumed to be caused by differences in the structural analysis methods used by the participants.

Important issues were raised in this and in previous workshops that point to the need for continuing CFD and experimental research. More detailed information about how the experimental data were generated is needed to better validate the CFD, and to provide the detailed information necessary to improve the turbulence models, unsteady simulations, etc. In particular, experimental force, moment, and pressure data is needed that adequately captures the flow separation and unsteadiness on these type configurations. While progress has been made with the prediction of premature SOB separation, this type of 3D corner flow separation continues to need more attention in turbulence model development and CFD application. Excessive "aft loading" was seen from every turbulence model, gridding scheme, and solver type presented in this workshop. It is highly unlikely that this excessive "aft loading" is due to experimental issues, and is more likely a turbulence modeling issue that needs further attention.

\section{References}

1. 1st AIAA CFD Drag Prediction Workshop, Anaheim, CA, June 2001, http://aiaadpw.larc.nasa.gov/Workshop1/workshop1.html, accessed 23 November 2016.

2. Redeker, G., "DLR-F4 Wing-Body Configuration," A Selection of Experimental Test Cases for the Validation of CFD Codes, number AR-303, pages B4.1-B4.21. AGARD, August 1994. 
3. Levy, D. W., Vassberg, J. C., Wahls, R. A., Zickuhr, T., Agrawal, S., Pirzadeh, S., and Hemsch, M. J., "Summary of data from the first AIAA CFD Drag Prediction Workshop," Journal of Aircraft, 40(5):875-882, Sep-Oct 2003.

4. Hemsch, M. J., "Statistical Analysis of CFD Solutions from the Drag Prediction Workshop," AIAA paper 20020842, 40 ${ }^{\text {th }}$ AIAA Aerospace Sciences Meeting \& Exhibit, Reno, NV, January 2002.

5. Rakowitz, M., Eisfeld, B., Schwamborn, D., and Sutcliffe, M., "Structured and Unstructured Computations on the DLR-F4 Wing-Body Configuration," Journal of Aircraft, 40(2):256-264, 2003.

6. Mavriplis, D. J. and Levy, D. W., "Transonic Drag Predictions Using an Unstructured Multigrid Solver," AIAA Journal of Aircraft, 42(4):887-893, 2005.

7. Pirzadeh, S. Z. and Frink, N. T., "Assessment of the Unstructured Grid Software TetrUSS for Drag Prediction of the DLR-F4 Configuration," AIAA Paper 2002-0839, 40 ${ }^{\text {th }}$ AIAA Aerospace Sciences Meeting \& Exhibit, Reno, NV, January 2002.

8. Vassberg, J. C., Buning, P. G., and Rumsey, C. L., "Drag Prediction for the DLR-F4 Wing/Body Using OVERFLOW and CFL3D on an Overset Mesh," AIAA Paper 2002-0840, 40 ${ }^{\text {th }}$ AIAA Aerospace Sciences Meeting \& Exhibit, Reno, NV, January 2002.

9. 2nd AIAA CFD Drag Prediction Workshop, Orlando, FL, June 2003, http://aiaadpw.larc.nasa.gov/Workshop2/workshop2.html, accessed 23 November 2016.

10. Laflin, K. R., Vassberg, J. C., Wahls, R. A., Morrison, J. H., Brodersen, O., Rakowitz, M., Tinoco, E. N., and Godard, J., "Summary of Data from the Second AIAA CFD Drag Prediction Workshop," Journal of Aircraft, 42(5):1165-1178, 2005.

11. Hemsch, M. and Morrison, J., "Statistical analysis of CFD solutions from 2nd Drag Prediction Workshop," AIAA Paper 2004-0556, 42 ${ }^{\text {nd }}$ AIAA Aerospace Sciences Meeting and Exhibit, Reno, NV, January 2004.

12. Pfeiffer, N., "Reflections on the Second Drag Prediction Workshop," AIAA Paper 2004-0557, 42 ${ }^{\text {nd }}$ AIAA Aerospace Sciences Meeting and Exhibit, Reno, NV, January 2004.

13. Brodersen, O. P., Rakowitz, M., Amant, S., Larrieu, P., Destarac, D., and Suttcliffe, M., "Airbus, ONERA and DLR Results from the Second AIAA Drag Prediction Workshop," Journal of Aircraft, 42(4):932-940, 2005.

14. Langtry, R. B., Kuntz, M., and Menter, F., "Drag Prediction of Engine-Airframe Interference Effects with CFX5," Journal of Aircraft, 42(6):1523-1529, 2005.

15. Sclafani, J., DeHaan, M. A., and Vassberg, J. C., "OVERFLOW Drag Predictions for the DLR-F6 Transport Configuration: A DPW-II Case study,” AIAA Paper 2004-0393, 42 ${ }^{\text {nd }}$ AIAA Aerospace Sciences Meeting and Exhibit, Reno, NV, January 2004.

16. Rumsey, C., Rivers, M., and Morrison, J., "Study of CFD Variations on Transport Configurations from the 2nd AIAA Drag Prediction Workshop," AIAA Paper 2004-0394, 42 ${ }^{\text {nd }}$ AIAA Aerospace Sciences Meeting and Exhibit, Reno, NV, January 2004.

17. Wutzler, K., “Aircraft Drag Prediction using Cobalt,” AIAA Paper 2004-0395, 42 ${ }^{\text {nd }}$ AIAA Aerospace Sciences Meeting and Exhibit, Reno, NV, January 2004.

18. May, G., Van derWeide, E., Jameson, A., and Shankaran, S., "Drag Prediction of the DLR-F6 Configuration," AIAA Paper 2004-0396, 42 ${ }^{\text {nd }}$ AIAA Aerospace Sciences Meeting and Exhibit, Reno, NV, January 2004.

19. Kim, Y., Park, S., and Kwon, J., "Drag Prediction of DLR-F6 Using the Turbulent Navier-Stokes Calculations with Multigrid," AIAA Paper 2004-0397, 42 ${ }^{\text {nd }}$ AIAA Aerospace Sciences Meeting and Exhibit, Reno, NV, January 2004.

20. Yamamoto, K., Ochi, A., Shima, E., and Takaki, R., "CFD Sensitivity to Drag prediction on DLR-F6 Configuration by Structured Method and Unstructured Method," AIAA Paper 2004-0398, 42 ${ }^{\text {nd }}$ AIAA Aerospace Sciences Meeting and Exhibit, Reno, NV, January 2004.

21. Tinoco, E. and Su, T., "Drag Prediction with the Zeus/CFL3D System," AIAA Paper 2004-0552, 42 ${ }^{\text {nd }}$ AIAA Aerospace Sciences Meeting and Exhibit, Reno, NV, January 2004.

22. 3rd AIAA CFD Drag Prediction Workshop, San Francisco, CA, June 2006, http://aiaadpw.larc.nasa.gov/Workshop3/workshop3.html, accessed 23 November 2016.

23. Vassberg, J. C., Sclafani, A. J., and DeHaan, M. A., "A Wing-Body Fairing Design for the DLR-F6 Model: A DPW-III Case Study," AIAA Paper 2005-4730, AIAA 23 ${ }^{\text {rd }}$ Applied Aerodynamics Conference, Toronto, Canada, June 2005.

24. Vassberg, J. C., Tinoco, E. N., Mani, M., Brodersen, O. P., Eisfeld, B., Wahls, R. A., Morrison, J. H., Zickuhr, T., Laflin, K. R., and Mavriplis, D. J., "Abridged Summary of the Third AIAA CFD Drag Prediction Workshop," Journal of Aircraft, 45(3):781-798, May-June 2008.

25. Vassberg, J. C., Tinoco, E. N., Mani, M., Brodersen, O. P., Eisfeld, B., Wahls, R. A., Morrison, J. H., Zickuhr, T., Laflin, K. R., and Mavriplis, D. J., "Summary of DLR-F6 Wing-Body Data from the Third AIAA CFD Drag Prediction Workshop," RTO AVT-147 Paper 57, RTO AVT-147 Symposium, Athens, Greece, December 2007.

26. Morrison, J. H. and Hemsch, M. J., "Statistical Analysis of CFD Solutions from the Third AIAA Drag Prediction Workshop," AIAA Paper 2007-0254, 45 ${ }^{\text {th }}$ AIAA Aerospace Sciences Meeting and Exhibit, Reno, NV, January 2007. 
27. Tinoco, E. N., Winkler, C., Mani, M., and Venkatakrishnan, V., "Structured and Unstructured Solvers for the 3rd CFD Drag Prediction Workshop," AIAA Paper 2007-0255, 45 ${ }^{\text {th }}$ AIAA Aerospace Sciences Meeting and Exhibit, Reno, NV, January 2007.

28. Mavriplis, D. J., "Results from the 3rd Drag Prediction Workshop Using the NSU3D Unstructured Mesh Solver," AIAA Paper 2007-0256, 45 ${ }^{\text {th }}$ AIAA Aerospace Sciences Meeting and Exhibit, Reno, NV, January 2007.

29. Sclafani, A. J., Vassberg, J. C., Harrison, N. A., DeHaan, M. A., Rumsey, C. L., Rivers, S. M., and Morrison, J. H., "Drag Predictions for the DLR-F6 Wing/Body and DPW Wings Using CFL3D and OVERFLOW on an Overset Mesh," AIAA Paper 2007-0257, 45 ${ }^{\text {th }}$ AIAA Aerospace Sciences Meeting and Exhibit, Reno, NV, January 2007.

30. Brodersen, O., Eisfeld, B., Raddatz, J., and Frohnapfel, P., "DLR Results from the Third AIAA CFD Drag Prediction Workshop," AIAA Paper 2007-0259, 45 ${ }^{\text {th }}$ AIAA Aerospace Sciences Meeting and Exhibit, Reno, NV, January 2007.

31. Tinoco, E. N., Venkatakrishnan, V., Winkler, C., and Mani M., "Structured and Unstructured Solvers for the Third AIAA CFD Drag Prediction Workshop,” Journal of Aircraft, 45(3):738-749, May-June 2008.

32. Mavriplis, D. J., "Third Drag Prediction Workshop Results Using NSU3D Unstructured Mesh Solver," Journal of Aircraft, 45(3):750-761, May-June 2008.

33. Sclafani, A. J., Vassberg, J. C., Harrison, N. A., Rumsey, C. L., Rivers, S. M., and Morrison, J. H., "CFL3D / OVERFLOW Results for DLR-F6 Wing/Body and Drag Prediction Workshop Wing," Journal of Aircraft, 45(3):762-780, May-June 2008.

34. Murayama, M. and Yamamoto, K., "Comparison Study of Drag Prediction by Structured and Unstructured Mesh Method," Journal of Aircraft, 45(3):799-822, May-June 2008.

35. Brodersen, O., Eisfeld, B., Raddatz, J., and Frohnapfel, P., "DLR results from the third AIAA Computational Fluid Dynamics Drag Prediction Workshop,” Journal of Aircraft, 45(3):823-836, May-June 2008.

36. Eliasson, P. and Peng, S.-H., "Drag Prediction for the DLR-F6 Wing-Body Configuration Using the Edge Solver," Journal of Aircraft, 45(3):837-847, May-June 2008.

37. Mavriplis, D. J., Vassberg, J. C., Tinoco, E. N., Mani, M., Brodersen, O. P., Eisfeld, B., Wahls, R. H., Morrison, J., Zickuhr, T., Levy, D., and Murayama, M., "Grid quality and Resolution Issues from the Drag Prediction Workshop Series," Journal of Aircraft, 46(3):935-950, 2009.

38. $4^{\text {th }}$ AIAA CFD Drag Prediction Workshop, San Antonio, TX, June 2009, http://aiaadpw.larc.nasa.gov/Workshop4/workshop4.html, accessed 23 November 2016.

39. Vassberg, J. C., DeHaan, M. A., Rivers, S. M., and Wahls, R. A., "Development of a Common Research Model for Applied CFD Validation Studies," AIAA Paper 2008-6919, 26 ${ }^{\text {th }}$ AIAA Applied Aerodynamics Conference, Hawaii, HI, August 2008.

40. Vassberg, J., Tinoco, E., Mani, M., Rider, B., Zickuhr, T., Levy, D., Broderson, O., Eisfeld, B., Crippa, S., Wahls, R., Morrison, J., Mavriplis, D., Murayama, M., "Summary of the Fourth AIAA CFD Drag Prediction Workshop," AIAA 2010-4547, 28 ${ }^{\text {th }}$ AIAA Applied Aerodynamics Conference, Chicago, IL, June 2010.

41. Morrison, J., "Statistical Analysis of CFD Solutions from the Fourth Drag Prediction Workshop," Journal of Aircraft, 2014, 51:4, 1070-1089.

42. Sclafani, A. J., Vassberg, J. C., Rumsey, C., DeHaan, M. A., and Pulliam, T. H., "Drag Prediction for the NASA CRM Wing/Body/Tail Using CFL3D and OVERFLOW on an Overset Mesh," Journal of Aircraft, 2014, 51:4, 1101-1117.

43. Hue, D., Gazaix, M., and Esquieu, S., "Computational Drag and Moment Prediction of the DPW4 Configuration with elsA," AIAA Paper 2010-4220, 28 ${ }^{\text {th }}$ AIAA Applied Aerodynamics Conference, Chicago, IL, June 2010.

44. Mani, M., Rider, B. J., Sclafani, A. J., Winkler, C., Vassberg, J. C., Dorgan, A. J., Cary, A., and Tinoco, E. N., "RANS Technology for Transonic Drag Prediction; a Boeing Perspective of the 4th Drag Prediction Workshop," Journal of Aircraft, 2014, 51:4, 1118-1134.

45. Yamamoto, K., Tanaka, K., and Murayama, M., "Comparison Study of Drag Prediction for the 4th CFD Drag Prediction Workshop Using Structured and Unstructured Mesh Methods," AIAA Paper 2010-4222, $28^{\text {th }}$ AIAA Applied Aerodynamics Conference, Chicago, IL, June 2010.

46. Brodersen, O., Crippa, S., Eisfeld, B., Keye, S., and Geisbauer, S., "DLR Results for the Fourth AIAA CFD Drag Prediction Workshop," Journal of Aircraft, 2014, 51:4, 1135-1148.

47. Eliasson, P., Peng, S., and Tysell, L., "Computations from the 4th Drag Prediction Workshop Using the Edge Solver," AIAA Paper 2010-4548, $28^{\text {th }}$ AIAA Applied Aerodynamics Conference, Chicago, IL, June 2010.

48. Li, G. and Zhou, Z., "Validation of a Multigrid-Based Navier-Stokes Solver for Transonic Flows," AIAA Paper 2010-4549, $28^{\text {th }}$ AIAA Applied Aerodynamics Conference, Chicago, IL, June 2010.

49. Mavriplis, D. J. and Long, M., "NSU3D Results for the Fourth AIAA Drag Prediction Workshop," Journal of Aircraft, 2014, 51:4, 1161-1171.

50. Lee-Rausch, E., Hammond, E., Nielsen, E., Pirzadeh, S., and Rumsey C., "Application of the FUN3D Unstructured-Grid Navier-Stokes Solver to the 4th AIAA Drag Prediction Workshop Cases," Journal of Aircraft, 2014, 51:4, 1149-1160. 
51. Vos, J., Sanchi, S., Gehri, A., and Stephani, P., "DPW4 Results Using Different Grids, Including Near-Field/FarField Drag Analysis," AIAA Paper 2010-4552, $28^{\text {th }}$ AIAA Applied Aerodynamics Conference, Chicago, IL, June 2010.

52. Hashimoto, A., Lahur, P., Murakami, K., and Aoyama, T., "Validation of Fully Automatic Grid Generation Method on Aircraft Drag Prediction," AIAA Paper 2010-4669, $28^{\text {th }}$ AIAA Applied Aerodynamics Conference, Chicago, IL, June 2010.

53. Hashimoto, Atsushi, Keiichi Murakami, Takashi Aoyama, Kazuomi Yamamoto, Mitsuhiro Murayama, and Paulus R. Lahur, "Drag Prediction on NASA Common Research Model Using Automatic Hexahedra Grid-Generation Method," Journal of Aircraft, 2014, 51:4, 1172-1182

54. Temmerman, L. and Hirsch, C., "Simulations of the CRM Configuration on Unstructured Hexahedral Grids: Lessons Learned from the DPW-4 Workshop," AIAA Paper 2010-4670, $28^{\text {th }}$ AIAA Applied Aerodynamics Conference, Chicago, IL, June 2010.

55. Chaffin, M. and Levy, D., "Comparison of Viscous Grid Layer Growth Rate of Unstructured Grids on CFD Drag Prediction Workshop Results,” AIAA Paper 2010-4671, $28^{\text {th }}$ AIAA Applied Aerodynamics Conference, Chicago, IL, June 2010.

56. Crippa, S., "Application of Novel Hybrid Mesh Generation Methodologies for Improved Unstructured CFD Simulations," AIAA Paper 2010-4672, 28 ${ }^{\text {th }}$ AIAA Applied Aerodynamics Conference, Chicago, IL, June 2010.

57. $5^{\text {th }}$ AIAA CFD Drag Prediction Workshop, http://aiaa-dpw.larc.nasa.gov/Workshop5/workshop5.html, accessed 23 November 2016.

58. Vassberg, J. C., "A Unified Baseline Grid about the Common Research Model Wing-Body for the Fifth AIAA CFD Drag Prediction Workshop," AIAA Paper 2011-3508, 29 ${ }^{\text {th }}$ AIAA Applied Aerodynamics Conference, Honolulu, HI, June 2011.

59. Rumsey, C., "Langley Research Center Turbulence Modeling Resource," http://turbmodels.larc.nasa.gov/, accessed 23 November 2016.

60. Levy, D. W., Laflin, K. R., Tinoco, E. N., Vassberg, J. C., Mani, M., Rider, B., Rumsey, C. L., Wahls, R. A., Morrison, J. H., Brodersen, O. P., Crippa, S., Mavriplis, D. J., and Murayama, M., "Summary of Data from the Fifth Computational Fluid Dynamics Drag Prediction Workshop," Journal of Aircraft, 2014, 51:4, 1194-1213

61. Morrison, J. H., "Statistical Analysis of the Fifth Drag Prediction Workshop Computational Fluid Dynamics Solutions," Journal of Aircraft, 2014, 51:4, 1214-1222

62. Sclafani, A. J., Vassberg, J. C., Winkler, C., Dorgan, A. J., Mani, M., Olsen, M. E., and Coder, J. G., “Analysis of the Common Research Model Using Structured and Unstructured Meshes," Journal of Aircraft, 2014, 51:4, 12231243

63. Murayama, M., Yamamoto, K., Hashimoto, A., Ishida, T., Ueno, M., Tanaka, K., and Ito, Y., “Japan Aerospace Exploration Agency Studies for the Fifth AIAA Drag Prediction Workshop," Journal of Aircraft, 2014, 51:4, 1244-1267

64. Park, M. A., Laflin, K. R., Chaffin, M. S., Powell, N., and Levy, D. W., "CFL3D, FUN3D, and NSU3D Contributions to the Fifth Drag Prediction Workshop," Journal of Aircraft, 2014, 51:4, 1268-1283

65. Ceze, M. and Fidkowski, K. J., "Drag Prediction Using Adaptive Discontinuous Finite Elements," Journal of Aircraft, 2014, 51:4, 1284-1294

66. Hue, D., "Fifth Drag Prediction Workshop: Computational Fluid Dynamics Studies Carried Out at ONERA," Journal of Aircraft, 2014, 51:4, 1295-1310

67. Hue, D., "Fifth Drag Prediction Workshop: ONERA Investigations with Experimental Wing Twist and Laminarity," Journal of Aircraft, 2014 51:4, 1311-1322

68. Keye, S., Brodersen, O., and Rivers, M. B., "Investigation of Aeroelastic Effects on the NASA Common Research Model," Journal of Aircraft, 2014, 51:4, 1323-1330

69. Eberhardt, S., Benedict, K., Hedges, L., Robinson, A., and Tinoco, E. N.,"Inclusion of Aeroelastic Twist into the CFD Analysis of the Twin-Engine NASA Common Research Model," AIAA Paper 2014-0251, National Harbor, MD, January 2014.

70. Togiti, V., Eisfeld, B., and Brodersen, O., "Turbulence Model Study for the Flow Around the NASA Common Research Model," Journal of Aircraft, 2014, 51:4, 1331-1343

71. Special Section: Drag Prediction Workshops IV and V, Journal of Aircraft, Volume 51, Number 4, July-August 2014.

72. $6^{\text {th }}$ AIAA CFD Drag Prediction Workshop, Washington DC, June 2016, http://aiaa-dpw.larc.nasa.gov, accessed 23 November 2016.

73. Roy, C. J., et al, "Summary of Data from the Sixth AIAA CFD Drag Prediction Workshop: Case 1 Code Verification," AIAA Paper 2017-xxxx, 55 ${ }^{\text {th }}$ AIAA Aerospace Sciences Meeting, AIAA Science and Technology Forum and Exposition 2017, Grapevine, TX, January 2017.

74. Derlaga, J. M. and Morrison, J. H., "Statistical Analysis of CFD Solutions from the Sixth AIAA Drag Prediction Workshop,” AIAA-2017-XXX, 55 ${ }^{\text {th }}$ AIAA Aerospace Sciences Meeting, AIAA Science and Technology Forum and Exposition 2017, Grapevine, TX, January 2017 
75. Keye, S. and Mavriplis, D., "Summary of Data from the Sixth AIAA CFD Drag Prediction Workshop: Case 5 (Coupled Aero-Structural Simulation)," AIAA Paper 2017-XXXX, 55 ${ }^{\text {th }}$ AIAA Aerospace Sciences Meeting, AIAA Science and Technology Forum and Exposition 2017, Grapevine, TX, January 2017

76. Rivers, M. and Dittberner, A., "Experimental Investigations of the NASA Common Research Model," AIAA Paper 2010-4218, $28^{\text {th }}$ AIAA Applied Aerodynamics Conference, Chicago, IL, June 2010.

77. Rivers, M. and Dittberner, A., "Experimental Investigations of the NASA Common Research Model in the NASA Langley National Transonic Facility and NASA Ames 11-Ft Transonic Wind Tunnel (Invited)," AIAA Paper 2011-1126, presented at the $49^{\text {th }}$ Aerospace Sciences Meeting, Orlando, FL, Jan 2011.

78. Common Research Model, http://commonresearchmodel.larc.nasa.gov/, accessed 23 November 2016.

79. European Commission (EU), "European Strategic Wind Tunnels Improved Research Potential," http://www.eswirp.aero/, accessed 23 November 2016.

80. ETW CRM wind tunnel test data, http://www.eswirp.eu/ETW-TNA-Dissemination.html, accessed 23 November 2016.

81. Cartieri A., Hue D., and Chanzy Q, "Experimental Investigations on the Common Research Model at ONERA-S1 - Comparison with DPW Numerical Results", AIAA Paper 2017-XXXX, 55 ${ }^{\text {th }}$ AIAA Aerospace Sciences Meeting, AIAA Science and Technology Forum and Exposition 2017, Grapevine, TX, January 2017.

82. Ueno, M., Kohzai, T., and Koga, S., “Transonic Wind Tunnel Test of the NASA CRM (Volume 1), JAXA-RM13-01E, March 2013.

83. Keye, S. and Gammon, M. R., "Development of Deformed CAD Geometries of NASA's Common Research Model for the 6th AIAA CFD Drag Prediction Workshop," AIAA Paper 2016-3431, 34 ${ }^{\text {th }}$ AIAA Applied Aerodynamics Conference, June 2016.

84. Martineau, D., Stokes, S., Munday, S., Jackson, A., Gribben, B., and Verhoeven, N., “Anisotropic Hybrid Mesh Generation for Industrial RANS Applications,” AIAA Paper 2006-0534, Jan. 2006.

85. König, B., and Fares, E., "Validation of a Transonic Lattice-Boltzmann Method on the NASA Common Research Model," AIAA 2016-2023, January 2016.

86. Venkatakrishnan, V., Allmaras, S.R., Kamenetskii, D., and Johnson, F.T., "Higher Order Schemes for the Compressible Navier-Stokes Equations," AIAA Paper 2003-3987, $16^{\text {th }}$ AIAA Computational Fluid Dynamics Conference, June 23-26, 2003, Orlando, FL.

87. Glasby, R. S. , Erwin, J. T., Stefanski, D. L., Allmaras, S. R., Galbraith, M. C., Anderson, W. K., and Nichols, R. H., "Introduction to COFFE: The Next-Generation HPCMP CREATETM-AV CFD Solver," AIAA Paper 20160567, 54th AIAA Aerospace Sciences Meeting, AIAA SciTech, January 2016.

88. Buning, P. G. and Pulliam, T. H., "Near-Body Grid Adaption for Overset Grids," June 2016.

89. Michael, T., and Krakos, J., "Anisotropic Mesh Adaptation Through Edge Primitive Operations," AIAA Paper 2012-159, January 2012.

90. Rivers, M. and Hunter, C., "Support System Effects on the NASA Common Research Model," AIAA Paper 2012707, January 2012.

91. Rivers, M., Hunter, C., and Campbell, R., "Further Investigation of the Support System Effects and Wing Twist on the NASA Common Research Model," AIAA Paper 2012-3209, June 2012.

Table 1. Reference quantities for the CRM.

\begin{tabular}{|c|c|c|c|c|}
\hline$S_{\text {ref }}$ & $594,720.0 \mathrm{in}^{2}$ & $=4,130 \mathrm{ft}^{2} \quad\left[458.89 \mathrm{~m}^{2}\right]$ & $\mathrm{X}_{\text {ref }}$ & $1,325.9$ in $[33.68 \mathrm{~m}]$ \\
\hline$S_{\text {trap }}$ & $576,000.0 \mathrm{in}^{2}$ & $=4,000 \mathrm{ft}^{2} \quad\left[444.44 \mathrm{~m}^{2}\right]$ & $\mathrm{y}_{\text {ref }}$ & 468.75 in $[11.91 \mathrm{~m}]$ \\
\hline b & $2,313.5$ in & $=192.8 \mathrm{ft} \quad[58.765 \mathrm{~m}]$ & $Z_{\text {ref }}$ & $177.95 \mathrm{in}[4.520 \mathrm{~m}]$ \\
\hline ef & 275.800 in & $=16.07 \mathrm{ft} \quad[4.8978 \mathrm{~m}]$ & $\Lambda_{\mathrm{c} / 4}$ & $35.0^{\circ}$ \\
\hline AR & 9.0 & & $\lambda$ & 0.275 \\
\hline
\end{tabular}


Table 2. Gridding Guidelines for DPW-VI.

- Grid Family Names: Tiny, Coarse, Medium, Fine, Extra-fine, Ultra-fine

- $\quad$ Tiny Grid

- Viscous Wall Spacing: $\mathrm{Y}^{+} \sim 1.0 \rightarrow \Delta \mathrm{y}_{1}=0.001478 "$

- At Least 2 Constantly-Spaced Cells at Viscous Walls, $\Delta \mathrm{y}_{2}=\Delta \mathrm{y}_{1}$

- Growth Rates < 1.2X Normal to Viscous Walls

- Wing Spanwise Spacing $<0.1 \% *$ Semispan at Root, Engine \& Tip

- WNP Chordwise Spacing $<0.1 \% * \mathrm{C}$ (local chord) at LE \& TE

- Wing \& Nacelle TE Base >> 8 Cells [Pylon TE is Sharp]

- $\quad$ Spacing Near Fuselage Nose \& Afterbody $<1 \% *$ Cref

- Grow Next-Finer Grid in Family by $\sim 1.5 X$ in Size

- $\quad$ Scale Dimensions in All Three Computational Directions by 1.15X

- $\quad$ Grid Spacings Reduce by $0.87=(1 / 1.15)$ per Mesh Level - $\quad 0.1 \%$ in Tiny $\rightarrow[\mathrm{T}, \mathrm{C}, \mathrm{M}, \mathrm{F}, \mathrm{X}, \mathrm{U}]=[0.100,0.087,0.076,0.066,0.057,0.050] \%$

- WB Grids Consistent with Those within WBNP Systems

- Helps Minimize Deltas due to Grid $\rightarrow$ Better NP-Deltas

- WBNP Grid Sizes 1.3X-1.5X WB Grid Sizes, with Medium WB Mesh 45 M-DOFs

- $\quad$ Pick Factor, Then Keep Constant Throughout Grid Family

- $\quad$ Farfield Boundary $>100 *$ Semispans

- Note: This is Farther than before, which was $100 *$ Crefs

- Miscellaneous Notes:

- $\quad$ Try to be Multigrid Friendly on Structured Meshes

- Store Grid Coordinates in 64-bit Precision

- If Storing Grids in Plot3D Format, Keep Zones <33M Nodes

- Itemize Surface Elements by Components [W, B, N, P, Sym, Far]

- Itemize Element Count for Unstructured Meshes

- Volume: Tetrahedra, Prisms, Pyramids, Hexahedra

- $\quad$ Surface: Triangles, Quads

- WB Grids Consistent with Those within WBNP Systems

- Helps Minimize Deltas due to Grid $\rightarrow$ Better NP-Deltas

- WBNP Grid Sizes 1.3X-1.5X WB Grid Sizes

- $\quad$ Pick Factor, Then Keep Constant Throughout Grid Family

- $\quad$ Farfield Boundary $>100 *$ Semispans

- Note: This is Farther than before, which was $100 *$ Crefs

- Miscellaneous Notes:

- Try to be Multigrid Friendly on Structured Meshes

- Store Grid Coordinates in 64-bit Precision

- If Storing Grids in Plot3D Format, Keep Zones < 33M Nodes

- Itemize Surface Elements by Components [W, B, N, P, Sym, Far]

- Itemize Element Count for Unstructured Meshes

- Volume: Tetrahedra, Prisms, Pyramids, Hexahedra

- $\quad$ Surface: Triangles, Quads

Table 3. Overset Grid Family Statistics.

\begin{tabular}{|c|c|c|c|c|c|}
\hline Grid & $\begin{array}{c}\text { Viscous } \\
\text { Spacing }\end{array}$ & $\sim$ Y+ & $\begin{array}{c}\text { Maximum } \\
\text { Stretching }\end{array}$ & WB Size & WBNP Size \\
\hline Tiny & 0.001478 & 1.02 & 1.235 & $7,398,176$ & $11,865,177$ \\
\hline Coarse & 0.001182 & 0.80 & 1.186 & $14,355,678$ & $22,999,565$ \\
\hline Medium & 0.0009853 & 0.67 & 1.149 & $24,698,828$ & $39,542,953$ \\
\hline Fine & 0.0008446 & 0.58 & 1.128 & $39,098,858$ & $62,566,221$ \\
\hline Extra-fine & 0.0007390 & 0.50 & 1.112 & $58,227,000$ & $93,176,522$ \\
\hline Ultra-fine & 0.0006569 & 0.45 & 1.099 & $82,754,486$ & $132,381,764$ \\
\hline
\end{tabular}


Table 4. NASA GeoLab Wing-Body Grid Refinement Family Statistics.

\begin{tabular}{|c|c|c|c|c|c|c|c|c|}
\hline \multicolumn{9}{|c|}{ Wing Body Grid Refinement Study } \\
\hline & $1^{\text {ST }}$ CELL & $\begin{array}{r}\text { BLMAX } \\
\text { GROWTH }\end{array}$ & BOUNDARY & & & & & \\
\hline GRIDLEVEL & SIZE & RATE & NODES & BOUNDARYFACES & BLNODES & BL CELLS & TOTAL NODES & TOTAL CELLS \\
\hline TINY & 0.001478 & 1.15 & 655,339 & $1,310,674$ & $10,775,077$ & $60,647,514$ & $20,419,925$ & $119,554,125$ \\
\hline COARSE & 0.001285 & 1.15 & 860,282 & $1,720,560$ & $15,384,236$ & $87,036,885$ & $29,851,330$ & $174,999,801$ \\
\hline MEDIUM & 0.001118 & 1.15 & $1,127,127$ & $2,254,250$ & $22,397,227$ & $127,458,345$ & $44,162,574$ & $259,261,343$ \\
\hline FINE & 0.000972 & 1.15 & $1,475,823$ & $2,951,642$ & $33,385,212$ & $191,210,919$ & $66,089,940$ & $388,564,128$ \\
\hline X-Fine & 0.000845 & 1.15 & $1,938,196$ & $3,876,388$ & $52,391,237$ & $302,286,426$ & $100,550,619$ & $592,197,654$ \\
\hline U-Fine & 0.000735 & 1.15 & $2,554,937$ & $5,109,870$ & $78,076,307$ & $454,864,240$ & $151,009,898$ & $890,287,118$ \\
\hline
\end{tabular}

Table 5. NASA GeoLab Wing-Body-Nacelle-Pylon Grid Refinement Family Statistics.

\begin{tabular}{|c|c|c|c|c|c|c|c|c|}
\hline \multicolumn{9}{|c|}{ Wing Body Nacelle Pylon Grid Refinement Study } \\
\hline & $1^{\text {ST }}$ CELL & $\begin{array}{r}\text { BLMAX } \\
\text { GROWTH }\end{array}$ & BOUNDARY & & & & & \\
\hline GRID LEVEL & SIZE & RATE & NODES & BOUNDARYFACES & BL NODES & BL CELLS & TOTAL NODES & TOTAL CELLS \\
\hline TINY & 0.001478 & 1.15 & 765,536 & $1,531,072$ & $12,419,166$ & $69,823,581$ & $27,724,572$ & $162,407,703$ \\
\hline COARSE & 0.001285 & 1.15 & $1,005,542$ & $2,011,084$ & $17,706,490$ & $100,064,115$ & $40,742,401$ & $238,932,215$ \\
\hline MEDIUM & 0.001118 & 1.15 & $1,314,055$ & $2,628,110$ & $25,778,271$ & $146,575,107$ & $60,587,854$ & $355,766,178$ \\
\hline FINE & 0.000972 & 1.15 & $1,724,835$ & $3,449,670$ & $38,458,890$ & $220,091,481$ & $91,001,054$ & $535,012,345$ \\
\hline X-Fine & 0.000845 & 1.15 & $2,260,165$ & $4,520,330$ & $60,313,404$ & $347,780,457$ & $138,225,983$ & $813,868,087$ \\
\hline U-Fine & 0.000735 & 1.15 & $2,984,841$ & $5,969,682$ & $89,895,562$ & $520,670,697$ & $208,476,294$ & $1,228,538,520$ \\
\hline
\end{tabular}

Table 6. NASA GeoLab Wing-Body Aeroelastic Sweep Grid Family Statistics.

\begin{tabular}{|c|c|c|c|c|c|c|c|c|}
\hline \multicolumn{9}{|c|}{ Wing Body Aero-elastic Sweep } \\
\hline$A E$ & $1^{\text {ST }}$ CELL & BL MAX & BOUNDARY & & & & & \\
\hline DEG & SIZE & GROWTHRATE & NODES & BOUNDARYFACES & BL NODES & BL CELLS & TOTAL NODES & TOTAL CELLS \\
\hline 2.50 & 0.001118 & 1.15 & $1,125,555$ & $2,251,106$ & $22,400,868$ & $127,488,333$ & $44,158,719$ & $259,240,907$ \\
\hline 3.00 & 0.001118 & 1.15 & $1,121,242$ & $2,242,480$ & $22,339,744$ & $127,150,782$ & $44,076,098$ & $258,766,322$ \\
\hline 3.25 & 0.001118 & 1.15 & $1,123,880$ & $2,247,756$ & $22,348,358$ & $127,185,981$ & $44,077,100$ & $258,758,138$ \\
\hline 3.50 & 0.001118 & 1.15 & $1,124,294$ & $2,248,584$ & $22,396,204$ & $127,468,650$ & $44,145,329$ & $259,167,935$ \\
\hline 3.75 & 0.001118 & 1.15 & $1,124,810$ & $2,249,616$ & $22,382,789$ & $127,386,228$ & $44,132,000$ & $259,084,730$ \\
\hline 4.00 & 0.001118 & 1.15 & $1,124,743$ & $2,249,482$ & $22,392,352$ & $127,444,332$ & $44,138,539$ & $259,126,449$ \\
\hline
\end{tabular}

Table 7. Grid resolution DLR Solar grids (GG: gridding guidelines).

\begin{tabular}{|c|c|c|c|c|c|}
\hline \multirow{2}{*}{ Name } & \multicolumn{2}{|c|}{ WB } & \multicolumn{2}{c|}{ WBNP } & \multirow{2}{*}{$\Delta \mathrm{y}_{1}[\mathrm{in}]$} \\
\cline { 2 - 5 } & GG & Solar & GG & Solar & \\
\hline Tiny (T) & 20 & 7.15 & $25-30$ & 11.8 & 0.001478 \\
\hline Coarse (C) & 30 & 14.1 & $40-45$ & 23.2 & 0.001285 \\
\hline Medium (M) & 45 & 26.8 & $60-70$ & 44.9 & 0.001118 \\
\hline Fine (F) & 70 & 39.7 & $85-100$ & 81.1 & 0.000972 \\
\hline
\end{tabular}


Table 8. CRM Cases 2-5 Participants.

\begin{tabular}{|c|c|c|c|c|c|c|c|}
\hline Team & ID & SYM & Name & Organization & Code & Grid & Turbulence Model \\
\hline \multirow{2}{*}{1} & A1 & $\bar{A}$ & \multirow{2}{*}{ Tony Sclafani } & \multirow{2}{*}{$\begin{array}{l}\text { Boeing, BCA Advanced Concepts, } \\
\text { Long Beach CA }\end{array}$} & Overflow v2.2k & Overset & SA-RC \\
\hline & A2 & $a$ & & & Overflow v2.2k & Overset & SA-RC w/QCR on \\
\hline \multirow{3}{*}{2} & B1 & B & \multirow{3}{*}{ Khaled Abdol-Hamid } & \multirow{3}{*}{ NASA Langley Research Center } & FUN3D 12.8 & Unst-Geolab & k-kL-MEAH2015 w/Limiter \\
\hline & B2 & $\mathbf{b}$ & & & FUN3D 12.8 & Unst-Geolab & k-kL-MEAH2015 no-limiter \\
\hline & B3 & & & & FUN3D 12.8 & Unst-Geolab & SA no-limiter \\
\hline \multirow{2}{*}{3} & D1 & D & \multirow{2}{*}{ Jiangtao Chen } & \multirow{2}{*}{ CARDC } & Mflow & Unst-Geolab & SA \\
\hline & D2 & $d$ & & & Mflow & Unst-custom & SA \\
\hline 4 & E1 & $E$ & Atsushi Hashimoto & JAXA, Ryoyu Systems & FaSTAR & Unst-Geolab & SA-noft2-R w/QCR2000 \\
\hline 5 & F1 & $\mathbf{F}$ & Krishna Zore & Ansys & Fluent & Unst-custom & SST \\
\hline 6 & G1 & G & Benedikt König & EXA Powerflow & PowerfLOW & Custom Cart & LBM-VLES \\
\hline \multirow{2}{*}{7} & $\mathrm{H} 1$ & $\mathrm{H}$ & \multirow{2}{*}{ Ales Prachar/Peter Eliasson } & \multirow{2}{*}{$\begin{array}{c}\text { Aerospace Research and Test } \\
\text { Establishment, FOI }\end{array}$} & Edge & Unst-Geolab & SA \\
\hline & $\mathrm{H} 2$ & $\mathrm{~h}$ & & & Edge & Unst-Geolab & EARSM \\
\hline \multirow{3}{*}{8} & 11 & $\mathrm{I}$ & \multirow{3}{*}{ Anna Rubekinak } & \multirow{3}{*}{ Mentor Graphics } & FloEFD & Custom Cart & Default k-e Lam-Bremhorst \\
\hline & 12 & & & & FloEFD & Custom Cart & Subgrid k-e Lam-Bremhorst \\
\hline & 13 & & & & FloEFD & Custom Cart-B & Default k-e Lam-Bremhorst \\
\hline \multirow{4}{*}{9} & J1 & $\mathrm{J}$ & \multirow{4}{*}{ Brian Edge } & \multirow{4}{*}{ Metacomp } & CFD++ & Unst-Boeing & SA \\
\hline & J2 & & & & CFD++ & Unst-Boeing & SST \\
\hline & J3 & & & & CFD++ & Unst-Geolab & SA \\
\hline & $\mathrm{J4}$ & & & & CFD++ & Unst-custom & Realizable k-epsilon \\
\hline & $\begin{array}{lll}\text { K1 } & & \\
\end{array}$ & $\mathrm{K}$ & & & Cflow & Unst-Boeing & SA-noft2 \\
\hline 10 & K2 & $\mathbf{k}$ & Taleu Nagata $\mathrm{a}>\mathrm{C}$ & Kauasaki Hoapunductrios & Cflow & Unst-Boeing & SA-noft2 w/QCR200 \\
\hline 10 & $\mathrm{~K} 3$ & & Taku Nagata & Kawasakı Heavy Industries & Cflow & Custom Cart & SA-noft2 \\
\hline & $\mathrm{K} 4$ & & & & Cflow & Custom Cart & SA-noft2 w/QCR200 \\
\hline 11 & $\mathrm{~L} 1$ & $\bar{L}$ & Stefan Keye / Vamshi & DIR & TAU & Unst-custom & RSM- $\omega$ \\
\hline 11 & L2 & & Togiti & DLR & TAU & Unst-custom & SA-neg \\
\hline 12 & M1 & $\mathbf{M}$ & & Tennessee, Pointwise, NASA & COFFE/KCFD & Unst-custom & SA-neg \\
\hline 12 & M2 & $\mathbf{m}$ & Ryan S. Glasby & Langley, NAVAIR, MIT, U Ala & COFFE/KCFD & Unst-custom & SA-neg w/QCR2000 \\
\hline 13 & N1 & $\mathbf{N}$ & N. Balakrishnan & CAd Lab, Indian Institute of Sci & HiFun & Unst-custom & SA \\
\hline 19 & 01 & 0 & David Hur & ONCDA & elsA & Overset & SA \\
\hline & 02 & & Davia nue & UIVEKA & elsA & Overset & SA-QCR2000 \\
\hline 15 & P1 & $\mathbf{P}$ & Todd Michal & Boeing St I ouis & BCFD & Unst-Boeing & SA-RC \\
\hline 10 & P2 & & Toun ivictial & Dueinig, Ji. Ludis & GGNS & All Tets & SA-RC \\
\hline & Q1 & $\mathbf{Q}$ & & & ADflow & Embraer MB & SA 1stOrder \\
\hline 16 & Q2 & $q$ & Gaetan Kenway & MDOlab, University of Michigan & ADflow & Cust-Overset & SA 1stOrder \\
\hline & Q3 & & & & ADflow & Embraer MB & SA-QCR2000 \\
\hline 17 & R1 & $\mathbf{R}$ & Andrei Cimpoeru & CFMS, Zenotech, ARA & ZCFD & Unst-custom & SST \\
\hline 18 & S1 & $\mathrm{s}$ & Kelly Laflin & Textron Aviation (Cessna) & FUN3D & Unst-Geolab & SA-RC \\
\hline 19 & $\mathrm{T1}$ & $\mathrm{T}$ & Yuntao Wang & CARDC & TRIP & CommonMB & SST-2003 \\
\hline 20 & U1 & u & lim Coder & Annlied Research L ab Penn State & \begin{tabular}{|c|} 
Overflow 2.21 3rd \\
Order WENO
\end{tabular} & Overset & SA-RC W/QCF2000 \\
\hline 20 & U2 & u & Jim Coder & Applied Research Lab, Penn State & \begin{tabular}{|c|}
$\begin{array}{c}\text { Overflow 2.21 5TH } \\
\text { Order WENO }\end{array}$ \\
\end{tabular} & Overset & SA-RC W/QCF2000 \\
\hline & V1 & $\mathbf{v}$ & & & CFD++ & Unst-Geolab & SST \\
\hline 21 & V2 & & Rodriag Folix de Souza & Embraer $\mathrm{S} / \mathrm{A}$ & CFD++ & Embraer MB & SST \\
\hline 21 & V3 & & koanigo retix ae souza & Emidrder $\mathrm{S} / \mathrm{A}$ & CFD++ & Unst-custom-A & SST \\
\hline & V4 & & & & CFD++ & Unst-custom-I & SST \\
\hline 22 & W1 & w & Dominic Chandar & Institute of High Performance & $\mu \mathrm{SICS}$ & Unst-custom & SA \\
\hline 23 & $\mathrm{x} 1$ & $\mathrm{x}$ & Patrick Hanley & Hanley Innovations & Stallion3D & Custom Cart & k-e \\
\hline 24 & Y1 & $Y$ & Neil Ashton & $\begin{array}{c}\text { University of Oxford, } \\
\text { ESI Group, BETA CAE Systems }\end{array}$ & OpenFOAM & Unst-custom & SA \\
\hline & $\mathrm{Z1}$ & $\mathrm{z}$ & & & TAS limiter $\mathrm{K}=1$ & Unst-Geolab & SA-noft2-R w/QCR2000 \\
\hline & $\mathbf{Z 2}$ & & & & TAS limiter $\mathrm{K}=5$ & Unst-Geolab & SA-noft2-R w/QCR2000 \\
\hline & $\mathrm{Z3}$ & & & & TAS limiter $\mathrm{K}=\mathbf{1 0}$ & Unst-Geolab & SA-noft2-R w/QCR2000 \\
\hline 25 & $\mathrm{Z4}$ & & Yasushi Ito & JAXA, Ryoyu Systems & TAS limiter $\mathrm{K}=10$ & Unst-custom & SA-noft2-R w/QCR2000 \\
\hline & 25 & & & & TAS limiter K=5 & Unst-Geolab & SA-noft2-R \\
\hline & $\mathrm{Z6}$ & & & & TAS limiter K=5 & Unst-Boeing & SA-noft2-R \\
\hline & 27 & & & & TAS limiter $\mathrm{K}=5$ & Unst-Boeing & SA-noft2-R w/QCR2000 \\
\hline
\end{tabular}


Table 9. Overview of aeroelastic Simulation Methods used for Test Case 5.

\begin{tabular}{|c|c|c|c|c|}
\hline & \multicolumn{4}{|c|}{ Dataset Key } \\
\hline & $\mathrm{J4}$ & L2 & T1 & V5 \\
\hline $\begin{array}{l}\text { Coupling } \\
\text { Approach }\end{array}$ & linear static & linear static & linear static & linear modal \\
\hline Flow Solver & Finite-Volume & Finite-Volume & Finite-Volume & Finite-Volume \\
\hline Solver Name & CFD++ & TAU & TRIP & CMS AERO-F \\
\hline $\begin{array}{l}\text { Turbulence } \\
\text { Model }\end{array}$ & realizable k- $\varepsilon$ & SA-neg & SST-2003 & SA-QCR2013 \\
\hline Structural Solver & Finite-Element & Finite-Element & Finite-Element & Finite-Element \\
\hline Model Suspension & Wing Root & Balance Interface & Wing Root & Center of Gravity \\
\hline $\begin{array}{l}\text { Force } \\
\text { Interpolation } \\
\text { Algorithm }\end{array}$ & $\begin{array}{l}\text { Nearest-Neighbor } \\
\text { Search }\end{array}$ & $\begin{array}{l}\text { Nearest-Neighbor } \\
\text { Search }\end{array}$ & Thin Plate Spline & $\begin{array}{l}\text { Nearest-Neighbor } \\
\text { Search }\end{array}$ \\
\hline $\begin{array}{l}\text { Mesh } \\
\text { Deformation } \\
\text { Method }\end{array}$ & $\begin{array}{l}\text { Radial Basis } \\
\text { Functions }\end{array}$ & $\begin{array}{l}\text { Radial Basis } \\
\text { Functions }\end{array}$ & $\begin{array}{l}\text { Radial Basis } \\
\text { Functions }\end{array}$ & $\begin{array}{l}\text { linear Torsional } \\
\text { Spring Analogy }\end{array}$ \\
\hline
\end{tabular}

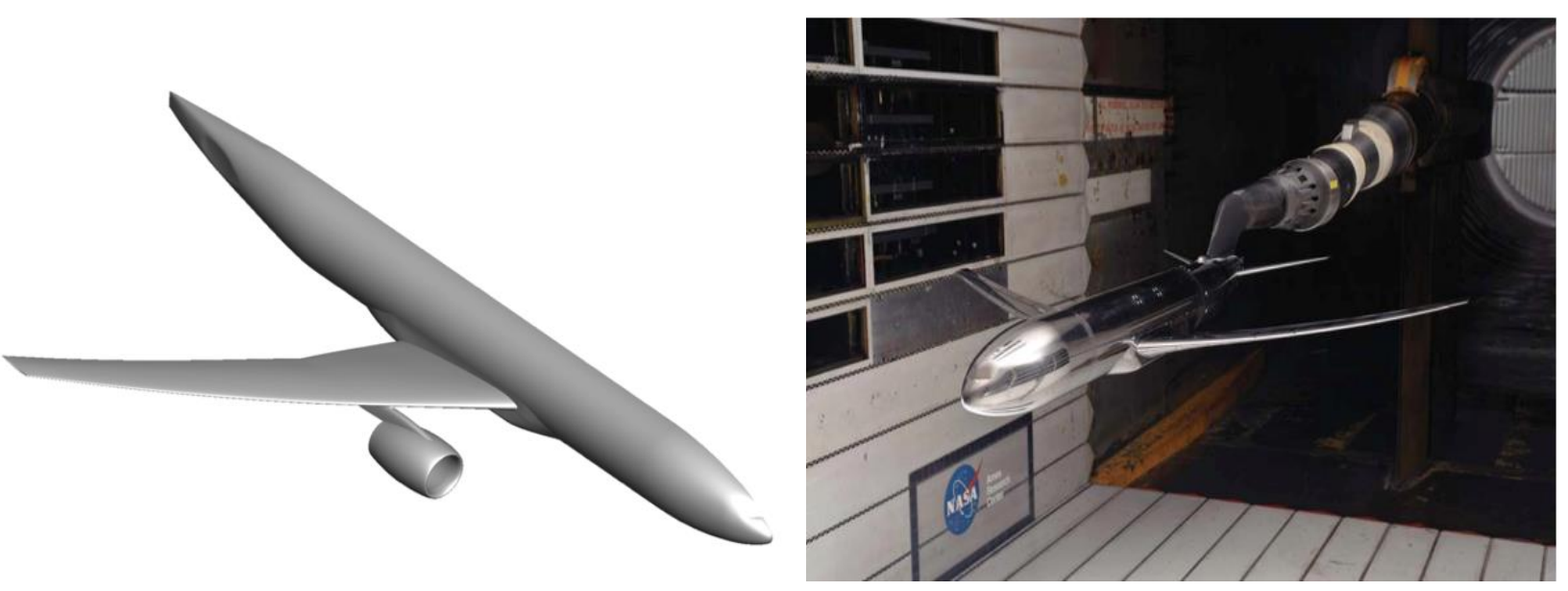

Figure 1. NASA Common Research Model (CRM) geometry for DPW-V cases 2-5.

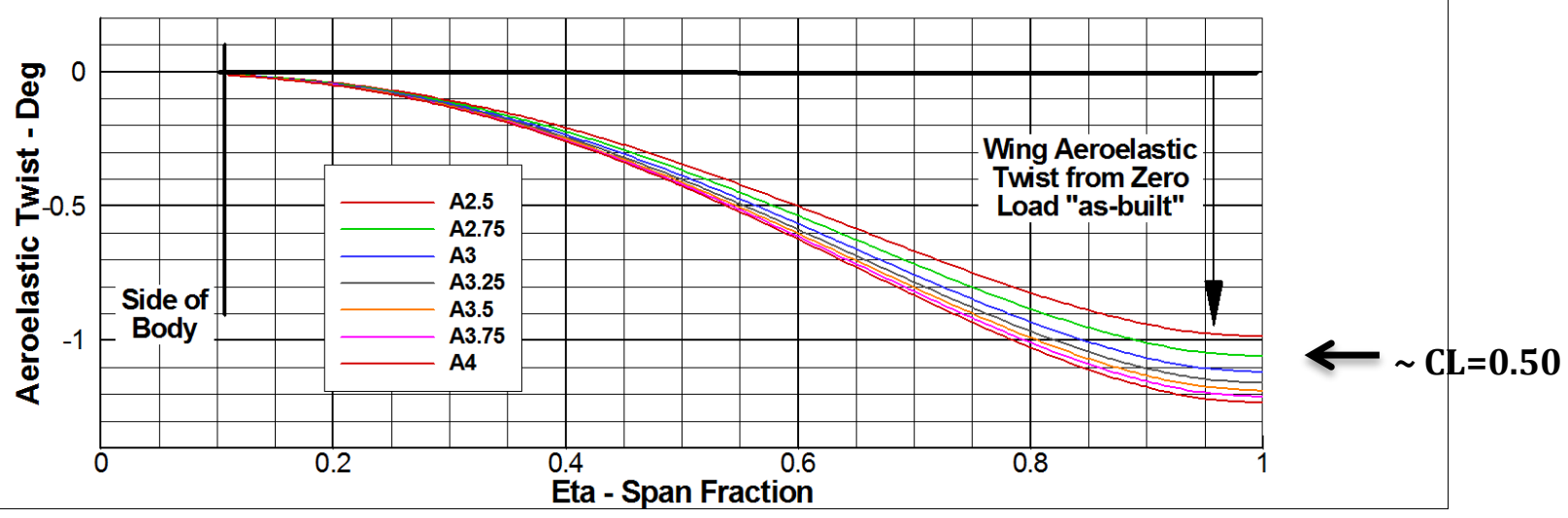

Figure 2. Static Aeroelastic Twist Distributions Derived from Wing Tunnel Measurements.

American Institute of Aeronautics and Astronautics 

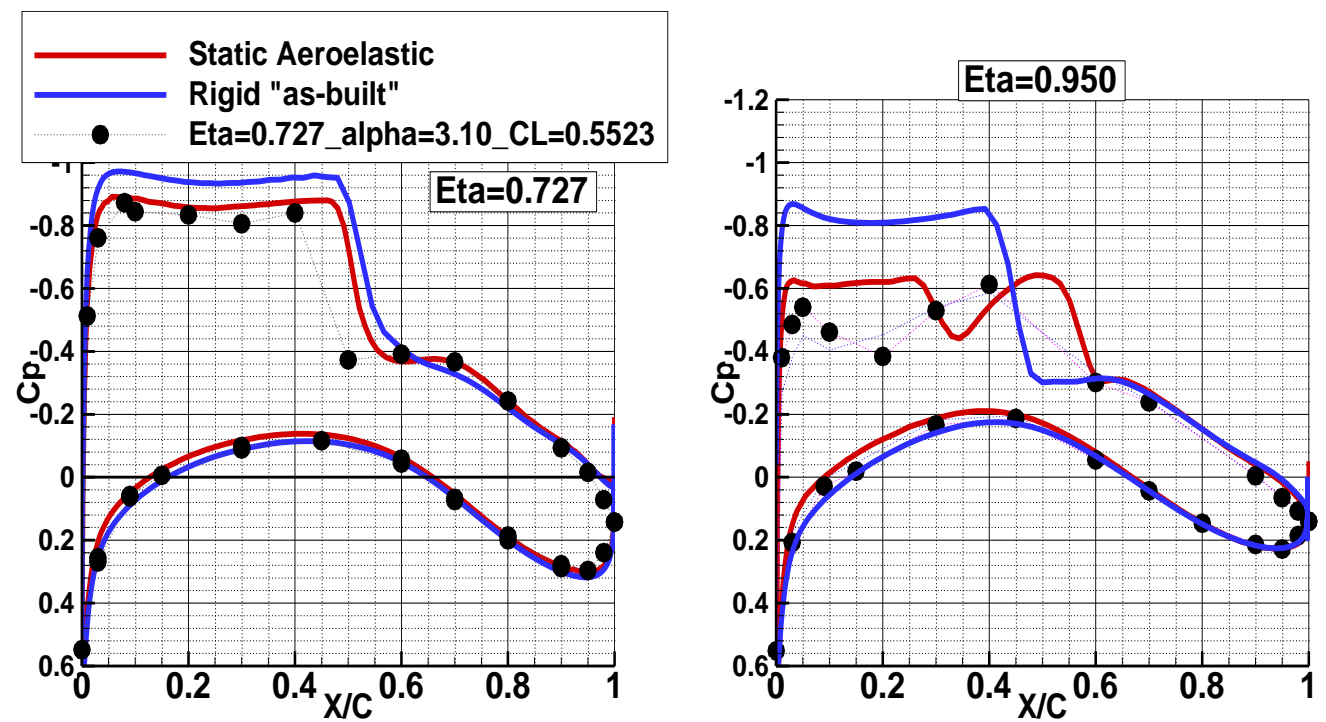

Figure 3. Impact of Static Aeroelastic Deformation on Wing Pressure Distributions $-3^{\circ}$ Angle-ofAttack.
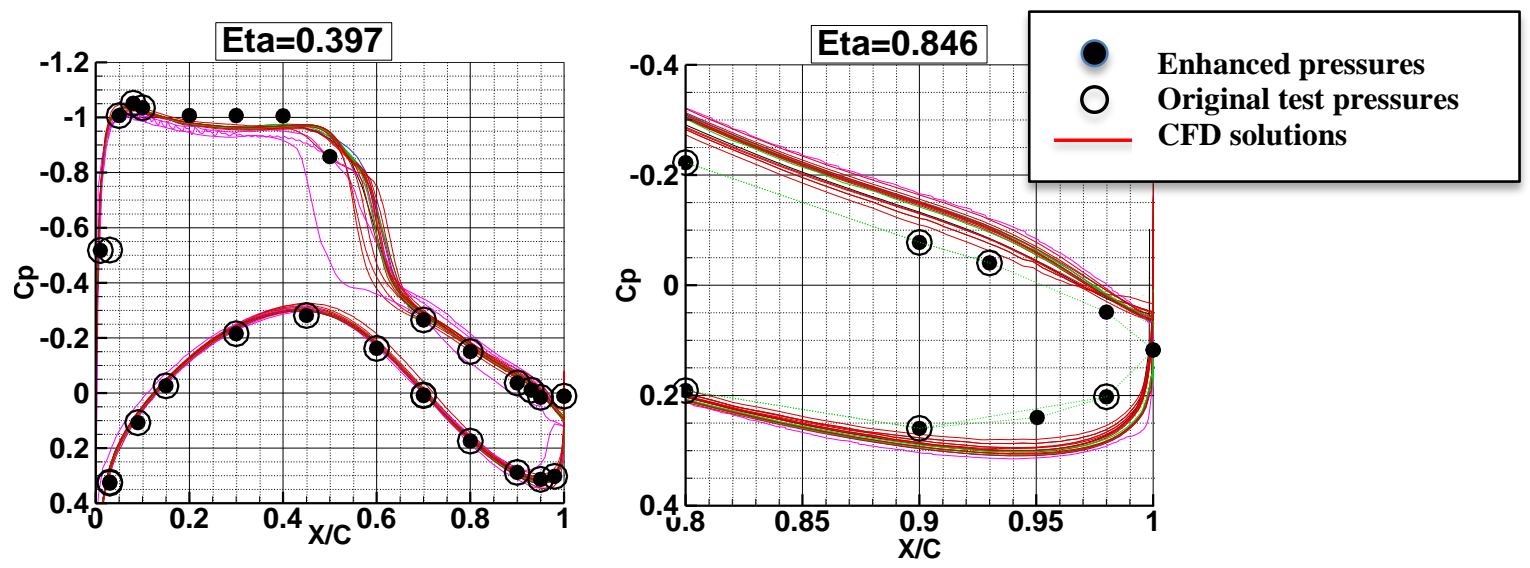

Figure 4. Enhancement of Wing Tunnel Pressure Measurements. 


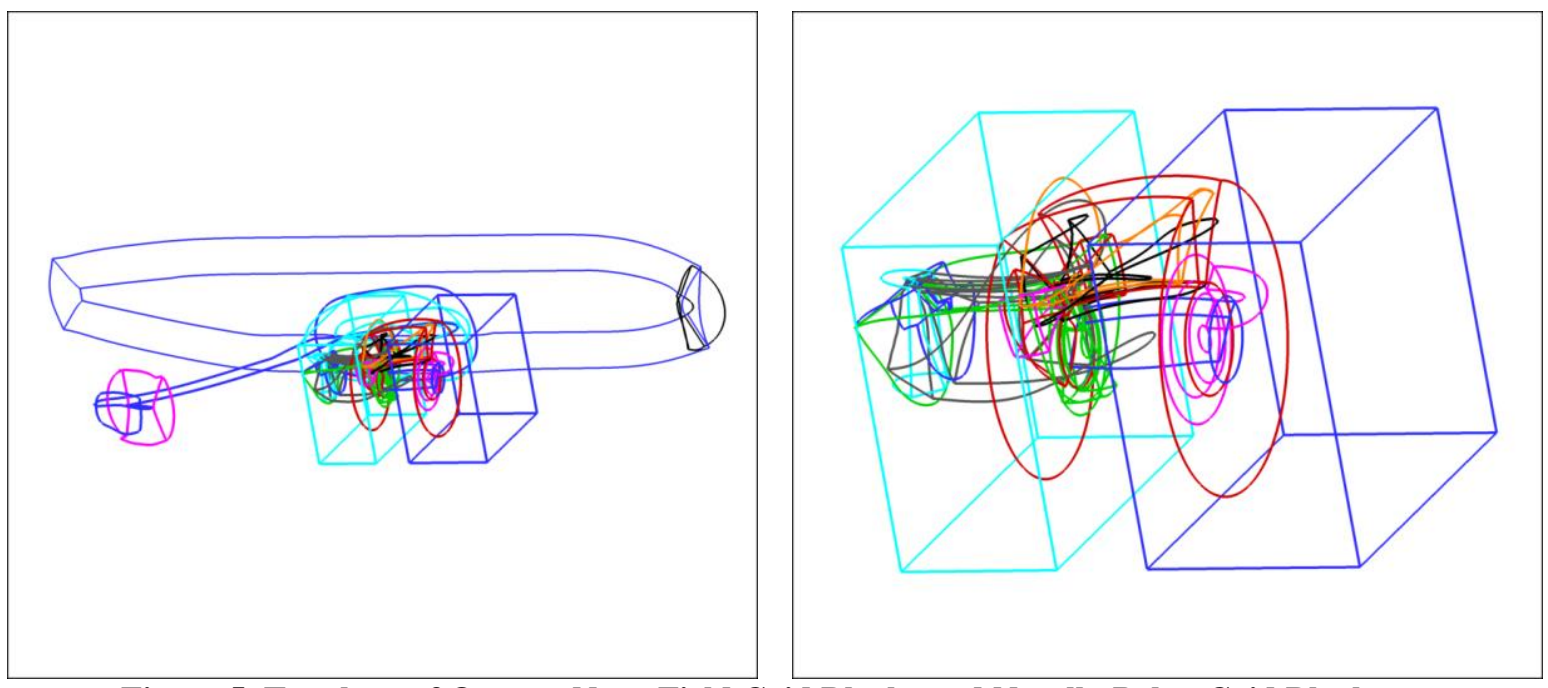

Figure 5. Topology of Overset Near-Field Grid Blocks and Nacelle-Pylon Grid Blocks.

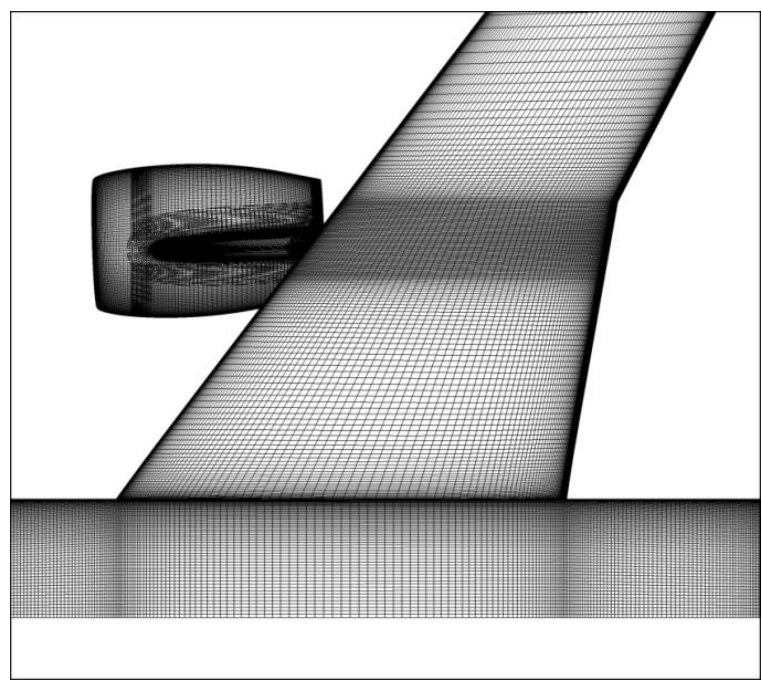

a. WBNP Surface Grids

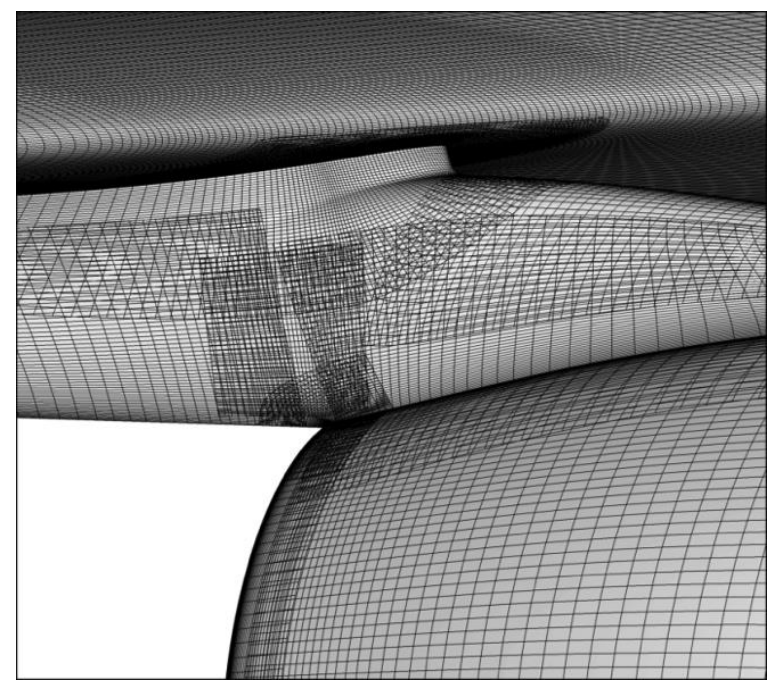

b. Nacelle/Pylon Surface Grids

Figure 6. Close-Up of WBNP Surface and Nacelle/Pylon Surface Grids for the Medium Overset Mesh.

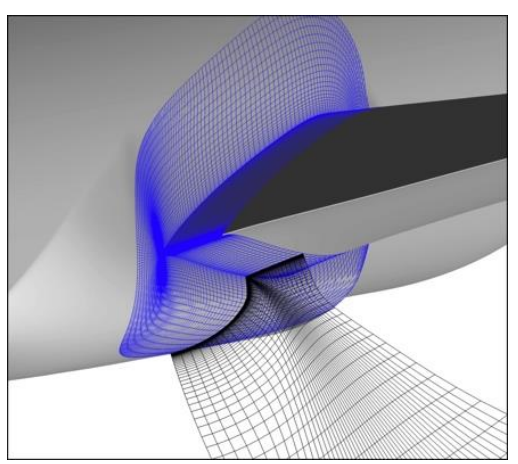

a. WB Collar Grid

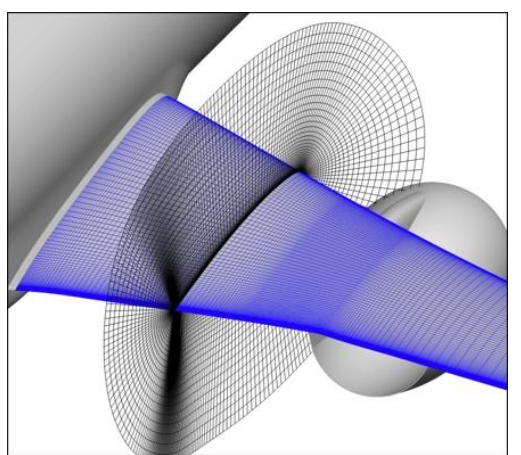

b. O-Mesh Abutting the Wing

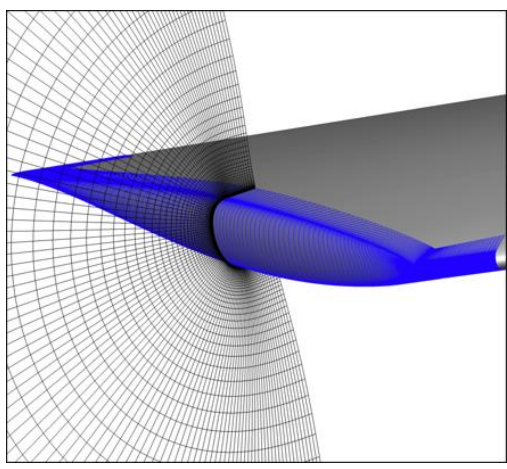

c. Wingtip Clamp Grid

American Institute of Aeronautics and Astronautics 
Figure 7. Close-Up of Overset Features for Medium Overset Mesh.
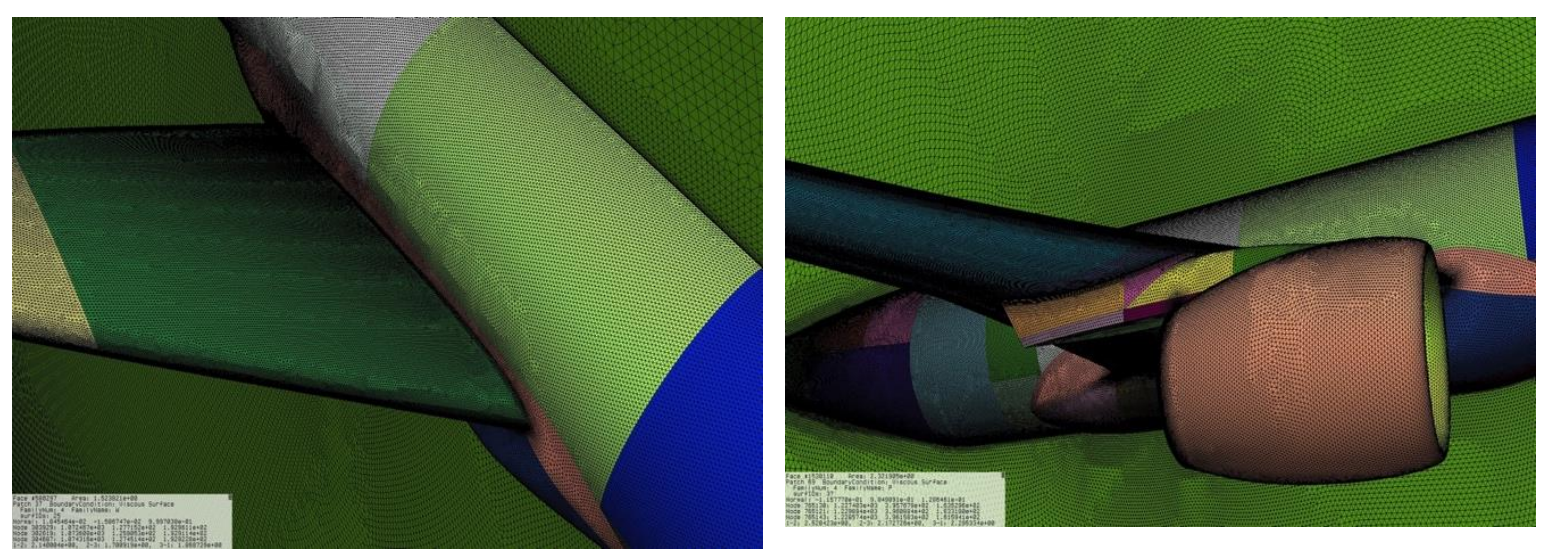

Figure 8. Close-Up of NASA GeoLab Unstructured Surface Meshes.

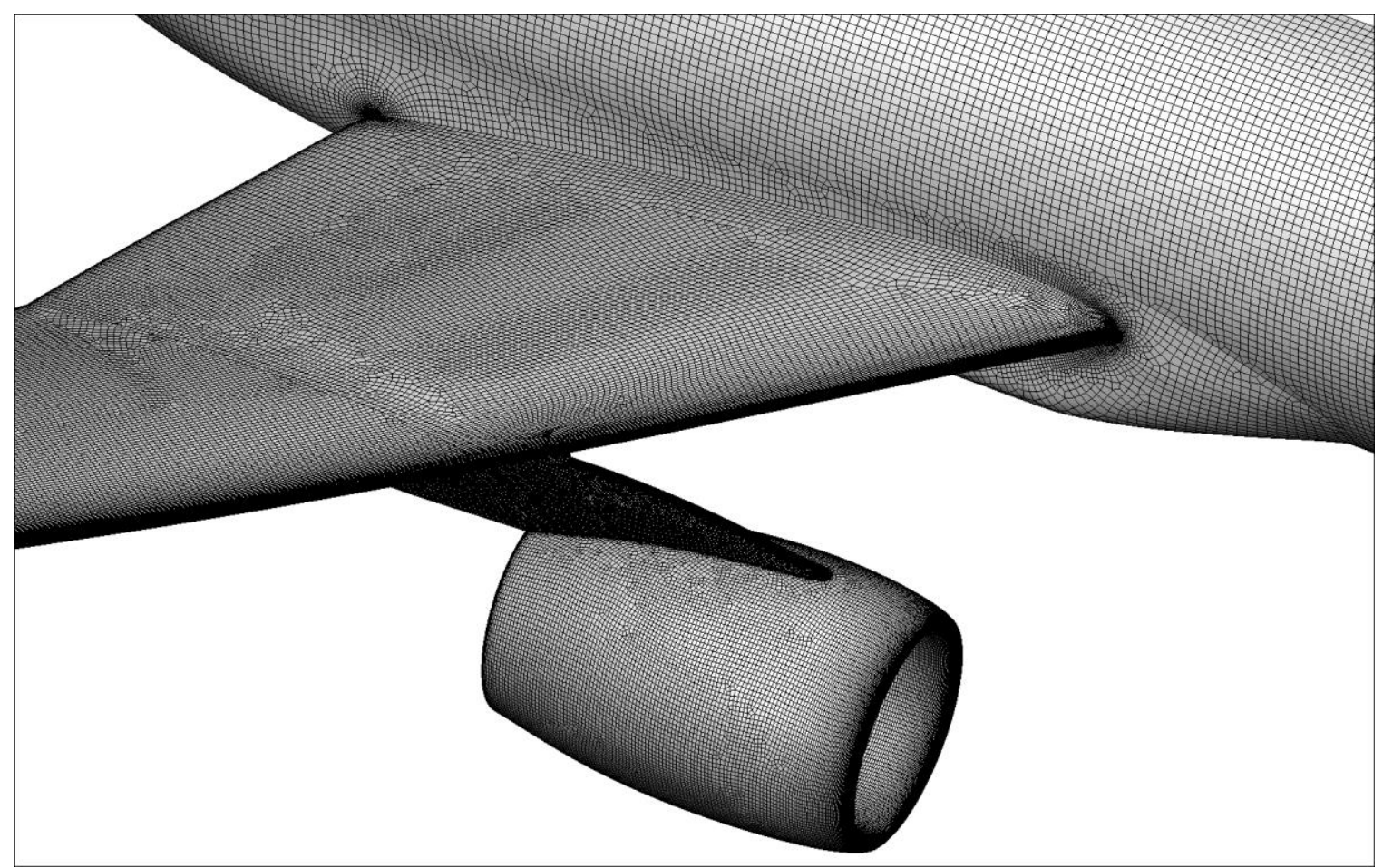

Figure 9. Close-Up of DLR Solar Unstructured Surface Mesh. 

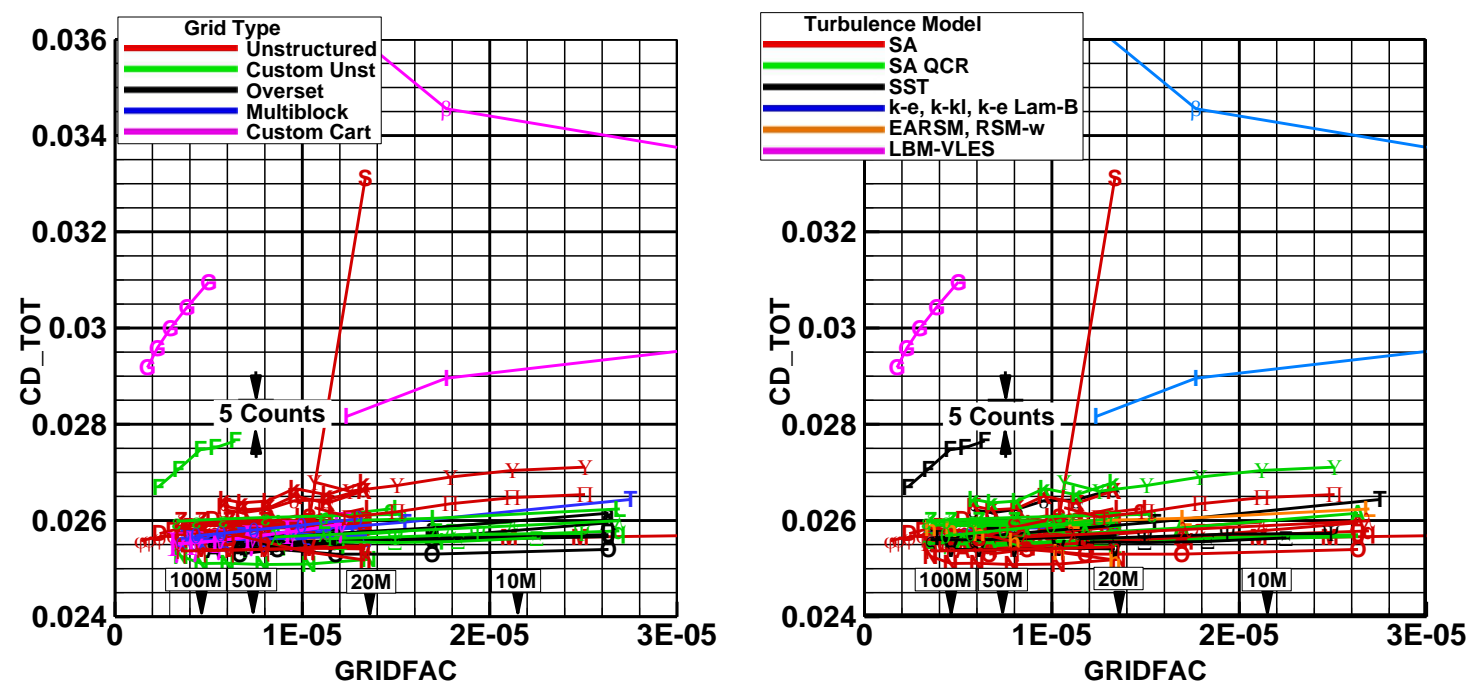

Figure 10. Case 2: CRM WB total drag by grid type and turbulence model, $M=0.85, C L=0.50$.
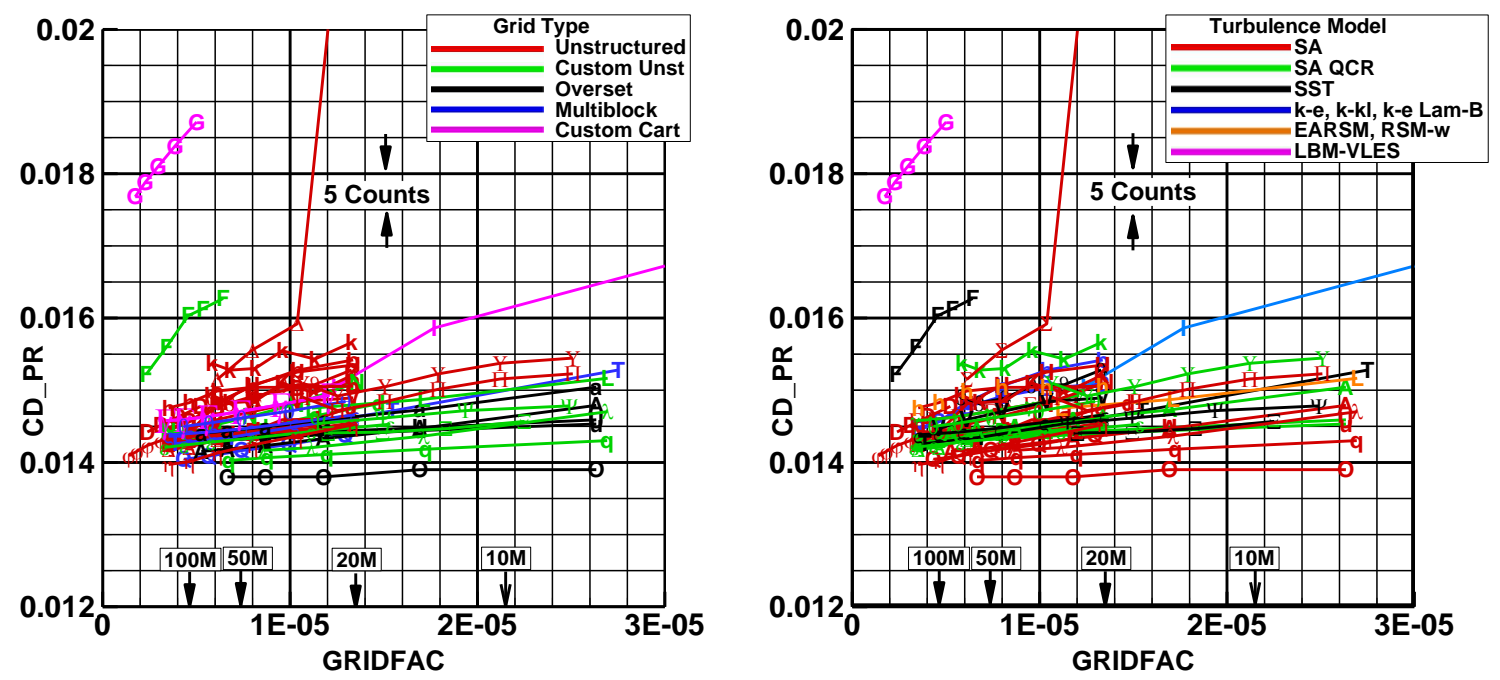

Figure 11. Case 2: CRM WB pressure drag by grid type and turbulence model, $M=0.85, C L=0.50$. 

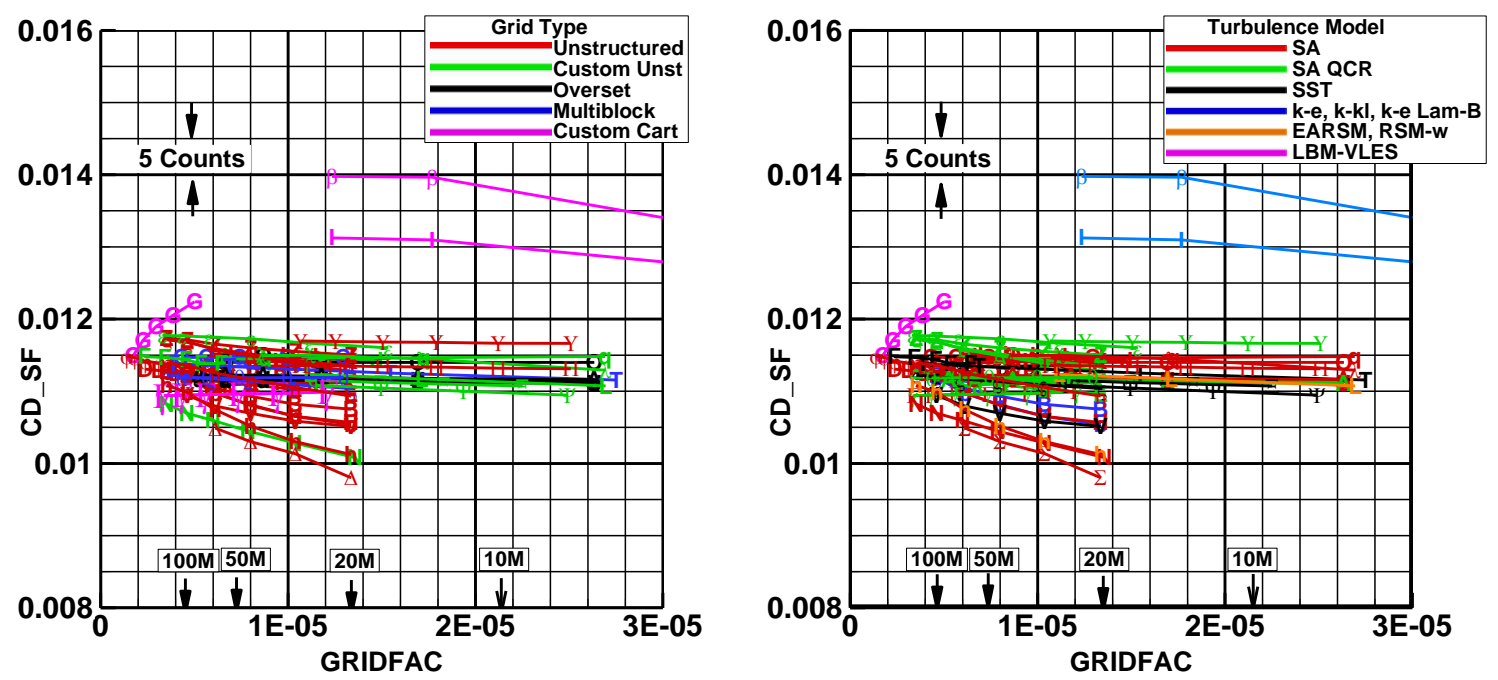

Figure 12. Case 2: CRM WB skin friction drag by grid type and turbulence model, $M=0.85$, CL=0.50.
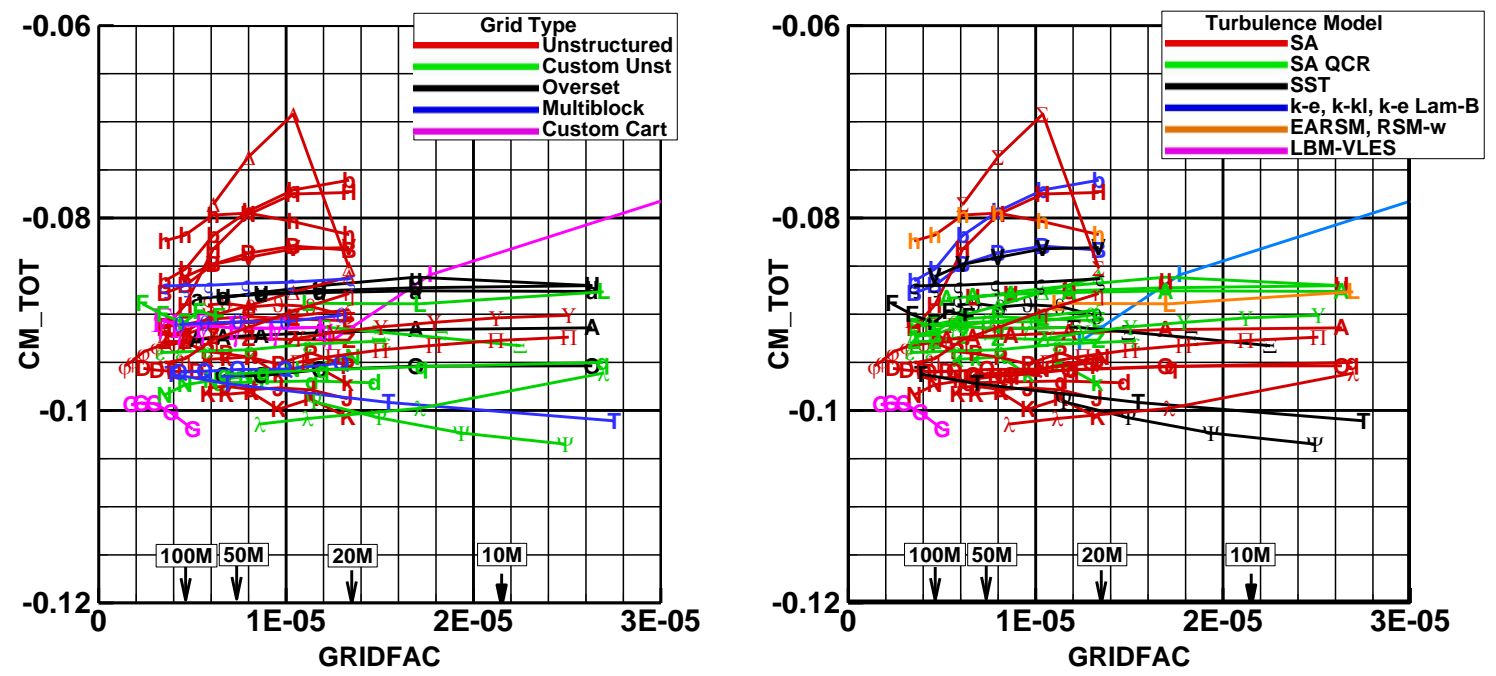

Figure 13. Case 2: CRM WB pitching moment by grid type and turbulence model, $M=0.85$, CL=0.50. 



Figure 14. Case 2: CRM WB total drag by grid type and turbulence model, $M=0.85, C L=0.50$.
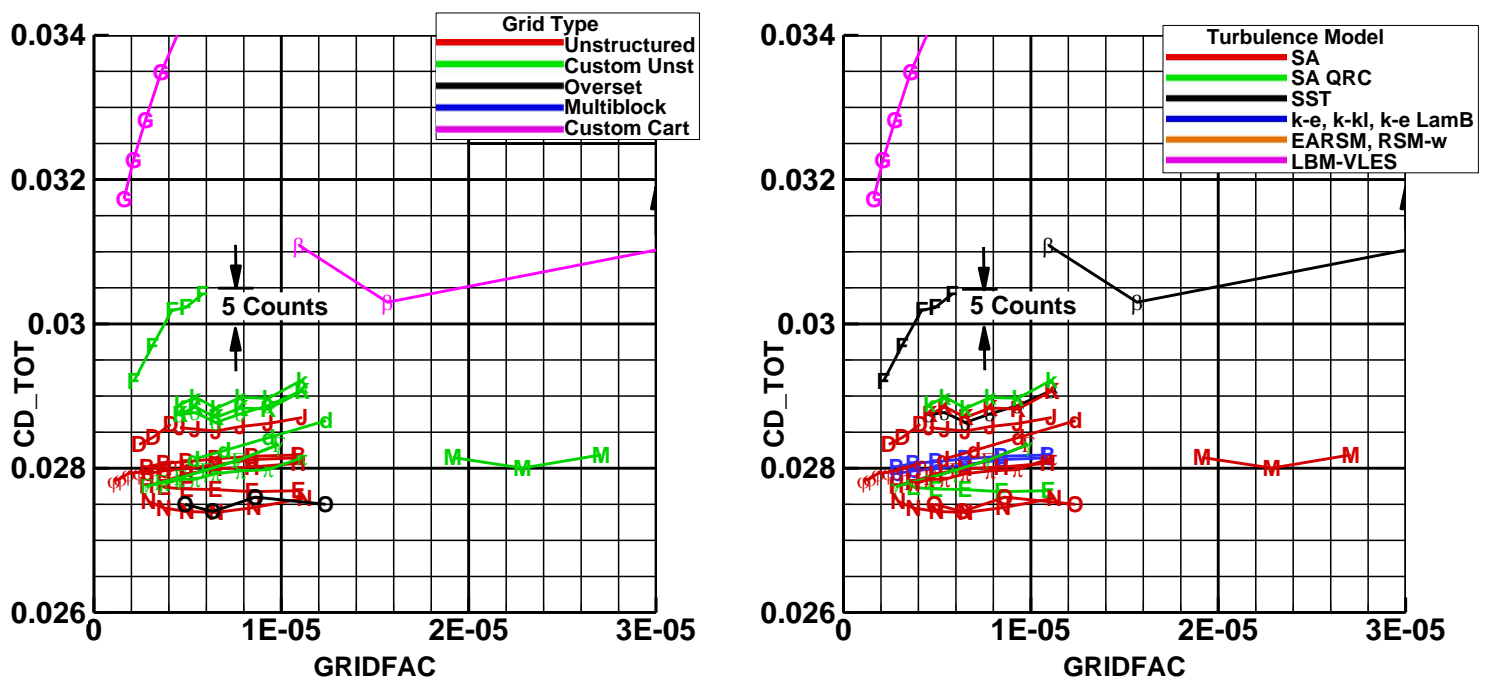

Figure 15. Case 2: CRM WBNP total drag by grid type and turbulence model, $M=0.85, C L=0.50$. 

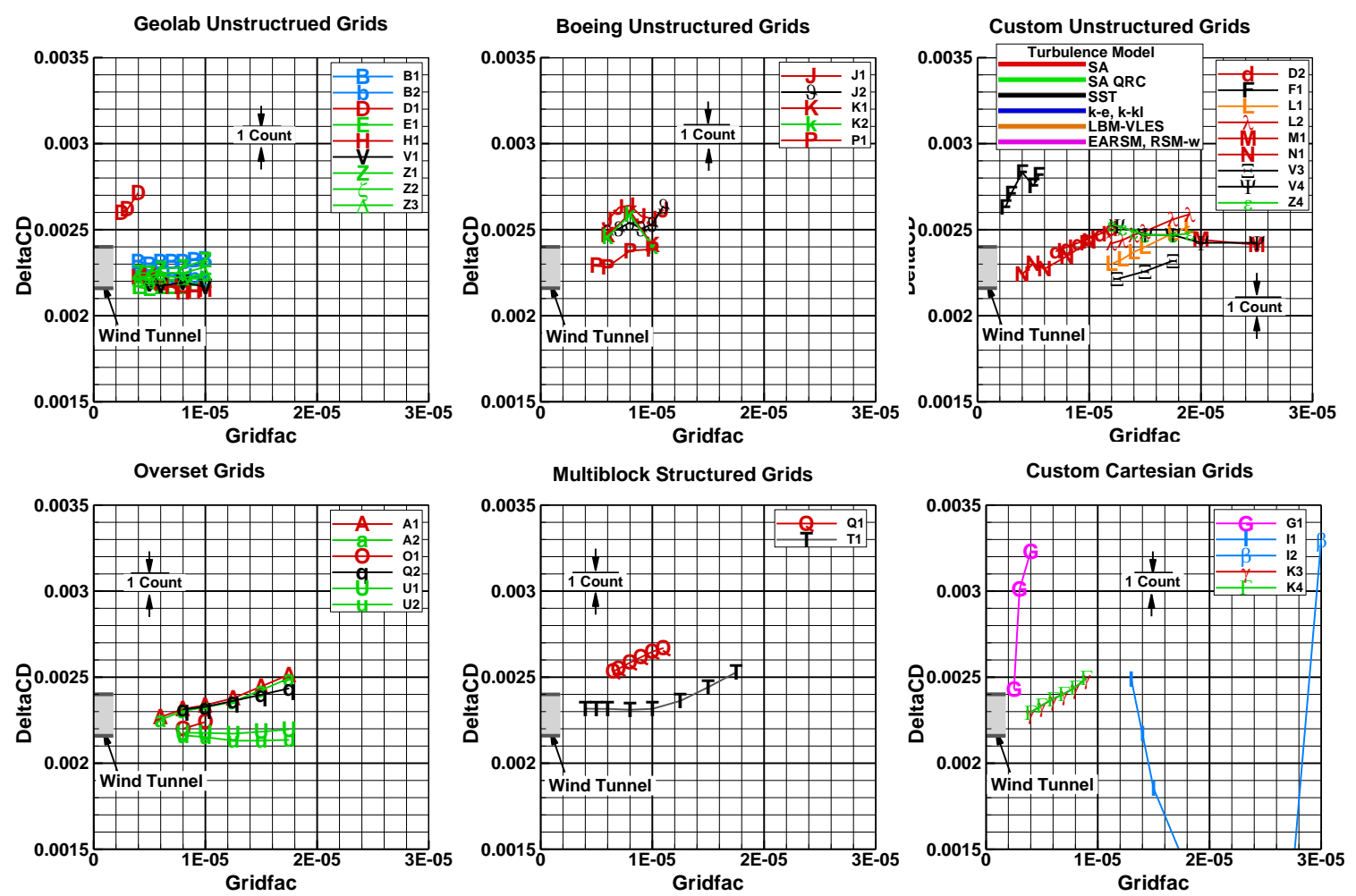

Figure 16. Case 2: CRM WBNP - WB drag increment by grid type and turbulence model, $M=0.85$, $\mathbf{C L}=\mathbf{0 . 5 0}$.
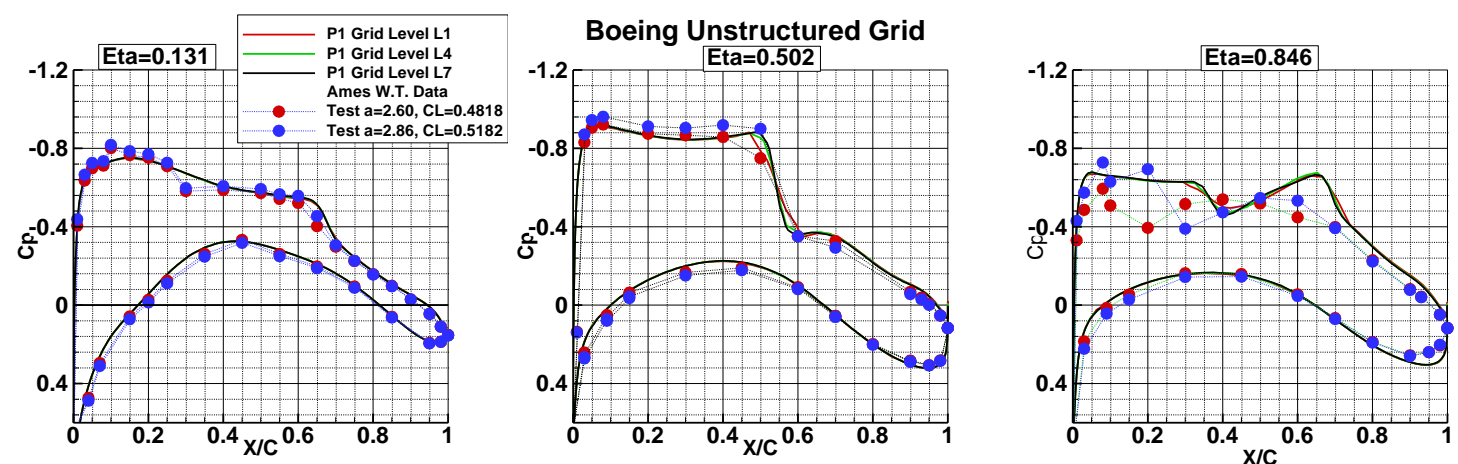

Figure 17. Case 2: CRM WB wing pressure distributions - grid convergence, $M=0.85, C L=0.50$. 

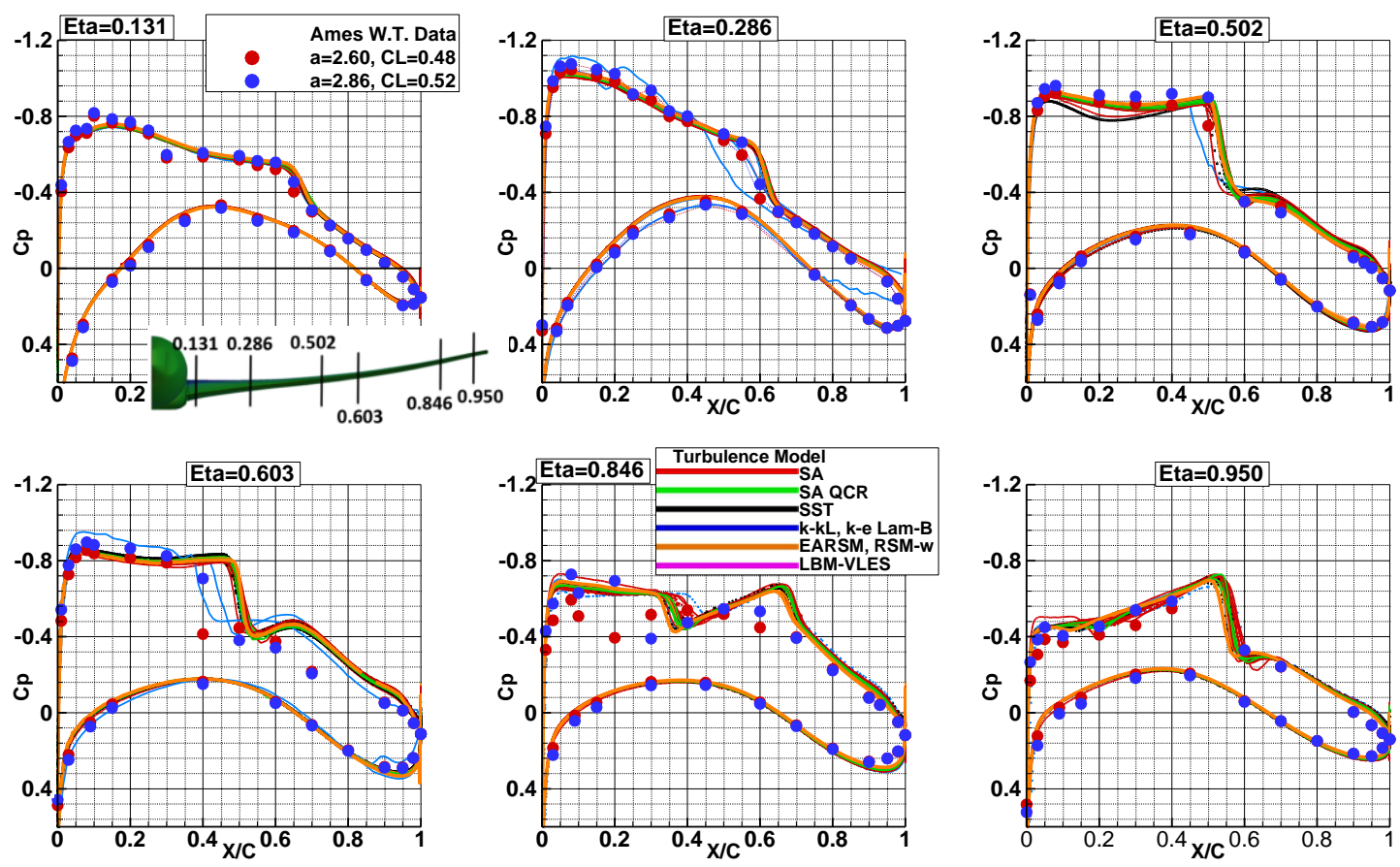

Figure 18. Case 2: CRM WB wing pressure distributions, all solutions - finest grids, $M=0.85$, CL=0.50.
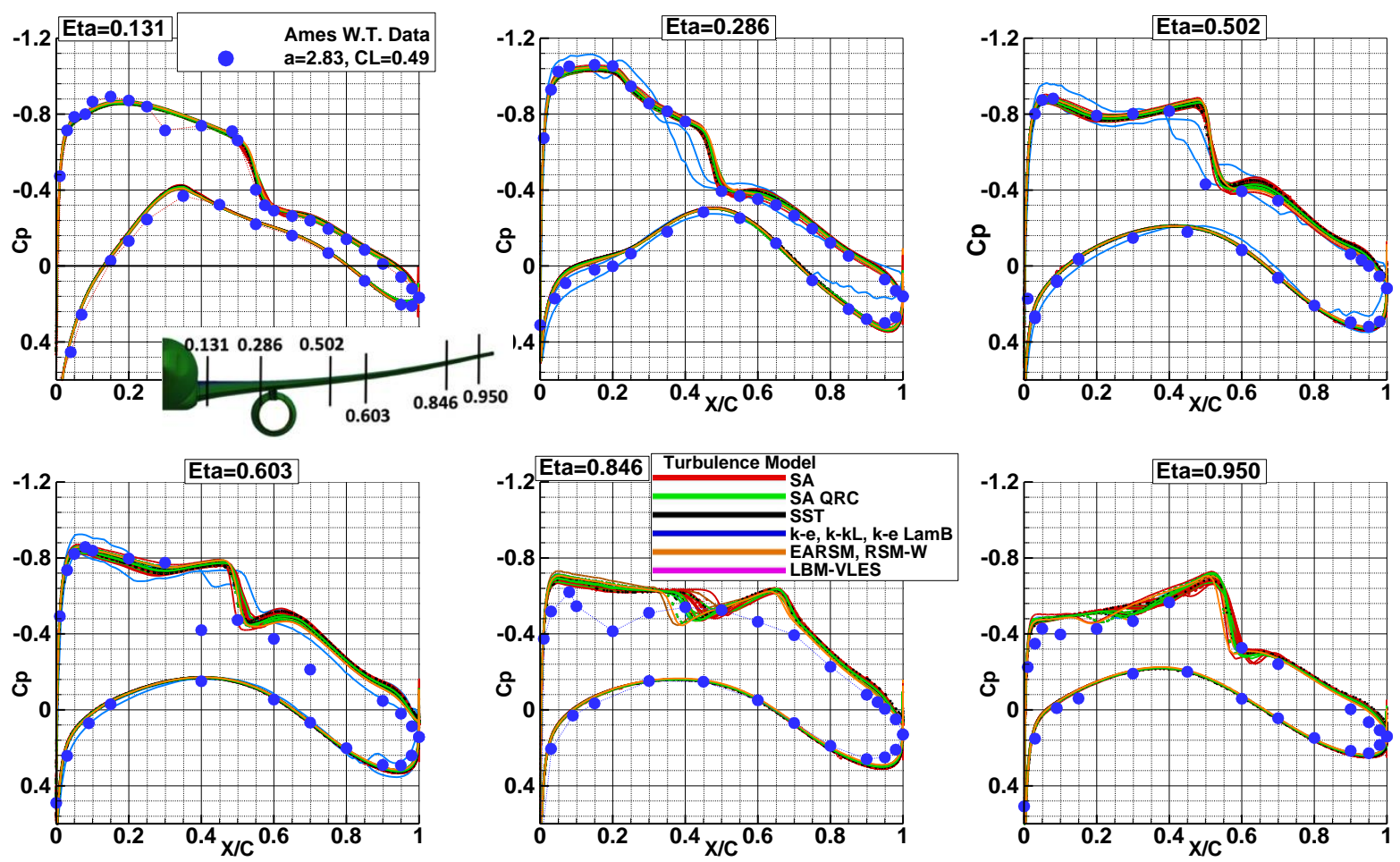

Figure 19. Case 2: CRM WBNP wing pressure distributions, all solutions - finest grids, $M=0.85$, CL $=\mathbf{0 . 5 0}$. 

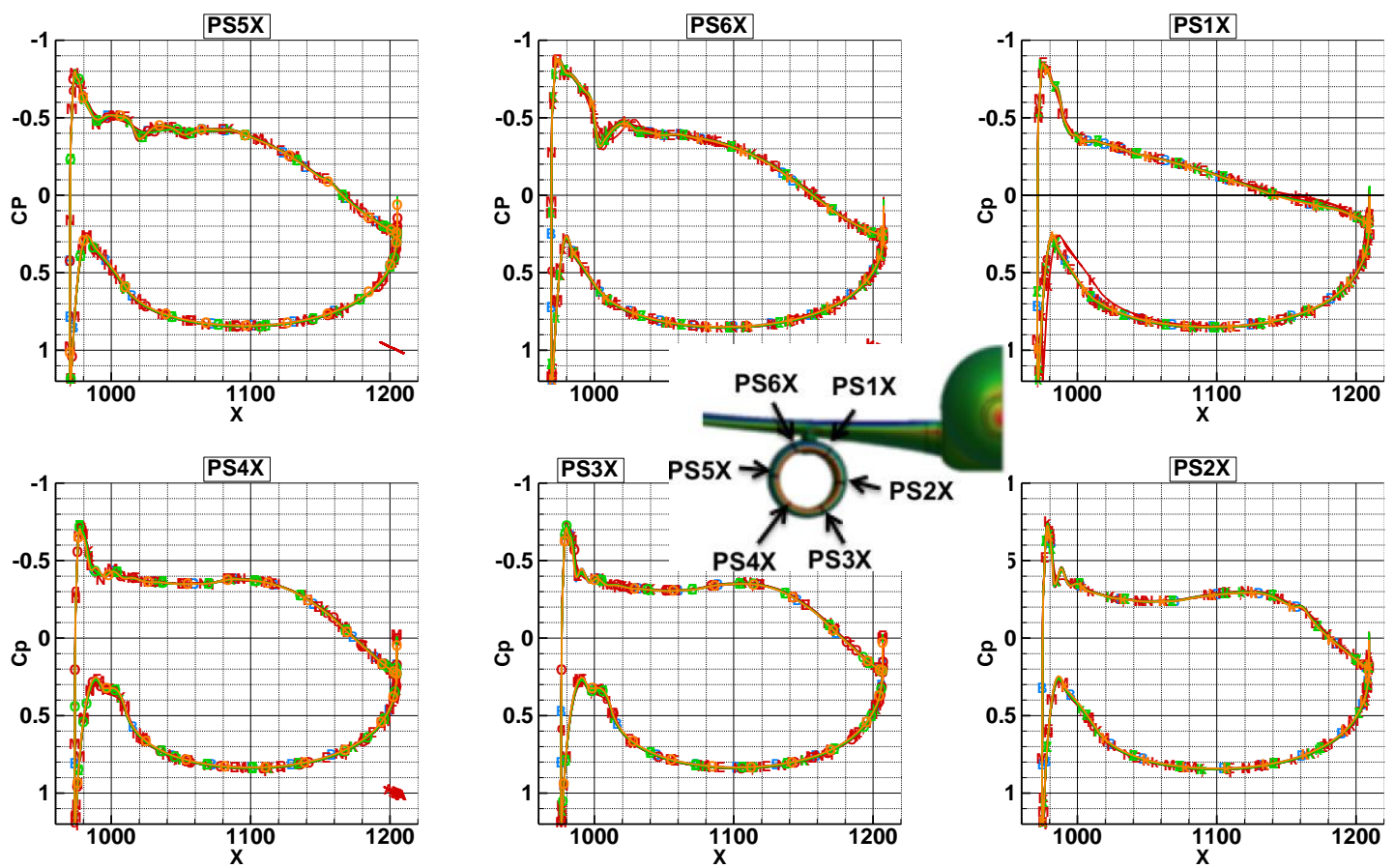

Figure 20. Case 2: CRM WBNP nacelle pressure distributions, all solutions - finest grids, $M=0.85$, $\mathbf{C L}=\mathbf{0 . 5 0}$.

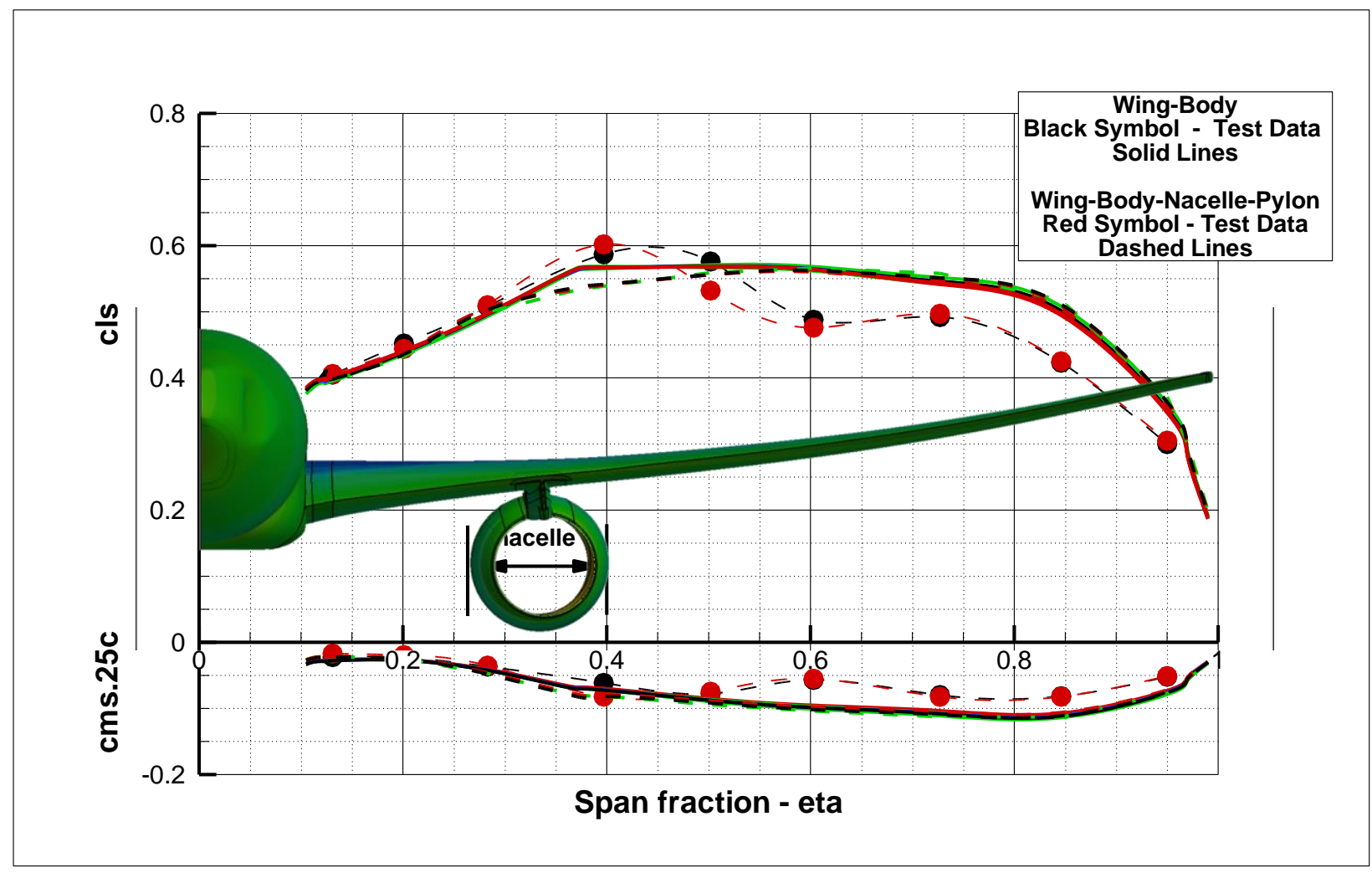

Figure 21. Case 2: CRM WBNP and WB wing section lift and pitching moment, $M=0.85, C L=0.50$. 

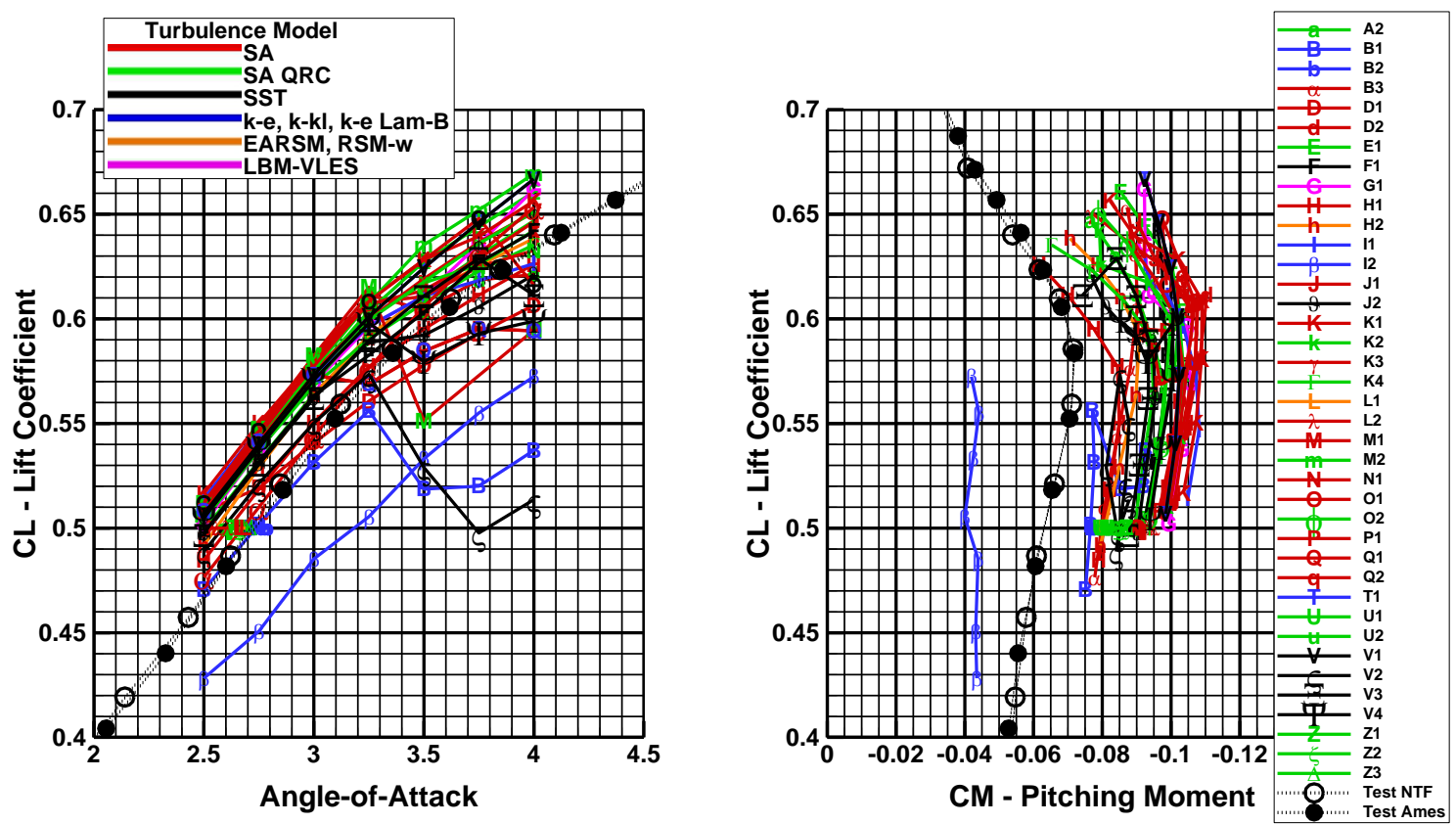

Figure 22. CRM WB Lift and pitching moment for all solutions, $M=0.85$.
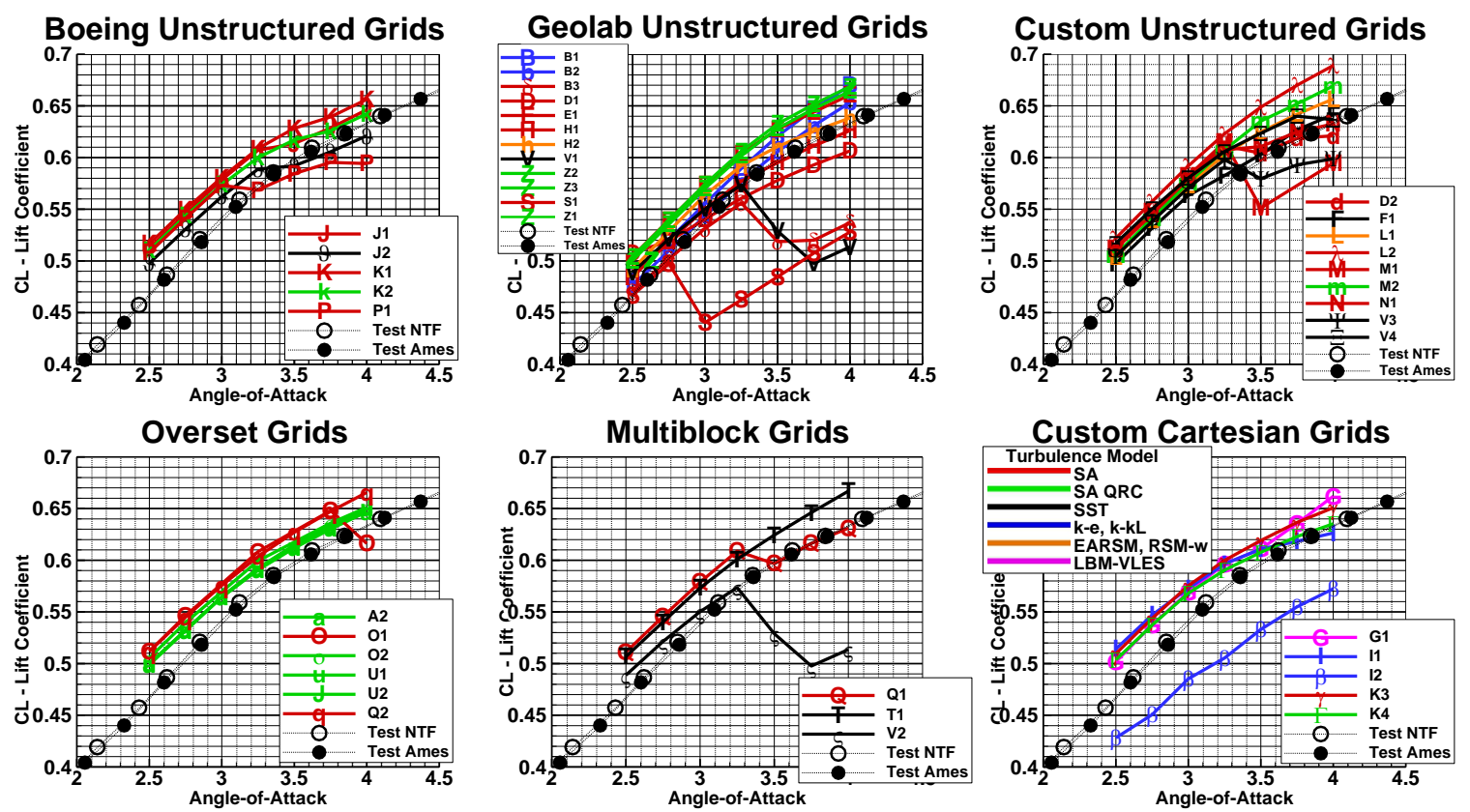

Figure 23. CRM WB total lift by grid type and turbulence model, $M=0.85$. 


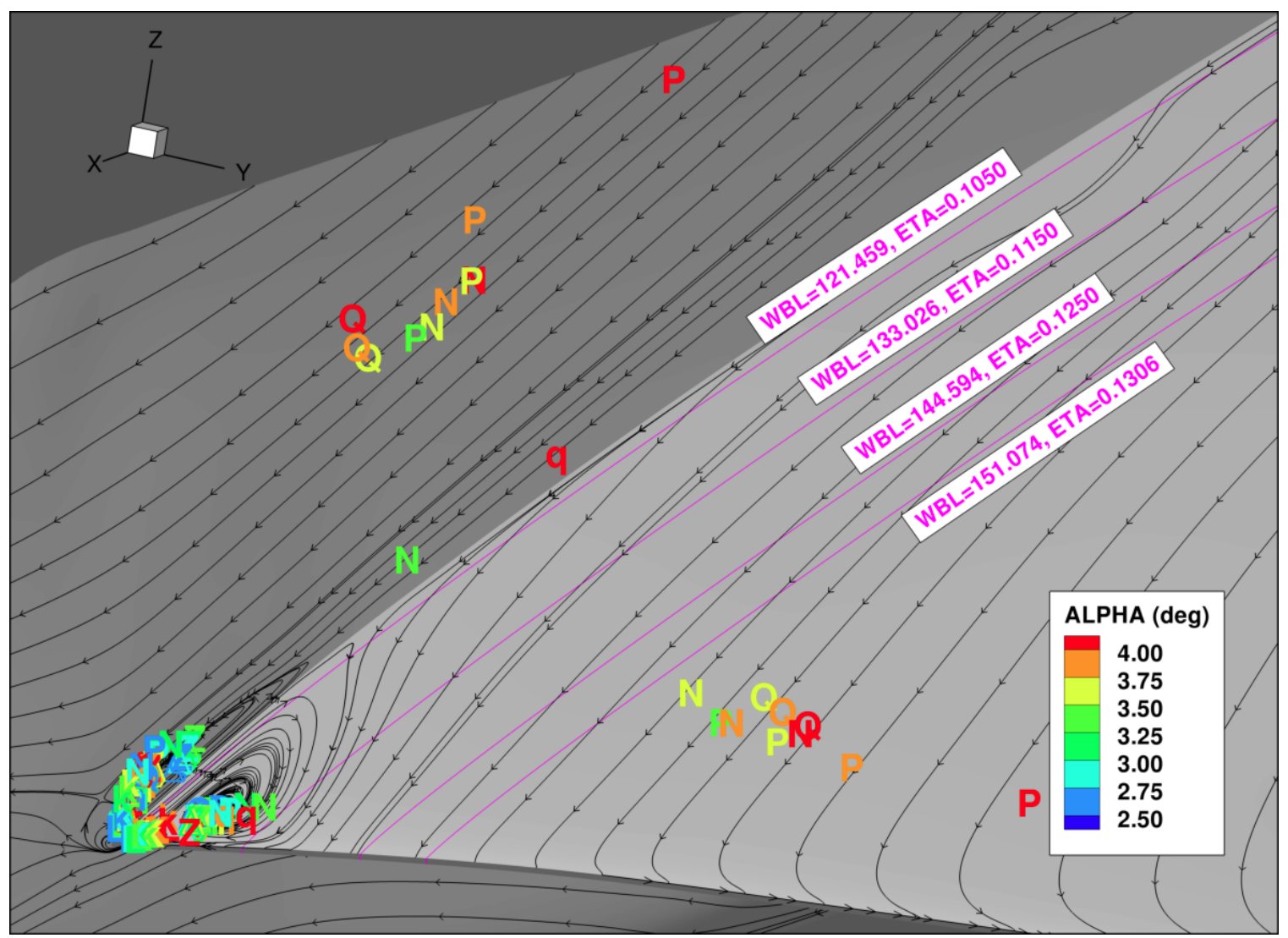

Figure 24. CRM Separation bubble extant vs. angle-of-attack.
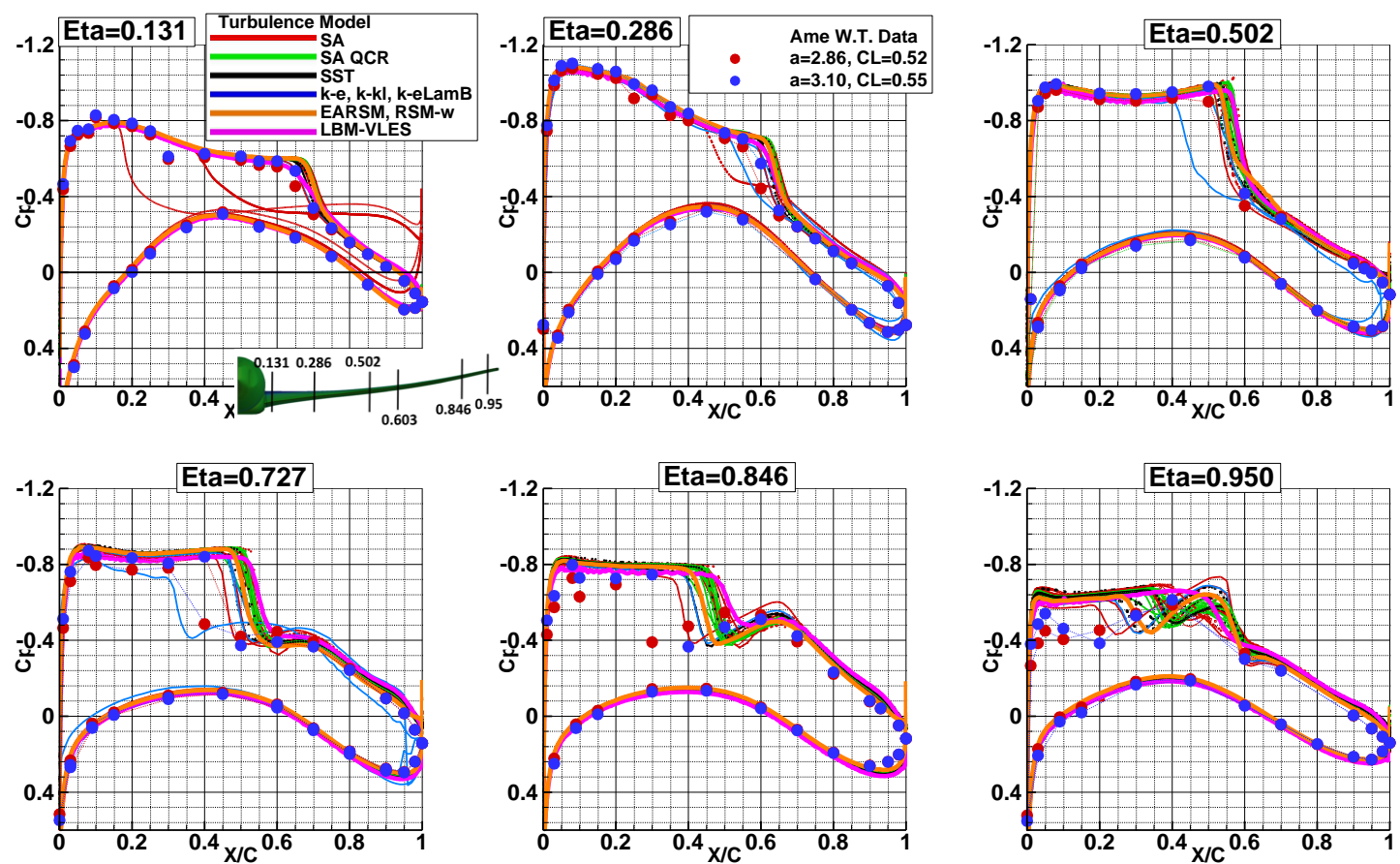

Figure 25. CRM Wing-Body Pressure Distributions $-3.0^{\circ}$ angle-of-attack.

American Institute of Aeronautics and Astronautics 

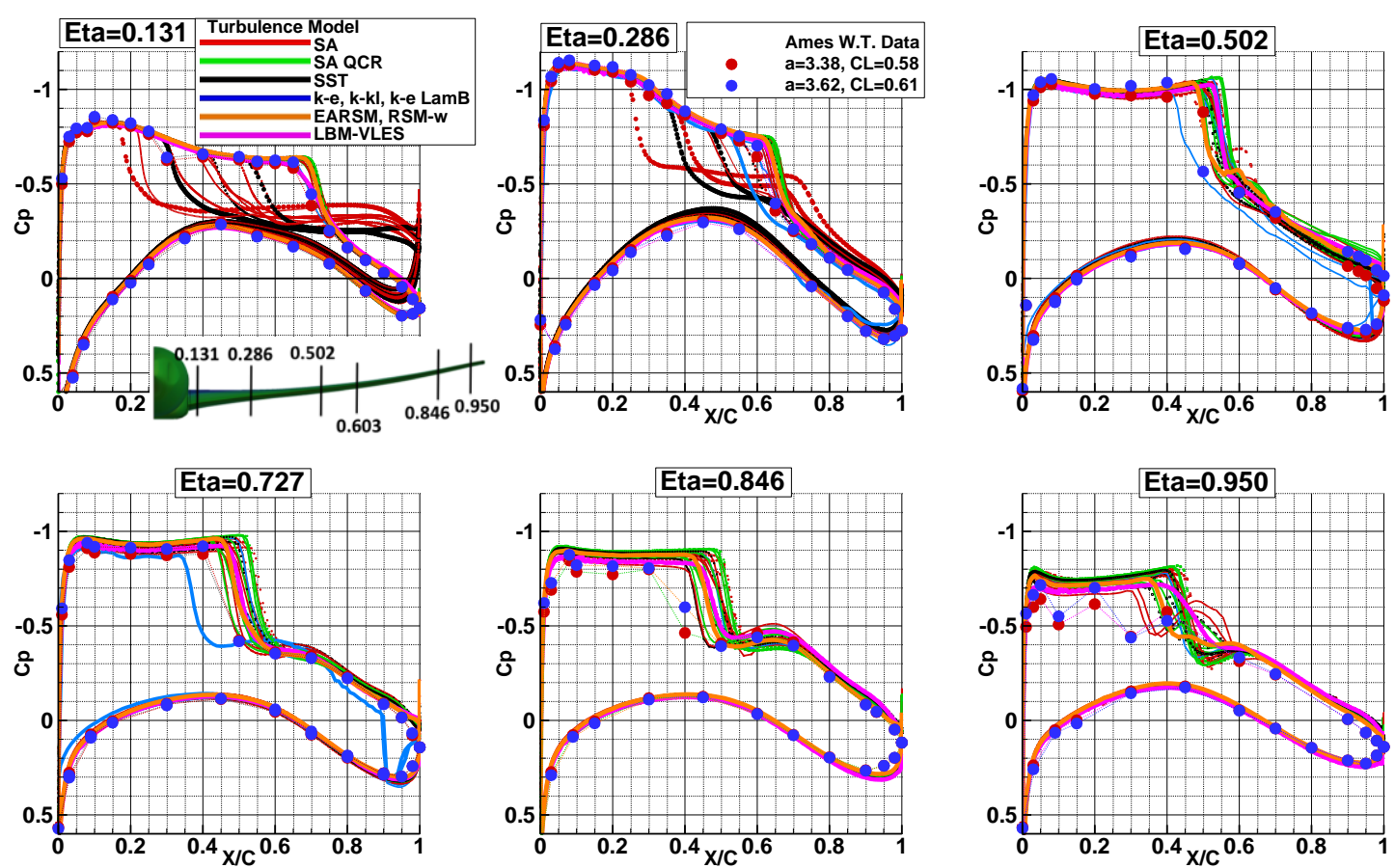

Figure 26. CRM Wing-Body Pressure Distributions $-3.5^{\circ}$ angle-of-attack.
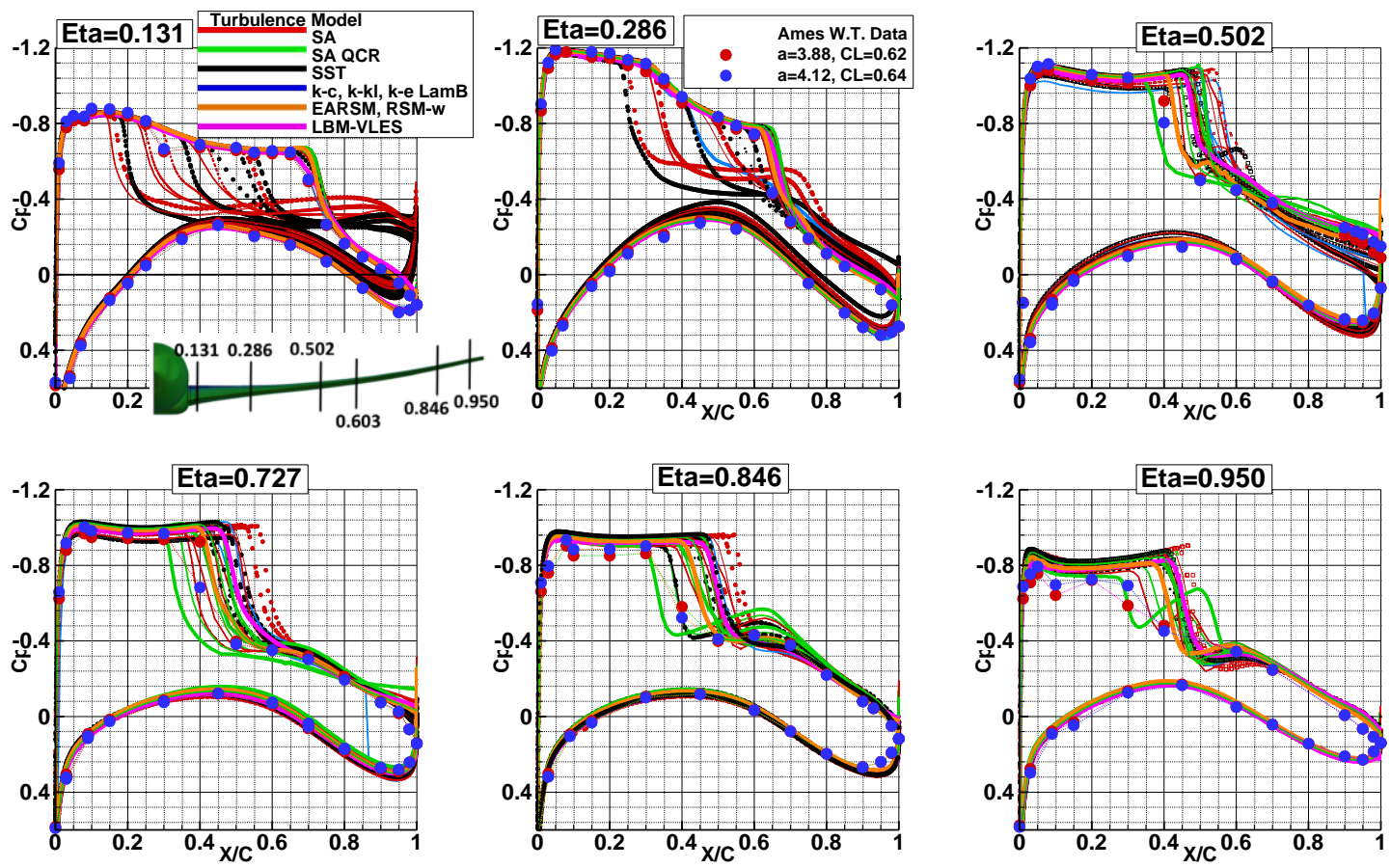

Figure 27. CRM Wing-Body Pressure Distributions $-4.0^{\circ}$ angle-of-attack. 

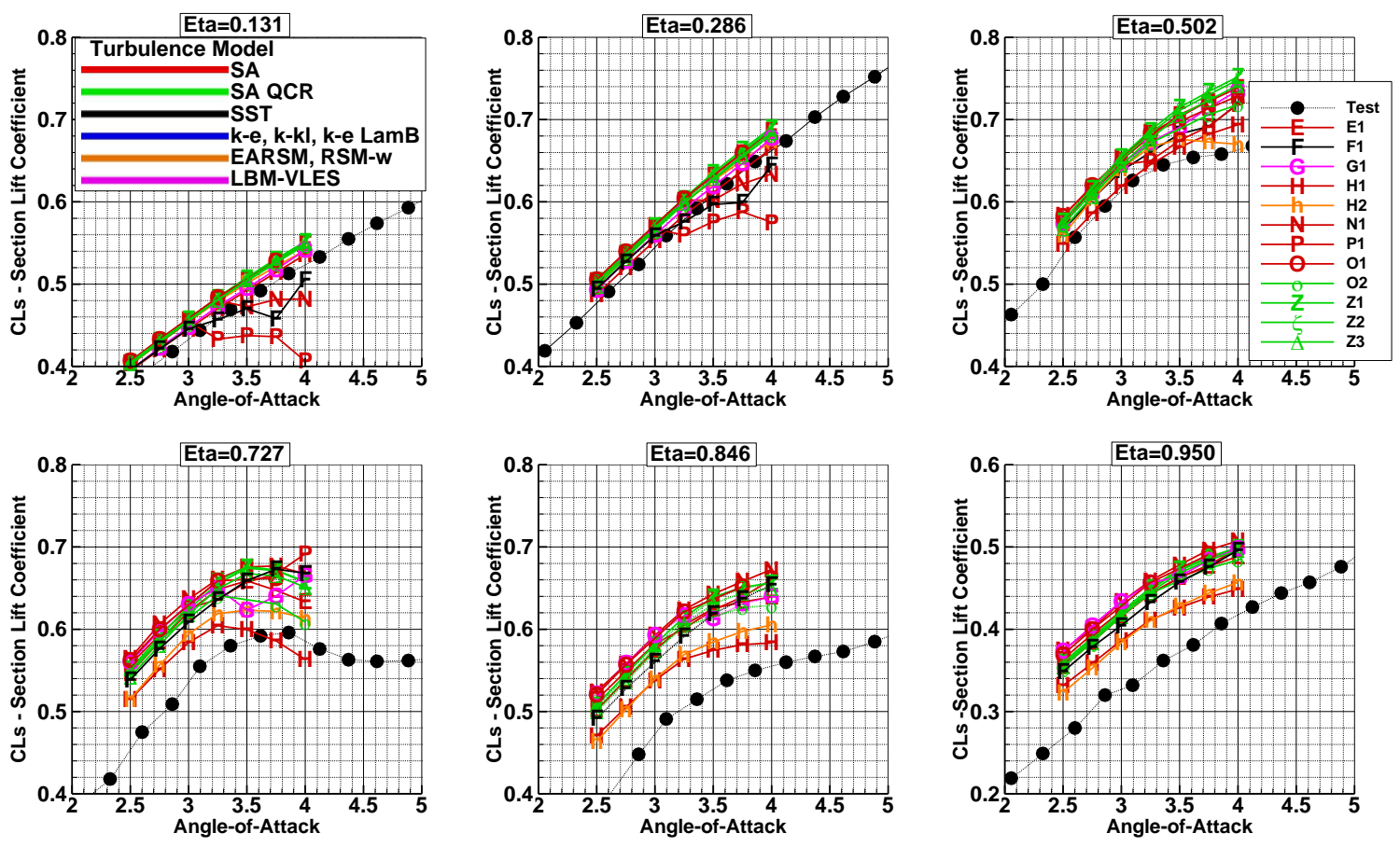

Figure 28. CRM Wing-Body Section Lift (Normal Force), $M=0.85$.
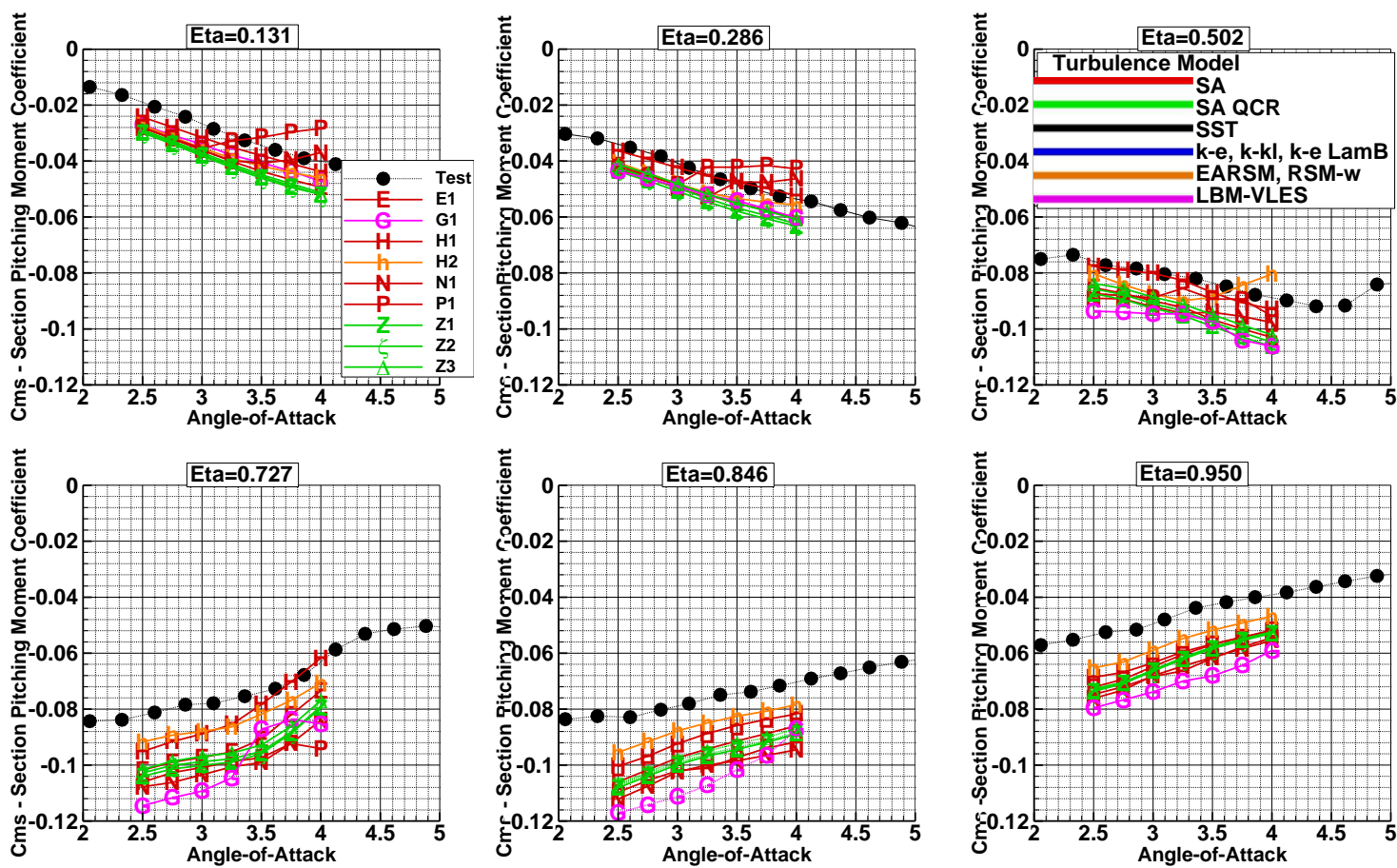

Figure 29. CRM Wing-Body Section 0.25 Chord Pitching Moment, $M=0.85$. 

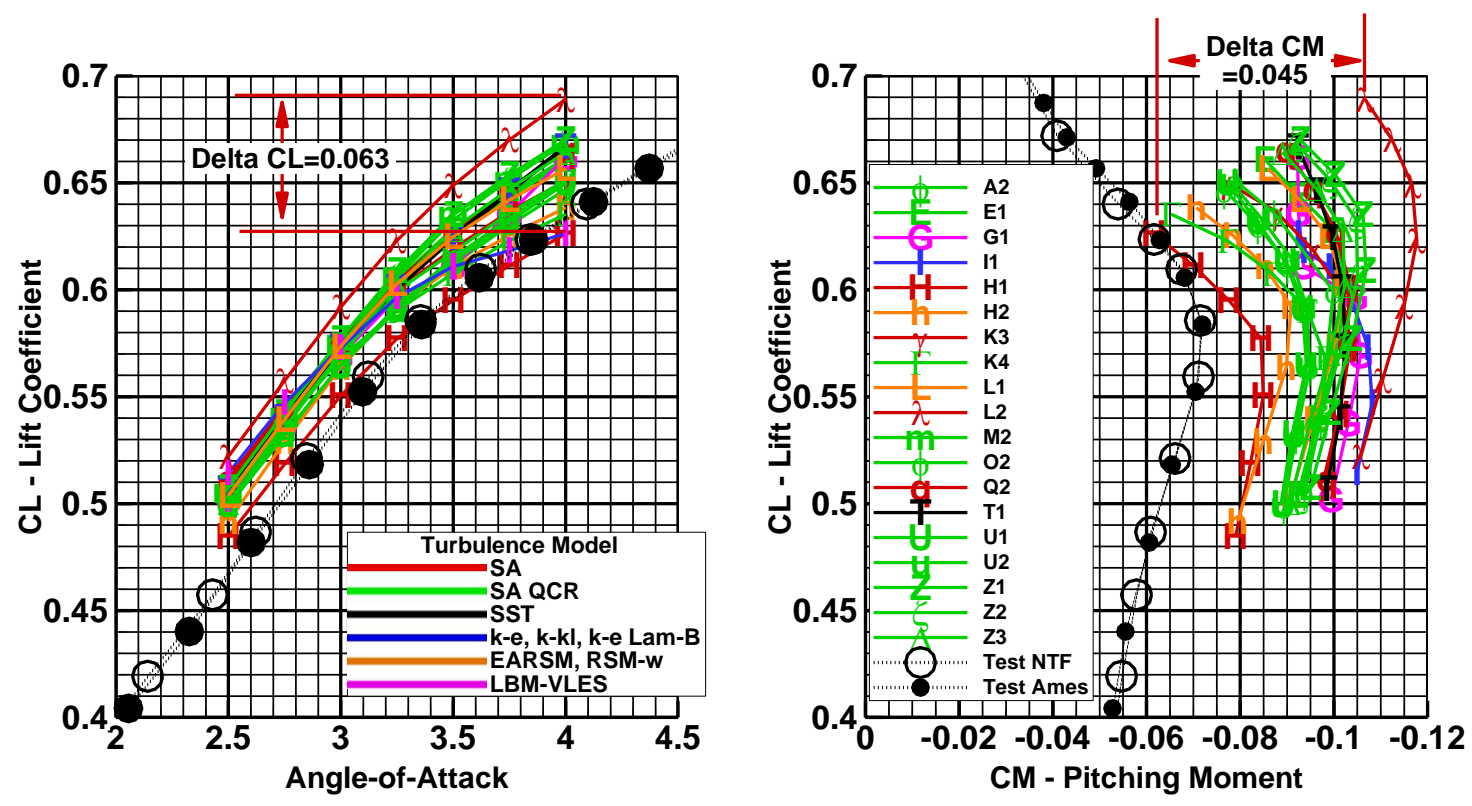

Figure 30. CRM Wing-Body Lift and Pitching Moment minus Outliers, $M=0.85$.

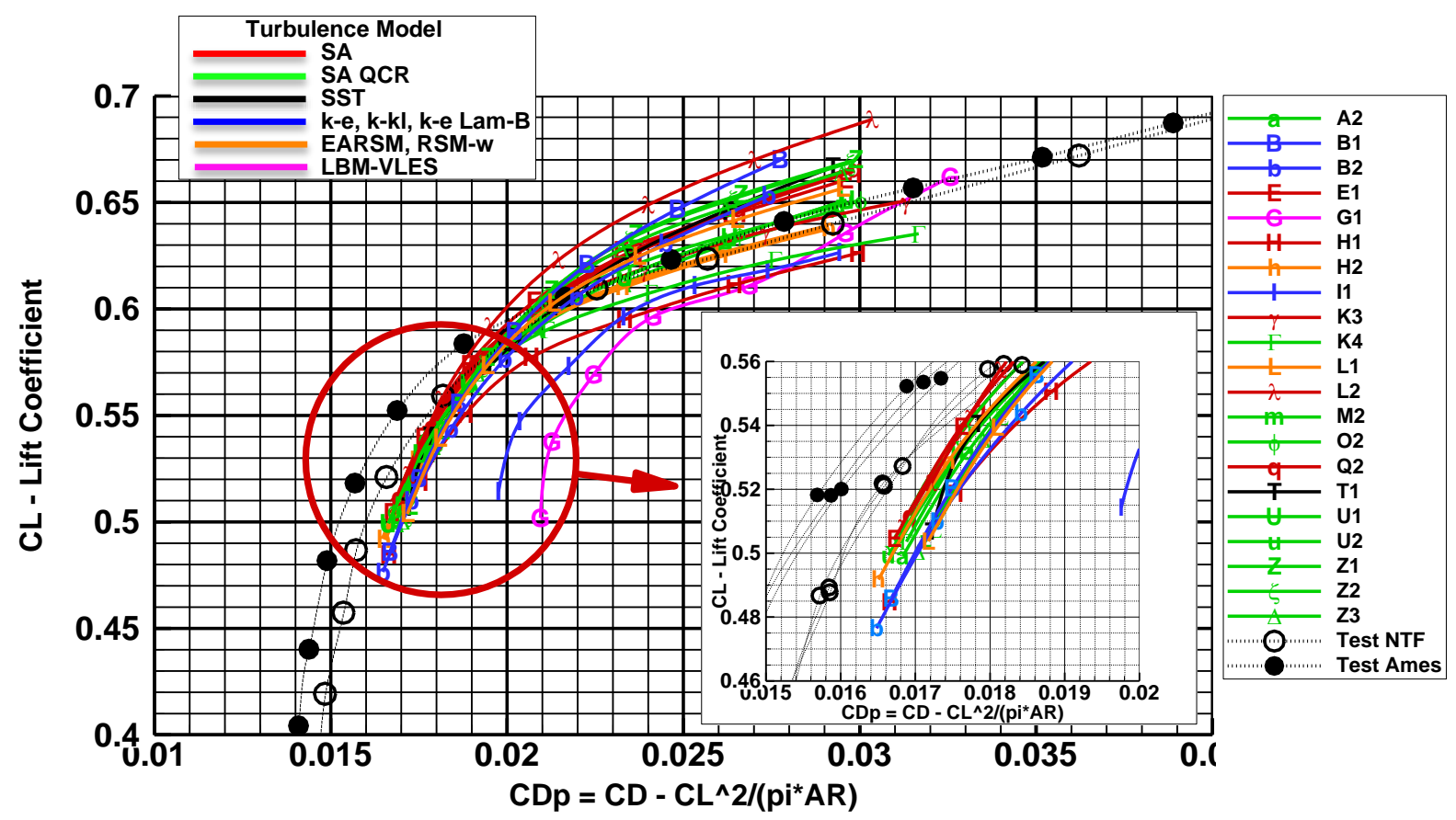

Figure 31. CRM Wing-Body Idealized Drag minus Outliers, $M=0.85$. 

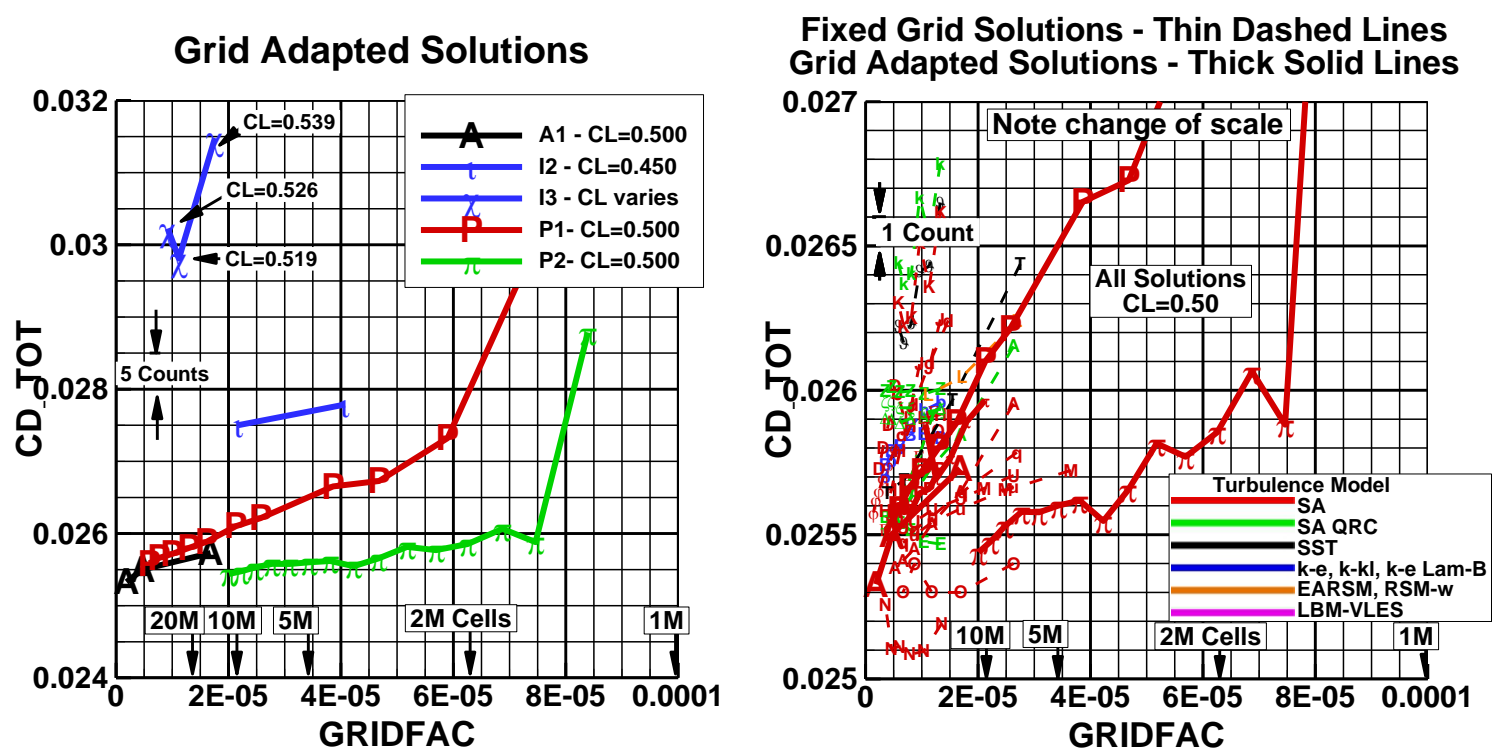

Figure 32. Case 4: CRM Wing-Body Adapted Grid Total Drag, $M=0.85$.


Figure 33. Wing static Pressure Distributions, Case 5. 

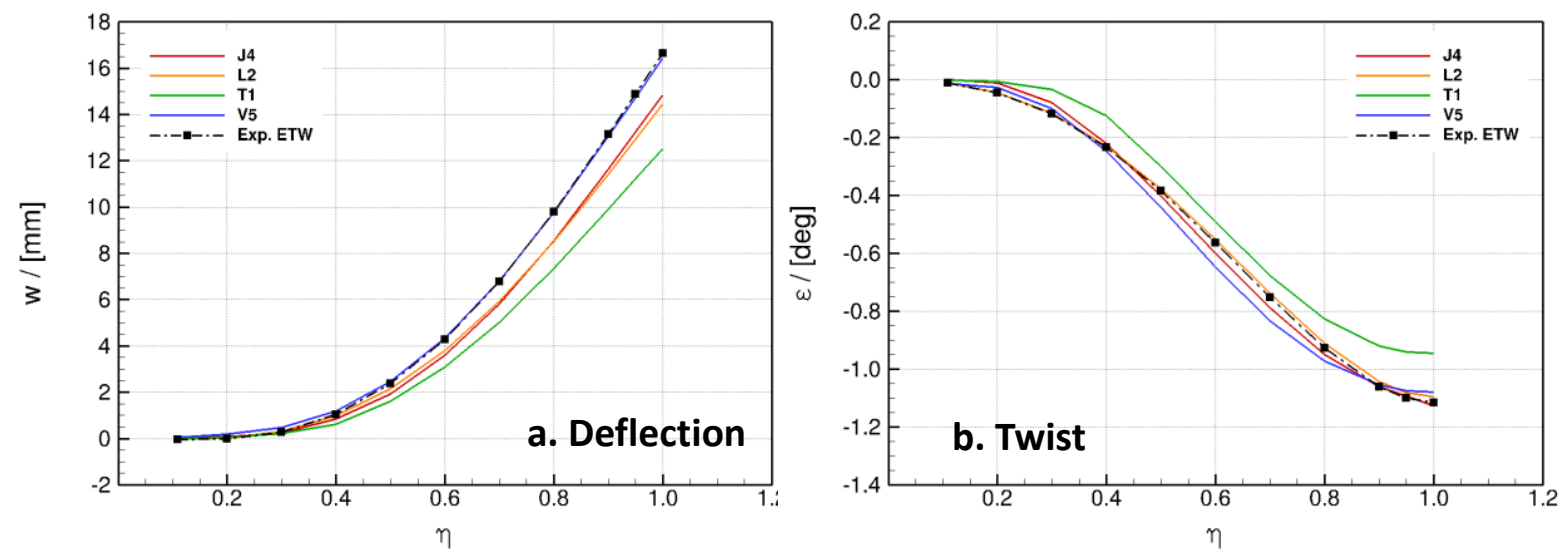

Figure 34. Wing Deformations, Case 5.
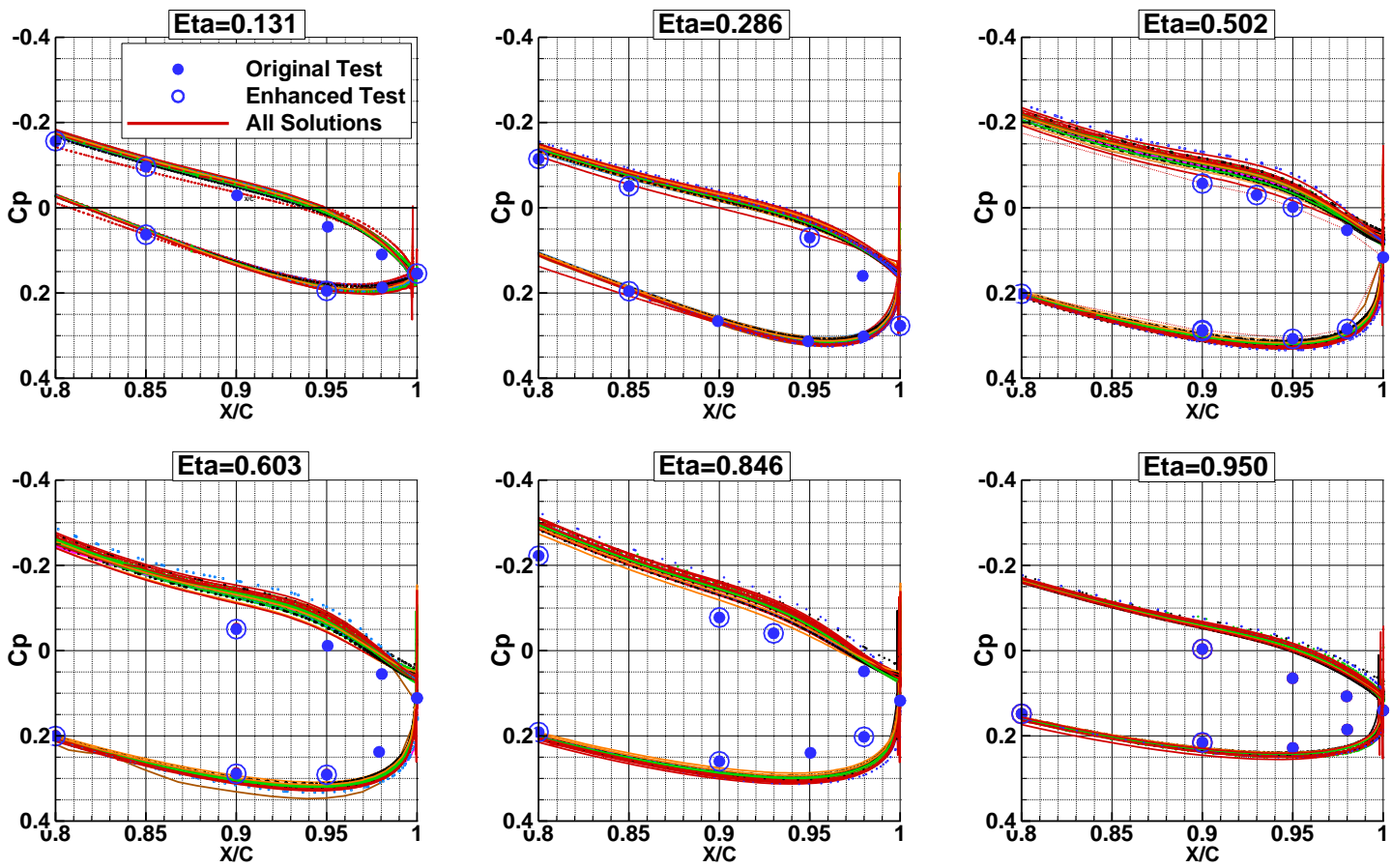

Figure 35. CRM Wing-Body Trailing Edge Wing Pressures $M=0.85, C L=0.50$ - All Solutions.
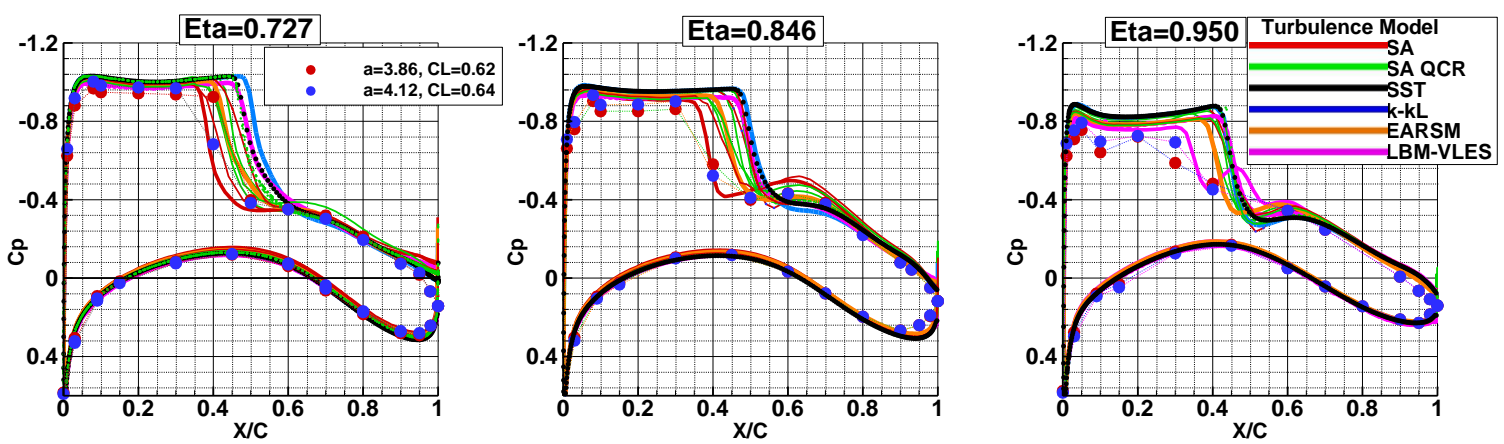

Figure 36. CRM Wing-Body Pressure Distributions, $M=0.85, \alpha=4^{\circ}-$ All Solutions Minus Outliers.

American Institute of Aeronautics and Astronautics 